\title{
Bias for the (un)attractive self; on the role of attention in eating disorders and body dissatisfaction
}

Citation for published version (APA):

Smeets, E. (2009). Bias for the (un)attractive self; on the role of attention in eating disorders and body dissatisfaction. [Doctoral Thesis, Maastricht University]. Datawyse / Universitaire Pers Maastricht. https://doi.org/10.26481/dis.20091009es

Document status and date:

Published: 01/01/2009

DOI:

10.26481/dis.20091009es

Document Version:

Publisher's PDF, also known as Version of record

\section{Please check the document version of this publication:}

- A submitted manuscript is the version of the article upon submission and before peer-review. There can be important differences between the submitted version and the official published version of record.

People interested in the research are advised to contact the author for the final version of the publication, or visit the DOI to the publisher's website.

- The final author version and the galley proof are versions of the publication after peer review.

- The final published version features the final layout of the paper including the volume, issue and page numbers.

Link to publication

\footnotetext{
General rights rights.

- You may freely distribute the URL identifying the publication in the public portal. please follow below link for the End User Agreement:

www.umlib.nl/taverne-license

Take down policy

If you believe that this document breaches copyright please contact us at:

repository@maastrichtuniversity.nl

providing details and we will investigate your claim.
}

Copyright and moral rights for the publications made accessible in the public portal are retained by the authors and/or other copyright owners and it is a condition of accessing publications that users recognise and abide by the legal requirements associated with these

- Users may download and print one copy of any publication from the public portal for the purpose of private study or research.

- You may not further distribute the material or use it for any profit-making activity or commercial gain

If the publication is distributed under the terms of Article $25 \mathrm{fa}$ of the Dutch Copyright Act, indicated by the "Taverne" license above, 
Bias for the (un)attractive self

On the role of attention in eating disorders and body dissatisfaction 
Graphic Design by Hugo Alberts, Luc Sillen, \& Elke Smeets Layout and Print Datawyse / Universitaire Pers Maastricht

\section{(1) Copyright Elke Smeets, Maastricht 2009} ISBN 978-90-5278-862-3

The studies presented in this dissertation were funded by the Netherlands Organization for Scientific Research (NWO, The Hague, grant 400-04-197). They were conducted at Maastricht University and at Flinders University, Australia. 
Bias for the (un) attractive self

On the role of attention in eating disorders and body dissatisfaction

PROEFSCHRIFT

Ter verkrijging van de graad van doctor aan de Universiteit Maastricht, op gezag van de Rector Magnificus, Prof. Mr. G.P.M.F. Mols, volgens het besluit van het College van Decanen, in het openbaar te verdedigen op vrijdag 9 oktober 2009 om 12.00 uur

door

Elke Smeets 


\section{Promotor}

Prof. Dr. A.T.M Jansen

\section{Copromotor}

Dr. A. Roefs

Beoordelingscommissie

Prof. Dr. A. Arntz (voorzitter)

Dr. A. van Elburg

Dr. N. Nicolson

Prof. Dr. D. A. Stapel (Universiteit Tilburg)

Prof. Dr. J. Vlaeyen 


\section{conterts}

$\begin{array}{lll}\text { Chapter } 1 \text { General Introduction } & 7\end{array}$

Chapter 2 Attentional bias for body and food in eating disorders 23

Chapter 3 Selective attention for unattractive body parts causes body 39 dissatisfaction

Chapter 4 Self-activation in high restrained eaters causes body dissatisfaction 55

Chapter 5 Body checking induces an attentional bias for body-related cues $\quad 69$

Chapter 6 Experimentally induced chocolate craving leads to increased 83 distraction

$\begin{array}{lll}\text { Chapter } 7 & \text { General discussion } & 97\end{array}$

$\begin{array}{lll}\text { Chapter } 8 & \text { References } & 107\end{array}$

$\begin{array}{lll}\text { Chapter } \mathbf{9} & \text { Summary } & 117\end{array}$

$\begin{array}{lll}\text { Chapter } 10 & \text { Samenvatting } & 123\end{array}$

$\begin{array}{lr}\text { Dankwoord } & 129\end{array}$

$\begin{array}{ll}\text { Curriculum Vitae } & 135\end{array}$ 


\section{Chapter 1}

General Introduction 
Margaret Wolfe Hungerford, an Irish novelist from the 19th century once said that "beauty is in the eye of the beholder". Today, in our appearance-focused Western society, looking beautiful, slim, and attractive is a big issue for many women. Over $25 \%$ of all women report feeling extremely dissatisfied with the way their body looks (Bearman, Presnell, \& Martinez, 2006; Stice \& Whitenton, 2002), and approximately 1 to 2\% of our population suffers from an eating disorder in which body dissatisfaction is a key symptom (APA, 1994). Yet, if we consider these percentages it seems that not every woman feels dissatisfied with her body. An important question in this respect is how women who do not feel body dissatisfied differ from women who do. Try and imagine the following scenario: you are standing in front of the mirror of a dressing room while trying on a new dress, what do you see? Do you see how fabulous you actually look in that red dress (option a), or do you think it is absolutely not done because you think your hips look way too fat in it (option b)? In either of these two options, our mind (i.e. beholder) is processing new incoming information. However, in the second option the act of information processing is selectively directed to unattractive body parts. So, whether or not we feel beautiful in that new red dress is dependent upon the way our minds direct attention. Indeed, according to cognitive-behaviaural accounts of eating disorders, biased information processing is thought to lead to the development and maintenance of eating disorder psychopathology (e.g., Williamson, Muller, Reas, \& Thaw, 1999).

The present dissertation focuses on the role of attentional biases in the development and maintenance of eating disorder psychopathology, and in particular body dissatisfaction. Three main themes will be addressed: (1) The precise nature of the attentional bias in eating disorders, (2) Factors that cause body dissatisfaction, and (3) Factors that cause an attentional bias. In the present chapter an overview on eating disorders, the cognitive theory of eating disorders, the role of attentional bias in eating disorders, and factors that cause an attentional bias, will be provided.

\section{Eating disorders: State of the art}

In the last decade eating disorders have received considerable coverage in the media. Eating disorders are severe psychiatric disorders that are characterized by a definite disturbance of eating habits that seriously compromises an individual's physical health and psychosocial functioning (APA, 1994). Of all common psychiatric disorders, eating disorders are marked by the highest levels of mortality and suicide attempts. Over $10 \%$ of all anorexia nervosa patients die during the course of their illness, with the two most prominent causes of death being suicide and medical complications (e.g., electrolyte 
imbalance, starvation; APA, 1994). DSM-IV divides eating disorders in three diagnostic categories: anorexia nervosa (AN), bulimia nervosa (BN), and the eating disorders not otherwise specified (EDNOS). Of all women between 15 and 30, approximately $0,5 \%$ suffers from anorexia nervosa and $1 \%$ from bulimia nervosa. In men eating disorders are much less frequent; of all eating disorder cases, only $5-10 \%$ occurs in men. Anorexia nervosa patients refuse to maintain a weight that is in the normal range for their age and height, whereas bulimia nervosa patients have a normal weight.

While the clinical presentation may slightly differ between eating disorder subtypes, in essence, they are strikingly similar as they share a typical core psychopathology; the over-evaluation of shape and weight, and the extent to which these can be controlled. In this respect, the British Psychiatrist Fairburn emphasizes that eating disorders are essentially "cognitive disorders" (Fairburn, 2008; Fairburn \& Harrison, 2003). Whereas most people judge their self-worth in terms of personal accomplishments in various domains of life (e.g., work, relationships, hobbies), eating disorder patients almost exclusively judge their self-worth in terms of shape and weight. As a consequence they are thought to become extremely preoccupied and concerned about their weight, shape and eating habits (Fairburn, 2008; Fairburn \& Harrison, 2003). Indeed, most characteristic eating disorder features are believed to be a direct expression of the over-evaluation of shape and weight and the effects this has. Being preoccupied with weight drives many patients to engage in a range of extreme weightcontrol behaviours like frequent weighing to closely monitor weight changes, excessive exercising, misusing laxatives and diuretics, and self-induced vomiting. Furthermore, most patients constantly try to lose weight by restricting their food intake in an extreme way, and setting themselves highly demanding dieting rules that determine when, how much, and what they will eat (APA, 1994). In this way patients try to exert control over their eating patterns.

Even though many of them are underweight, eating disorder patients struggle with the intense fear of becoming fat or gaining weight. They experience their body shape as highly negative and ugly, and feel extremely dissatisfied. Some patients repeatedly check and scrutinize their body parts in for example the mirror (body checking) whereas others actively avoid doing so (body avoidance) by for example wearing over-sized clothes. Sometimes periods of dietary restraint are interrupted by episodes of bingeeating. A binge can be defined as "eating in a discrete period of time an amount of food that is definitely larger than most individuals would eat under similar circumstances" in addition to feelings of loss of control during that time (APA, 1994, p. 589). These episodes are often followed by inappropriate compensatory weight-control behaviors to prevent weight gain. Binge eating is mostly seen in bulimia nervosa and binge eating disorder patients, although it also occurs in anorexia nervosa patients of the purging 
subtype. Eating disorder patients commonly shift between diagnostic categories during the course of their illness (Fairburn, 2008).

Apart from specific eating disorder psychopathology, eating disorders are often accompanied by symptoms of depression, anxiety, and low self-esteem. In addition, symptoms of personality disorders can be observed in individuals suffering from eating disorders (APA, 1994).

Even though there has been a long tradition in eating disorders research, there is still a lot of uncertainty about the causes of eating disorders. Luckily, researchers did make important progress with regard to the treatment of bulimia nervosa. It has been shown that cognitive behaviour therapy is the treatment of choice for bulimia nervosa patients, with a third to a half of all patients who received it making a complete and lasting recovery (Wilson \& Fairburn, 2002). Even though evidence-based management is now possible for bulimia nervosa, clinicians are still in the dark when it comes to the treatment of anorexia nervosa. Very few randomized controlled studies were done to assess the treatment of anorexia nervosa whereas over 50 studies were conducted into the treatment of bulimia nervosa (Fairburn \& Harrison, 2003). This complicates the formulation of evidence-based guidelines for treating anorexia nervosa.

According to longitudinal research, body dissatisfaction is one of the main risk factors for the development of eating disorders (Stice, 2002). At this point, experimental research into the mechanisms that maintain eating disorders is a vital necessity. The aim of the present dissertation is to investigate some of these mechanisms in experimental studies and to fuel our theoretical understanding of the origin of eating disorder psychopathology, thereby creating possibilities to provide clinicians with evidencebased clues for improving treatment programs.

\section{Cognitive theory of eating disorders}

As described in the previous section, eating disorder patients are extremely concerned about their shape and weight and judge their self-worth almost exclusively in terms of these parameters. The central premise of the cognitive theory is that anorexia nervosa and bulimia nervosa are maintained through the over-evaluation of shape and weight (Fairburn, Cooper, \& Shafran, 2003; Fairburn, Shafran, \& Cooper, 1998; Garner \& Bemis, 1982, 1985; Vitousek \& Hollon, 1990; Williamson, Muller, Reas, \& Thaw, 1999). Cognitive accounts of eating disorders have been highly influential. Not only did they encourage many researchers to investigate the mechanisms involved in eating disorders, they also led to significant advances in treatment. 
Eating disorder individuals are characterized by a dysfunctional way of judging selfworth, but how is it that this core psychopathology maintains eating disorders? According to the cognitive theory, it has got to do with dysfunctional schemata. Schemata can be defined as highly efficient knowledge structures that act to simplify, stabilize, and organize the experience of the self and the environment (Vitousek \& Hollon, 1990). It is hypothesized that "eating disordered individuals develop organized cognitive structures (schemata) around the issues of weight and its implications for the self that may influence their perceptions, thoughts, affect, and behaviour" (Vitousek \& Hollon, 1990; p.192). In this respect, the operation of these schemata is presumed to produce systematic errors in the processing of weight-related information, and as a result contribute to the maintenance of eating disorder symptoms. Despite their maladaptive effects, schemata seem to serve a rather adaptive function for eating disorder patients. It provides them with structure and simplicity in a world that is experienced by them as dauntingly complex. Eating disorder patients often describe feeling overwhelmed by all the expectations and responsibilities in life. In addition, they are highly demanding, requiring from themselves to achieve excellence in virtually everything they do. As a result it becomes adaptive for them to decrease the range of variables that are central in determining their self-worth by developing schemata around a few central themes (i.e., weight, shape)

These typical eating disorder-related schemata contain "stereotyped, affectively loaded, and overvalued information concerning weight and shape, especially as it applies to the self" (Williamson et al., 1999; p. 558). The influence of these disordered schemata in information processing is thought to take place automatically, without conscious awareness of its operation. In that regard, the cognitive theory of eating disorders holds that the activation of these schemata causes disorder-relevant information to be processed in a biased way, leading to a range of cognitive biases in attention, judgment, memory, and body image. These cognitive biases, in turn, are presumed to cause disturbed behavioural patterns that are typical to eating disorder symptomatology (i.e., body checking, dietary restriction, purging, etc.).

Taken together, the cognitive theory of eating disorders describes the influence of cognitive biases on the maintenance of pathological eating disorder-related behaviours. In the present dissertation the focus will be on one of these cognitive biases: namely the attentional bias. 


\section{Attentional bias in eating disorders}

The formulation of the cognitive model of eating disorders has greatly inspired researchers to conduct studies into some of the cognitive mechanisms that are involved in eating disorders. More specifically since the nineties, this has led to an explosion of research that has addressed the prediction that eating disorder individuals show an attentional bias for shape-, weight-, and eating-related information. An attentional bias is defined as the tendency to selectively attend to disorder-relevant information over neutral information (Mathews \& Macleod, 2005; Williamson et al., 1999).

To investigate the existence of attentional biases in patients with eating disorders, researchers have adapted paradigms from cognitive psychology. The benefit of attentional bias paradigms over self-report measures is that they can reveal the cognitive essence of eating disorders in an indirect way.

One paradigm that has been extensively used to study attentional biases in eating disorders is the emotional Stroop task (Williams, Mathews, \& Macleod, 1996). In this paradigm participants are presented with disorder-relevant and neutral stimuli (i.e. words or pictures), which are printed in different colours. The task of participants is to name the colour of the stimuli as fast as possible while ignoring the content. Interference scores are calculated by comparing reaction times for the colour naming of disorder-related words (e.g., fat) with reactions times for the colour naming of neutral words (e.g., pen). Slower reaction times for naming the colour of disorder-relevant words relative to neutral words represent an increased interference effect which is commonly interpreted as evidence for an attentional bias. Research shows that eating disorder patients indeed show increased interference scores. As indicated by three review articles, the majority of studies employing the emotional Stroop task found that anorexia nervosa and bulimia nervosa patients show increased interference when naming the colour of disorder-relevant stimuli (i.e., shape, weight, and food-related) as opposed to neutral stimuli (for reviews see: Dobson \& Dozois, 2004; Faunce, 2002; Lee \& Shafran, 2004).

Even though these interference effects have been generally interpreted as evidence for an attentional bias, researchers have expressed their concerns about this interpretation and have pointed to the significant weaknesses of the emotional Stroop paradigm as a measure of selective attention (Jansen, Nederkoorn, \& Mulkens, 2005; Lee \& Shafran, 2004; Macleod, 2005). Given that the emotional Stroop paradigm is unable to distinguish between the components that might underlie a bias in attentional processing, it is unclear whether increased interference scores are due to attention direct towards or away from disorder-relevant information (Macleod \& Matthews, 1991). In this line, De Ruiter and Brosschoot (1994) have argued that attempts to 
cognitively avoid the processing of disorder-relevant word stimuli might also result in increased interference scores. Furthermore, it is difficult to distinguish attentional bias effects from other non-attentional processes such as distraction or response biases which result from induced emotional arousal (Eysenk, 1992; Macleod, Rutherford, Campbell, Ebsworthy, \& Holker, 2002). Because of these limitations, no firm conclusions can be drawn about the existence of an attentional bias in eating disorder patients on the basis of the results in the emotional Stroop paradigm.

Not surprisingly, researchers have turned to other paradigms, like the dot-probe paradigm (Macleod, Mathews, \& Tata, 1986), for investigating the existence of attentional biases in eating disorder patients. The dot-probe paradigm has been argued to be a superior alternative and a more direct test of attention than the emotional Stroop task because it allows for the differentiation between attention directed towards or away from a particular type of information (Mogg \& Bradley, 1998). In this task, on each trial the participant is presented with a word pair (i.e., mostly a threat word and a neutral word) on a computer screen. After the presentation of the word pair, a probe (e.g., $p$ or q) appears on one of the two locations that was previously occupied by one of the members of the word pair. Participants are instructed to classify the probe as being a " $p$ " or a " $q$ " as fast as possible. The rationale behind the dot-probe task is that participants will be quicker to classify the probe when it replaced the word they were attending to, as opposed to when it replaced the word they were not attending to. In that respect, participants with an attentional bias for body-related words for example will be quicker to classify the probe on trials where it replaces body-related words rather than neutral words. However, when participants avoid body-related words for example, they will be quicker to classify the probe on trials where it replaces neutral words rather than body-related words, because their attention was directed away from these words during the word pair presentation. The difference between response latencies to classify disorder-relevant and neutral words is an index for attentional bias, which either consists of attention directed towards, or away from a particular word category.

To date, two studies have investigated attentional processes in eating disorder patients using the dot-probe paradigm. Rieger et al. (1998) demonstrated that eating disorder patients showed a tendency to direct their attention towards words denoting a large physique and away from words denoting a thin physique. More recently, using a pictorial version of the dot-probe paradigm, Shafran, Lee, Cooper, Palmer, and Fairburn (2007) found robust attentional bias effects for eating and weight-related stimuli in eating disorder patients in comparison to controls, but less consistent effects for shaperelated stimuli. However, future research should determine whether the attentional bias in eating disorder patients can be understood in terms of initial orienting to disor- 
chapten 1

der-relevant information, or of greater maintained attention by disorder-relevant information.

At this point the eating disorders field is in need of research that can help to illuminate the exact nature of the biased attentional processes that are presumed to be involved in eating disorders. With this perspective in mind, an alternative attentional bias paradigm that is able to distinguish two subcomponents of attention: speeded detection (i.e., increased orienting towards relevant stimuli) and distraction (i.e., increased distraction by relevant stimuli), was used in the present dissertation. The odd-one-out visual search paradigm was originally developed by Hansen and Hansen (1998) and was used by Rinck, Reinecke, Ellwart, Heuer, and Becker (2005) to study the nature of attentional bias in spider-fearful individuals. Participants were presented with matrices of 20 pictures and they were instructed to indicate whether the matrix consisted of 20 animal pictures of the same category or whether it included one animal picture from a different category. Results indicated that both speeded detection of threatening target pictures (i.e., faster detection of a spider among 19 neutral pictures than a neutral picture among 19 neutral pictures from another category) and increased distraction by threatening distractors (i.e., slower detection of a neutral image among 19 spider pictures than a neutral image among 19 neutral images from another category) were involved in the attentional processing of spider-fearful individuals.

Taken together, even though there has been a substantial body of research into the existence of attentional biases in eating disorders since the early nineties, the main findings since then seem to be somewhat obscured by methodological concerns. Given both the controversy concerning the interpretation of emotional Stroop effects and the lack of knowledge about which components underlie an attentional bias in eating disorders, it is of great interest to investigate more precisely the attentional bias for body and food stimuli in eating disorder patients. In chapter 2 the precise nature of the attentional bias in eating disorder patients will be addressed.

\section{Factors that might cause body dissatisfaction}

\section{Causal role of attentional bias in eating disorder psychopathology}

Despite its tremendous influence on eating disorders treatment, there has been surprisingly little experimental research to systematically address the main predictions of the cognitive behavioural theory. One essential prediction is that cognitive biases, like for instance an attentional bias, lead to eating disorder psychopathology (Williamson et al., 1999). To address the causal status of this relationship, one would need to experimen- 
tally induce an attentional bias for body-related information in a group of healthy participants and then address its effects on a dependent variable that provides us with a representation of eating disorder psychopathology. One dependent variable that fits this profile is body dissatisfaction. Body dissatisfaction has been classified as one of the main diagnostic characteristics of eating disorders (APA, 1994), and has been found to be a powerful risk factor for eating disorders (Stice, Hayward, Cameron, Killen, \& Taylor, 2000). If training healthy participants to selectively attend to body-related information is found to negatively affect the way they feel about their body, this could provide us with valuable insights in the development and maintenance of eating disorder psychopathology.

Indeed, pioneering research of this kind by Macleod et al. (2002) has led to important advances in the field of anxiety disorders. Macleod and his colleagues conducted two elegant studies to address the causal status of the association between individual differences in negative attentional bias and vulnerability to negative emotions. Using a modified dot-probe task, healthy participants were trained to either direct their attention towards or away from negative stimulus information. Following the attentional bias training, participants were exposed to an anagram stress manipulation, in which they had to solve highly difficult word anagrams. After participants completed the anagram task, a depression and anxiety scale was used to determine individual variations in the extent to which the anagram stressor task had elevated their negative mood. Results showed that healthy participants who were trained to direct their attention towards negative information, showed higher levels of emotional vulnerability on a subsequent stressor task than participants who were trained to direct their attention away from negative information. These results clearly enable the appraisal of the hypothesis that a negative attentional bias has a causal impact on emotional vulnerability.

In 2006, the ideas of Macleod (Macleod et al., 2002) also found their way to the eating disorders field. In that year, two research groups investigated the causal status of attentional biases in eating disorder symptoms (i.e., body dissatisfaction). Smith and Rieger (2006) used an attentional probe task to train healthy participant's attention toward negative shape/weight related words, neutral words, or negatively valenced emotion words. After the training, participants were presented with a body image challenge (i.e., exposure to advertisements of slender models) to assess their levels of body dissatisfaction. Results support the causal status of selective attention for body related words in body dissatisfaction. It was demonstrated that training an attentional bias toward shape/weight related words, in comparison to both control groups, led to increased levels of body dissatisfaction in healthy participants. Also using an attentiona probe task, Engel and colleagues (2006) trained healthy participant's attention toward or away from body/shape related words, after which concerns about eating and body 
were assessed. In contrast to the findings of Smith and Rieger (2006), Engel and colleagues (2006) found that training attention away from body/shape related words resulted in greater concerns about body and eating, than training attention towards body/shape related words. Both studies confirm a causal relation between disturbed attentional processes and the development of eating disorder symptoms. However, no conclusive information could be offered on whether body dissatisfaction is the result of training one's attention toward or away from body-related words.

Recent research from Jansen, Nederkoorn, and Mulkens (2005) showed that eating disorder patients not only show an attentional bias for body and food related word stimuli, but also for specific body parts. Jansen et al., (2005) studied the attentional bias in eating disorders in a direct way, by exposing participants to pictures of their own body and registering eye-movements. Results indicated that eating disorder patients show a dysfunctional way of looking at their own body, which might maintain eating disorders psychopathology. More specifically, results showed that when attending to their own body, eating disorder patients attend more to their unattractive body parts than to their attractive body parts, whereas healthy controls attend more to their own attractive body parts than to their unattractive body parts. When attending to another person's body, eating disorder patients attend more to the other person's attractive body parts, whereas healthy controls attend more to the other person's unattractive body parts.

It can be hypothesized that a tendency for selectively attending to unattractive body parts might maintain or even cause severe feelings of body dissatisfaction. Nevertheless, because the study by Jansen et al., (2005) is correlational in nature, no conclusions can be drawn about the causal status of an attentional bias for certain body parts in body dissatisfaction. In chapter 3 , the causal influence of an attentional bias for unattractive body parts in body dissatisfaction will be examined.

The role of the environment and self-activation in body dissatisfaction

Apart from cognitive factors, environmental factors like the media have been presumed to be involved in the development of eating disorder psychopathology and in particular body dissatisfaction (for a review: see Groesz, Levine, \& Murnen, 2002). Indeed, it is a commonly held belief that the focus on slenderness and beauty in today's society affects women adversely. By setting an unrealistic beauty standard, which most women desire but only few can meet, the media has been considered to promote feelings of body dissatisfaction in many women. Although, the role of environmental factors has not been incorporated in cognitive-behavioural accounts of eating disorders, there is a 
substantial body of literature that indicates that the media have a negative impact on women's body image.

Numerous studies have shown reliable correlations between exposure to thin-ideal images in the media and negative self-evaluations (e.g., Harrison \& Cantor, 1997; Stice, Schupak-Neuberg, Shaw, \& Stein, 1994; Tiggemann, \& Pickering, 1996). Moreover, a burgeoning body of experimental studies point to the detrimental effects of watching idealised music videos (Tiggemann \& Slater, 2004), television images (Lavine, Sweeney, \& Wagner, 1999), and advertisements (Stice \& Shaw, 1994) on women's body image. Two meta-analyses, considering the findings of correlational and experimental media studies conclude that exposure to media images depicting the thin-ideal body has a small but moderate negative effect (Groesz, Levine, \& Murnen, 2002; Grabe, Ward, \& Hyde, 2008) on women's satisfaction with their own bodies. Nevertheless, another meta-analysis, which included a number of different studies, suggests little influence of the media on body image (Holstrom, 2004). To complicate matters further, other studies have shown that restrained eaters feel more, as opposed to less, confident about their appearance after being exposed to pictures of thin and attractive models (Joshi, Herman, \& Polivy, 2004; Mills, Polivy, Herman, \& Tiggemann, 2002).

Taken together, the media's role in the development of body dissatisfaction and eating disorder psychopathology seems not as straightforward as generally assumed. Even though every single woman in our society is exposed to thin-ideal portrayals on an every day basis, not everyone develops an eating disorder or feelings of body dissatisfaction. If we consider that 25 to $50 \%$ of all young women report to feel dissatisfied with their bodies (Bearman, Presnell, \& Martinez, 2006; Stice \& Whitenton, 2002), and only 1 to $2 \%$ develop an eating disorder (APA, 1994), one could wonder what happens to the other women. What distinguishes women who are not vulnerable to the effects of the media from women who are? In what way do they differ from each other?

Research shows that not all women react in the same negative way to mediaportrayed idealized body images. In this respect it has been shown that women who have higher dispositional leveis of body dissatisfaction (Posavac, Posavac, \& Posavac 1998; Trampe, Stapel, \& Siero, 2007), and women who invest more in beauty and thinness (e.g., thin-ideal internalisation; Dittmar \& Howard, 2004; Stice \& Whitenton 2002) are more likely to be affected adversely than other women. Another individual difference variable that has been found to make women more vulnerable to the ad verse effects of the media, is the tendency to compare one's appearance to that of other women (Cattarin, Thompson, Thomas, \& Williams, 2005; Dittmar \& Howard 2004; Jones, 2001; Tiggemann \& McGill, 2004). Indeed social comparison (Festinger 1954) has generally been considered an important variable in explaining women's adverse reactions to thin-ideal images. Women who regularly make self-comparisons to 
images of idealised women's bodies have been found to feel less attractive and more dissatisfied with their own body (Stice, Schupak-Neuberg, Shaw, \& Stein, 1994; Stormer \& Thompson, 1996) than other women. Furthermore, a greater tendency to engage in upward social comparison (i.e., in which the comparison target is perceived as better looking) has been shown to predict the presence of eating disorder symptoms (Corning, Krumm, \& Smitham, 2006).

Although it is clear that the increased tendency to engage in social comparison is associated with feelings of body dissatisfaction, it is unclear where this tendency stems from in the first place. As yet, there has been very little research to address why some women have a higher need for social comparison than others. Trampe, Stapel, and Siero (2007) showed that body dissatisfaction is an important determinant in the occurrence of social comparison effects. In explaining this finding the authors hypothesize that body dissatisfied women are more likely to engage in social comparison because their self-related cognitions and feelings are more accessible (i.e., higher levels of self-activation) and because they consider a wider range of comparison targets as relevant (e.g., peers and fashion models). In this perspective, research from the field of social psychology has shown that self-activation is an important prerequisite for promoting social comparison tendencies (Stapel \& Tesser, 2001). Self-activation refers to a state in which one is more aware of one's self-related cognitions, feelings, behaviour and goals (like for example the goal of losing weight). Stapel and Tesser (2001) manipulated self-activation by instructing participants to name either four defining things about themselves (self-activation condition) or about a movie (control condition). Results indicated that participants in the self-activation condition showed higher social comparison tendencies than participants in the control condition.

Taken together, whereas the exact impact of the media on women's mental health is still unclear, there seem to be individual difference factors that mediate whether or not one will be affected adversely by thin-ideal images (e.g., social comparison). If one wants to decrease women's vulnerability to these images, one needs to investigate the processes that might account for individual differences between women. Given that self-activation has been found to increase people's interest in social comparison, it is worthwhile to investigate its effect on women's vulnerability to media exposure. In chapter 4 the effect of self-activation on how women deal with thin-ideal images will be examined. 


\section{Factors that might cause an attentional bias}

Despite the abundance of studies that have addressed the existence of an attentional bias in eating disorder individuals, so far not a single study has been conducted to address the possible factors that could lead to the development of an attentional bias. If one wants to gain a better understanding of the biased cognitive processes that cause or maintain eating disorders, it is important to study how they come about in the first place. In the present dissertation two factors that might be involved in causing an attentional bias will be investigated. Body checking is proposed to cause an attentional bias for body-related information, whereas craving is proposed to cause an attentional bias for food-related information.

The causal role of body checking in the attentional bias for body. Body checking is a frequently-observed phenomenon in patients with an eating disorder and has been considered to be a behavioural manifestation of the over-evaluation of shape and weight in these patients (Fairburn, Shafran, Cooper, 1999). It can be defined as the repeated and ritualistic monitoring of several aspects of the body, which consists for example of: scrutinizing specific body parts in the mirror, frequent weighing, and pinching certain body parts to measure fatness (Reas, Whisenhunt, Netemeyer, \& Williamson, 2002; Rosen, 1997). Cognitive-behavioural theoretical accounts suggest that body checking might contribute to the maintenance of eating disorders (Fairburn et al., 1999; Williamson, Muller, Reas, \& Thaw, 1999). More specifically, Williamson argues that body checking might have a maintaining role in eating disorder psychopathology, because it might lead to the development of cognitive biases, such as selective attention for body-related information (Williamson, 1996; Williamson, Muller, Reas, \& Thaw, 1999). Taken together, there is reason to believe that body checking might lead to an attentional bias for body-related information. Nevertheless, as of yet there have been no studies that have put this assumption to an empirical test. Therefore, it will be investigated in chapter 5 whether the act of body checking leads to the development of a body-related attentional bias in a group of healthy participants.

The causal role of craving in the attentional bias for food. Inspired by findings from the field of addiction, it is proposed in the present dissertation that craving might lead to the development of an attentional bias for food-related information. In explaining the occurrence of attentional biases for drug-related cues, addiction theorists have proposed a link between selective attentional processing and craving (Franken, 2003; Robinson \& Berridge, 1993). Indeed, a substantial number of addiction studies have found significant correlations between attentional bias for craving-related stimuli and levels of subjective craving (e.g., Field et al., 2005b, 2007a; Franken et al., 2000; Mogg, Field, \& Bradiey, 2005; Rosse et al., 1993, 1997). Drawing on these findings, the present 
thesis investigates the assumption that food-related attentional biases in eating disorder patients are the result of an intense craving for food. Furthermore, as food cravings have been associated with overeating (Jansen, 1998), it might be hypothesized that these cravings act to maintain eating disorder psychopathology by biasing information processing in favour of food cues.

In sum, because there has been no research investigating which factors might account for an attentional bias for food in eating disorder patients, chapter 6 will experimentally address the causal impact of craving on the attentional processing of food-related information.

\section{Outline of the present dissertation}

The aim of the present dissertation is to fuel our understanding of the role of attentional biases in the origin and maintenance of eating disorder psychopathology, and in particular body dissatisfaction. The studies presented in the following chapters will deal with three themes: (1) The precise nature of the attentional bias in eating disorders (chapter 2), (2) Attention and body dissatisfaction (chapter 3 and 4), and (3) Factors that cause an attentional bias (chapter 5 and 6 )

Chapter 2 describes a study in which the visual search paradigm is used to examine the underlying components and the existence of an attentional bias for body-and foodrelated information in a group of eating disorder patients. Given that this paradigm allows for the differentiation between two subcomponents of the attentional bias (i.e., speeded detection and increased distraction), the study in chapter 2 sheds further light on the specific nature of the attentional bias for both food and body related informa. tion in diverse groups of eating disorder patients. It is hypothesized that eating disorder patients show evidence of speeded detection of and increased distraction by body- and food-related information, in comparison to healthy controls

After having gained more insight in the nature of attentional biases in eating disorder patients, chapter 3 tests the hypothesis that an attentional bias for bodyrelated information causes body dissatisfaction. Building on prior research from Jansen et al., (2005) who found that eating symptomatic individuals show a selective tendency to attend to their most unattractive body parts, chapter 3 describes a study that examines whether this processing style is causal to body dissatisfaction. Using a selfdeveloped ecologically valid attentional training paradigm, healthy participants are trained to selectively attend to either their self-defined most unattractive body parts (negative bias training) or their self-defined most attractive body parts (positive bias training). To gain insight in the impact of the training, levels of body satisfaction are 
assessed before and after the training. It is hypothesized that the negative bias training will induce a decrease in body satisfaction, whereas the positive bias training will induce an increase in body satisfaction.

Chapter 4 addresses the role of an individual difference variable that might cause women to feel dissatisfied with their bodies, in the context of today's appearancefocused society. In recent years, individual difference variables that can mediate the impact of the media on women's mental health, have been identified (e.g., Posavac, Posavac, \& Posavac, 1998; Trampe, Stapel, \& Siero, 2007; Stice \& Whitenton, 2002) One of these variables is the increased tendency to engage in social comparison with other women (Cattarin, Thompson, Thomas, \& Williams, 2005; Dittmar \& Howard 2004; Jones, 2001; Tiggemann \& McGill, 2004). If one wants to protect women who have this tendency, it is important to gain a better understanding of the processes that might underlie this tendency to engage in social comparison. Given that self-activation has been found to increase people's interest in social comparison (Stapel \& Tesser, 2001), chapter 4 describes a study in which the causal role of self-activation on women's vulnerability to thin-ideal media images is examined. Restrained and unrestrained eaters are randomly assigned to either a self-activation condition or a contro condition, after which they are exposed to thin-ideal pictures. Levels of body satisfaction are assessed throughout the experiment. It is hypothesized that self-activated restrained eaters will show a decrease in body satisfaction after exposure to thin-ideal pictures compared to restrained eaters in the control condition. With regard to selfactivated unrestrained eaters in comparison to unrestrained eaters in the contro condition, no changes in body satisfaction after thin-ideal exposure are expected.

As of yet, there has been no research in the field of eating disorders that has investigated the factors that cause an attentional bias in eating disorder patients. In chapters 5 and 6 , the causal role of two typical eating disorder symptoms in the development of an attentional bias will be examined. Chapter 5 describes an experimental study in which the causal influence of body checking on the attentional bias for bodyrelated information is investigated. Body checking has been described as a typical behavioural manifestation of the over-evaluation of shape and weight (Fairburn, Shafran, Cooper, 1999), and has been considered to contribute to the maintenance of eating disorder symptoms (Fairburn, et al., 1999; Williamson, Muller, Reas, \& Thaw, 1999). In this perspective, the study in chapter 5 examines whether the act of body checking itself might lead to an attentional bias for body-related cues in the environment. Healthy participants are randomly assigned to one of three conditions: body checking condition, exposure condition, or control condition, and completed a body visual search task. It is hypothesized that participants who are assigned to the body checking condition will show evidence of speeded detection but not increased distrac- 
tion by body-related information in comparison to participants assigned to the exposure or control condition. Furthermore, no differences are expected in attentiona processing between the body exposure and control condition, as it is hypothesized that passive body exposure will not lead to an attentional bias for body-related information.

Furthermore, inspired by findings from the field of addiction (e.g., Field et al. 2005b, 2007a; Franken et al., 2000; Mogg, Field, \& Bradley, 2005; Rosse et al., 1993 1997), chapter 6 describes an experimental study that addresses the causal influence of craving on the development of a food-related attentional bias. A sample of chocoholics and non-chocoholics are randomly assigned to an exposure condition (i.e., craving induction) or a non-exposure condition, and complete a pictorial visual search task. Levels of craving are assessed throughout the experiment. It is hypothesized that chocoholics in the non-exposure condition will show speeded detection of chocolate pictures, in comparison to chocoholics in the exposure condition and non-chocoholics in either the exposure or the non-exposure condition. Furthermore, it is hypothesized that experimentally induced craving (i.e., exposure condition) will cause increased distraction by chocolate pictures in chocoholics, but not in non-chocoholics, as compared to a non-exposure control condition.

Finally, in chapter 7 the results of the present dissertation will be summarized and discussed. Furthermore, clinical implications and directions for future research will be discussed. 


\section{Chapter 2}

Attentional bias for body and food in eating disorders 


\section{Abstract}

Previous research suggests that eating disorder patients show an attentional bias for body and food related information. However, so far little is known about the mechanisms that underlie the attentional favouring of this particular information in eating disorder patients. In the present study, we used both a body and a food visual search task to study speeded detection and increased distraction in eating disorder patients ( $n$ $=67)$ and healthy controls $(n=60)$. Compared to controls, eating disorder patients showed evidence of speeded detection of body related information, and increased distraction by food information. These results suggest that the mechanism underlying the biased attentional allocation of eating disorder patients varies, and is dependent upon the type of information they are presented with.

Keywords: attentional bias, eating disorders, speeded detection, increased distraction

\section{Introduction}

It has been only two decades since researchers have begun to acknowledge the relevance of cognitive biases in the etiology and maintenance of eating disorders (fo reviews see: Faunce, 2002; Lee \& Shafran, 2004; Williamson, White, York-Crowe, \& Stewart, 2004). Cognitive models point out that eating pathology arises from maladaptive knowledge structures (e.g., schemas) that are involved in the allocation of attention, in memory and in the interpretation of incoming information (Hargreaves \& Tiggemann, 2002; Williamson et al., 2004). Activation of these knowledge structures causes disorder-relevant information to be processed in a biased manner, resulting in a range of cognitive biases in attention, judgement and memory (Williamson et al., 2004). The focus of the current study is on one of these biases: the exact nature of the attentional bias in eating disorders.

An attentional bias refers to the tendency to selectively attend to disorder-relevant stimuli (e.g., Mathews and MacLeod, 2005; Williamson et al. 2004). According to cognitive models, individuals suffering from eating disorders are more likely to give priority to cues pertaining to body and food related information than to neutral cues, in comparison to healthy people. Indeed, the great majority of studies employing the emotional Stroop paradigm (e.g., Williams, Mathews, \& MacLeod, 1996) found that eating disorder patients show increased interference when naming the color of disorder-relevant word stimuli as compared to neutral stimuli (for reviews see: Dobson \& Dozois, 2004; Lee \& Shafran, 2004). Although these interference effects have generally 
been interpreted as direct evidence for an attentional bias, alternative explanations have been put forward (Jansen, Nederkoorn, \& Mulkens, 2005; Macleod, 2005; Lee \& Shafran, 2004). For example, De Ruiter \& Brosschot (1994) have argued that attempts to cognitively avoid the processing of disorder-relevant word stimuli might also result in increased interference scores. Given this uncertainty about the meaning of increased interference scores, no firm conclusions can be drawn about the existence of an attentional bias in eating disorder patients on the basis of results in the emotional Stroop paradigm.

A better alternative for studying attentional biases is the dot-probe paradigm (Macleod, Mathews, \& Tata, 1986), because it allows for the differentiation between attention directed towards or away from a particular type of information. To date, two studies have investigated attentional processes in eating disorder patients using the dot-probe paradigm. Rieger and colleagues (1998) demonstrated that eating disorder patients showed a tendency to direct their attention towards words denoting a large physique and away from words denoting a thin physique. More recently, using a pictorial version of the dot-probe paradigm, Shafran and colleagues (2007) found robust attentional bias effects for eating and weight related stimuli in eating disorder patients in comparison to controls, but less consistent effects for shape related stimuli.

Although it is possible to use the dot-probe paradigm to distinguish engagement and disengagement subcomponents of attention, either by manipulating the presentation duration (Mogg, et al., 2004), or by including neutral trials (Koster, Crombez, Verschuere, \& De Houwer, 2004; Salemink, van den Hout, \& Kindt, 2007), the dot-probe paradigm has not been used in this way in eating disorders research. It thus remains an unresolved issue how the attentional bias in eating disorder patients can be understood in terms of facilitated attention to or slowed withdrawal from the disorder-relevant information.

Though possibly reflecting a somewhat different distinction, in this study we use a paradigm that is able to distinguish two subcomponents of attention: speeded detection (i.e., increased orienting toward relevant stimuli) and distraction (i.e., increased distraction by relevant stimuli). Like Rinck and colleagues (Rinck, Reinecke, Ellwart, Heuer, \& Becker, 2005) we use the odd-one-out variant of the visual search paradigm (Hansen \& Hansen, 1988). Rinck and colleagues (2005) studied the nature of attentional bias in spider-fearful individuals. Participants were presented with matrices of 20 pictures and they were instructed to indicate whether the matrix consisted of 20 animal pictures of the same category or whether it included one animal picture from a differ ent category. Results indicated that both speeded detection of threatening target pictures (i.e., faster detection of a spider picture among 19 neutral pictures than a neutral picture among 19 neutral pictures from another category) and increased 
distraction by threatening distractors (i.e., slower detection of a neutral image among 19 spider pictures than a neutral image among 19 neutral images from another category) were involved in the attentional processing of spider fearful participants.

To sum up, given both the controversy concerning the interpretation of increased interference scores in the emotional Stroop research and the lack of knowledge about which mechanism underlies an attentional bias in eating disorders, it is of interest to investigate more precisely the attentional bias for body and food stimuli in eating disorder patients. Inspired by the visual search methodology as adopted by Rinck et. al (2005), we designed a body and a food related version of the odd-one-out visual search task to study both speeded detection and increased distraction. Speeded detection of disorder-relevant concepts (i.e., body or food related words) is studied by comparing response latencies to detect a disorder-relevant target word vs. a neutral target word among neutral distractor words from another category. Increased distraction is studied by comparing response latencies to detect a neutral target word among disorderrelevant vs. neutral distractor words from another category. It is hypothesized that eating disorder patients show evidence of speeded detection of and increased distraction by body and food related information, in comparison to controls.

\section{Method}

\section{Participants}

A total of 128 participants took part in the experiment. Sixty-eight female eating disorder (ED) patients were recruited at the national Centre for Eating Disorders Ursula in Leidschendam, the Netherlands. At the time of intake, all patients fulfilled the DSM-IV diagnostic criteria for either anorexia nervosa (AN) or bulimia nervosa (BN). The ED group consisted of $22 \mathrm{AN}$ patients restrictive type, $24 \mathrm{AN}$ patients purging type, and 22 BN patients. The control group consisted of 60 female undergraduates of Maastricht University, the Netherlands. Inclusion criteria for the control group were: no past history of eating disorders, a Body Mass Index (BMI = weight $/$ height $^{2}$ ) within the norma range (18.5 - 25), and an unrestrained eating style, represented by a score below 15 on the Restraint Scale (Herman \& Polivy, 1980). Control participants scored on average $8.58(S D=4.17)$ on the Restraint Scale. All participants received a financial compensation of 7.50 euro for their participation. The study was approved by the medical ethical committee of the academic hospital Maastricht.

One control participant and two eating disorder patients were excluded from the analyses due to a high percentage of outliers responses and errors (> $M+3 S D=25 \%$ ) 
This left us with a total of 125 participants. At the time of testing, all patients were receiving inpatient treatment and part of the treatment is the obliged consumption of three meals a day. As a consequence their BMI had significantly increased from the time of intake to the testing day, $t(65)=6.49, p<.001$. There was no diagnostic interview repeated at testing day, but the patients completed the EDE-Q. Their scores still seem to be in the pathological range, being not different from clinical ED samples (see e.g., Fairburn \& Cooper, 1993).

Analyses of Variance (ANOVA) revealed that subgroups did not differ significantly on age, but the eating disorder groups differed significantly from the controls on all questionnaires. Post Hoc analyses indicated that eating disorder patients showed more eating pathology and were more body dissatisfied than controls. Moreover, it was shown that eating disorder patients were more depressed than control participants. The three eating disorder groups did not differ significantly from one another on these variables measuring more general aspects of psychopathology. See Table 1 for means, F-values and Post-Hoc comparisons.

\section{Materials}

General description Odd-one-out Visual Search Task. Each trial started with a brief tone, after which the participant was shown a fixation cross for $500 \mathrm{~ms}$ in the middle of the computer screen. Thereafter, she was presented with a $5 \times 4$ matrix of 20 words and was instructed to indicate whether the matrix contained 20 words of the same category or whether it contained one word from a different category (the odd-one-out). In the participant instructions, information was given about the possible categories stimuli could come from. If there was an odd-one-out word (henceforth called the target word) in the matrix, she had to press the right button of a response-box. If the matrix was made up of 20 words of the same category, she had to press the left button. The matrix remained on screen until response or for a maximum of 20 seconds. Immediately after the participant responded, a new trial began. 


\begin{tabular}{|c|c|c|c|c|c|}
\hline & $\begin{array}{l}\text { AN restrictive } \\
n=21\end{array}$ & $\begin{array}{l}\text { AN purging } \\
n=23\end{array}$ & $\begin{array}{l}\text { BN } \\
n=22\end{array}$ & $\begin{array}{l}\text { Controls } \\
n=59\end{array}$ & $\begin{array}{l}F \\
(3,121)\end{array}$ \\
\hline Measure & $M(S D)$ & $M(S D)$ & $M(S D)$ & $M(S D)$ & \\
\hline Age (vears) & $25.0_{\mathrm{a}}(9.0)$ & $25.7_{\mathrm{a}}(6.9)$ & $25.1_{a}(5.5)$ & $25.7 \mathrm{a}(7.72)$ & .17 \\
\hline BMl at intake & $15.0_{\mathrm{a}}(1.5)$ & $16.7_{b}(1.8)$ & $21.8_{\mathrm{s}}(3.6)$ & $\cdot$ & $42.1^{* \prime \prime}$ \\
\hline BMI at testing day & $16.7_{\mathrm{a}}(2.2)$ & $18.8_{b}(1.3)$ & $22.5_{c}(3.0)$ & $22.0_{c}(2.7)$ & $30.6^{*}$ \\
\hline $\begin{array}{l}\text { Eating Psychopathology } \\
\text { (EDE-Q global) }\end{array}$ & $3.3_{\mathrm{a}}(1.6)$ & $3.3_{a}(1.4)$ & $3.5_{\mathrm{a}}(1.2)$ & $0.8_{\mathrm{b}}(0.6)$ & $58.0^{*}$ \\
\hline Eating Concern (EDE-Q EC) & $3.0_{a}(1.4)$ & $2.7_{\mathrm{a}}(1.4)$ & $3.0_{a}(1.3)$ & $0.3_{\mathrm{b}}(0.3)$ & $67.0^{*}$ \\
\hline Shape Concern (EDE-Q SC) & $4.2_{\mathrm{a}}(1.8)$ & $4.5_{\mathrm{a}}(1.6)$ & $4.6_{\mathrm{a}}(1.1)$ & $1.0_{\mathrm{h}}(0.9)$ & $76.2^{*}$ \\
\hline Weight Concern (EDE-QW) & $3.7_{\mathrm{a}}(1.9)$ & $3.8_{\mathrm{a}}(1.6)$ & $4.1_{\mathrm{a}}(1.3)$ & $1.0_{\mathrm{b}}(0.8)$ & $52.6^{*}$ \\
\hline Restraint (EDE-Q R) & $2.4_{a}(1.7)$ & $2.2_{\mathrm{a}}(1.4)$ & $2.5_{a}(1.6)$ & $0.9_{\mathrm{b}}(0.8)$ & $13.5^{*}$ \\
\hline Body dissatisfaction (EDI-II B) & $4.5_{\mathrm{a}}(1.1)$ & $4.7_{\mathrm{a}}(0.8)$ & $4.7 \mathrm{a}(1.0)$ & $3.1_{b}(1.0)$ & $27.4^{*}$ \\
\hline Body dissatisfaction (BSQ) & $59.6_{\mathrm{a}}(30.3)$ & $62.2_{a}(15.7)$ & $61.0_{0}(14.7)$ & $26.3_{b}(8.8)$ & $46.2^{*}$ \\
\hline Depression (BDI) & $29.2_{a}(14.4)$ & $29.5_{a}(11.0)$ & $28.3_{\mathrm{a}}(12.6)$ & $4.2_{b}(4.6)$ & $67.7^{*}$ \\
\hline
\end{tabular}

Note. $\mathrm{BMI}=$ Body Mass Index = weight in kilograms/height in meters ${ }^{2}$ EDE-Q global = Eating Disorder Examination Questionnaire, global score; EDE-Q EC = Eating Disorder Examination Questionnaire, eating concern subscale; EDE-Q SC = Eating Disorder Examination Questionnalre, shape concern subscale; EDE$Q W C=$ Eating Disorder Examination Questionnaire, weight concern subscale; EDE- $Q R=$ Eating Disorder Examination Questionnaire, restraint subscale; EDI-II BD = Eating Disorders Inventory, Body Dissatisfaction Subscale; BSQ = Body Shape Questionnaire; BDI = Beck depression inventory. Means with different subscripts differ significantly at $p<.001$, as indicated by Bonferroni corrected Post-Hoc tests. ${ }^{*} p<.001$. " df $(2,62)$.

The matrix was either made up of one disorder-relevant target word among 19 neutral distractor words, one neutral target word among 19 disorder-relevant distractor words, one neutral target word among 19 neutral distractor words of a different category, or of 20 words of the same category (i.e., target absent trials). In line with Rinck et al. (2005), the majority of the trials were target present trials, because only this type of trials is relevant for testing the hypotheses. The location of each word in each matrix was chosen randomly for each trial and for each participant. However, the target word never appeared directly above or below the location of the fixation cross to avoid faclitated detection. Each of the visual search tasks lasted approximately 15 minutes, divided over two blocks of trials of 7.5 minutes. The participant was given a brief break 
between blocks and tasks. The distance between participant and screen was approximately $60 \mathrm{~cm}$.

Body related Visual Search Task. Word stimuli from three categories were used: body, countries (neutral), and musical instruments (neutral). Matrices on target present trials consisted of one body related word among 19 countries or 19 musical instruments, one musical instrument or country among 19 body related words, one musical instrument among 19 countries, or one country among 19 musical instruments. Each of these six types of matrices was shown 19 times to each participant. Matrices on target absent trials consisted of 20 countries, 20 musical instruments, or of 20 body related words. There were 114 target present trials, 30 target absent trials and 12 practice trials.

Food related visual search task. Word stimuli from four categories were used: high caloric food, low caloric food, colors (neutral), and names (neutral). The function (i.e., target or distractor) of the neutral categories (colors and names) was counterbalanced over participants. Matrices on target present trials consisted of one high caloric or lowcaloric food word among 19 names/colors, one name/color among 19 high-caloric or low-caloric food words, one name among 19 colors, one color among 19 names. Each of the six types of matrices was shown 19 times to each participant. Matrices on target absent trials consisted of 20 high caloric food words, 20 low caloric food words, 20 colors, or of 20 names. There were 114 target present trials, 40 target absent trials, and 12 practice trials.

Stimulus material. For the current study, 140 words were selected to create 20 item word lists from disorder-relevant (i.e., body, high caloric food, low caloric food) and neutral (i.e., music, countries, colors, names) categories. Stimulus words of the seven categories did not differ significantly in length, all $t^{\prime} s<.119$, all $p^{\prime} s>.05$. Within the frame of the matrix, words were horizontally separated by $6.76 \mathrm{~cm}$ and vertically by $6.5 \mathrm{~cm}$ (measured from the middle point of the stimulus word). All words were displayed on a light-grey background on a 17-inch monitor with a resolution of $1280 \times$ 1024 pixels.

Questionnaires. Participants filled out Dutch versions of four questionnaires. (1) The Eating Disorders Examination Questionnaire (EDE-Q; Fairburn \& Beglin, 1994), a 36 item self-report measure of eating attitudes and behaviors, was used to measure the presence and severity of eating pathology. The EDE-Q has excellent test-retest reliability and internal consistency (Luce \& Crowther, 1999). (2) The Body Dissatisfaction subscale of the Eating Disorders Inventory (EDI-II BD; Gardner, 1991) was used to measure overall satisfaction with body and shape. The psychometric qualities of the EDI-II have been well established (Espelage et al., 2003). (3)The Body Shape Questionnaire (BSQ; Cooper, Taylor, Cooper, \& Fairburn, 1987) was used to measure shape and 
weight concerns, and is a psychometrically sound 16-item self-report measure (Rosen, Jones, Ramirez, \& Waxman, 1996). (4) Depression was measured by The Beck Depression Inventory (BDI; Beck, Ward, Mendelsohn, Mock, \& Erbaugh, 1961), which has ver good construct validity and reliability (Beck, Steer, \& Garbin, 1988). Control participants filled out one additional questionnaire: The Restraint Scale (RS; Herman \& Polivy, 1980). This scale measures the extent to which participants try to restrain their food intake and show weight fluctuations. All participants were weighed and their height was measured to calculate their BMI.

\section{Procedure}

All participants were tested individually between 9 am and 12 am or $1 \mathrm{pm}$ and $4 \mathrm{pm}$. Upon entering the experimental room, the participant was told that the study consisted of a computer task and some questionnaires. After signing the informed consent, she was given instructions about the visual search task. She then completed both the body and the food related version of the visual search task. The order in which participants completed both versions of the task was counterbalanced. After the visual search task the participant was asked to complete the EDE-Q, the EDI-II BD, the BSO, and the BDI respectively. Control participants were asked to also fill out the RS. Hereafter, height and weight were measured. Finally, she received a financial compensation for her participation. All participants were debriefed in writing after the experiment was completed.

\section{Results}

\section{Data reduction and target-absent trials}

The main analyses were done on the target-present trials. For both tasks, errors (i.e., misses; food: $8.60 \%$; body: $8.93 \%$ of the target-present trials) and responses faster than $200 \mathrm{~ms}$ and slower than $20.000 \mathrm{~ms}$ (food: $0.03 \%$; body: $0.06 \%$ of the targetpresent trials) were discarded. Furthermore, response latencies higher than three standard deviations (SD) above the overall mean of the remaining response latencies were excluded (body: $1.0 \%$; food: $1.0 \%$ of the target-present trials). None of the response latencies was lower than three SD below the mean.

False alarm rates to the target absent trials in the body visual search task were low (body: $4.96 \%$; country: $3.92 \%$; music: $5.20 \%$ ). A 3 (Stimulus category: body vs. music vs. country) $\times 2$ (Group: ED vs. controls) repeated measures ANOVA, revealed that the 
Stimulus category $\times$ Group interaction was not significant, $F(2,121)=0.35, n s$, indicating no significant differences between ED and controls on the false alarm rates for body (ED: $5.45 \%$, controls: $4.40 \%$ ), country (ED: $3.94 \%$, controls: $3.90 \%$ ), and music (ED: 5.9 $\%$, controls: $4.41 \%)$ target-absent trials. Main effects of Stimulus category, $F(2,122)=$ $.35, n s$, and of Group, $F(1,123)=.61, n s$, were also non-significant.

False alarm rates to the target-absent trials in the food visual search task were also low (HCF: $2.48 \%$; LCF: $3.68 \%$; colors: $2.32 \%$; names: $4.48 \%$ ). A 4 (Stimulus category: HCF vs. LCF vs. colors vs. names) $\times 2$ (Group: ED vs, controls) repeated measures ANOVA, revealed a significant main effect of Stimulus category, $F(3,121)=4.53, p<.01$, but not of Group, $F(1,123)=0.05$, ns. The Stimulus category $\times$ Group interaction was not significant, $F(3,120)=0.42$, ns, indicating no significant differences between $E D$ and controls on the false alarm rates for HCF (ED: $2.73 \%$, controls: $2.20 \%$ ), LCF (ED: $3.48 \%$, controls: $3.90 \%$ ), colors (ED: $2.42 \%$, controls: $2.20 \%$ ), and names (ED: $3.94 \%$, controls: $4.92 \%)$ target absent trials.

Hypothesis 1: ED patients show evidence of speeded detection of body related information in comparison to controls.

Results were analysed in a 2 (Group: ED vs. controls) $\times 2$ (Target type: body vs. neutral) repeated measures ANOVA. Consistent with our hypothesis, a significant Group $\times$ Target type interaction, $F(1,123)=11.98, p<.01, \eta_{p}{ }^{2}=.09$, was found, qualifying main effects of Target Type, $F(1,123)=30.95, p<.001, \eta_{\mathrm{p}}{ }^{2}=.20$, and Group, $F(1,123)=15.03, p<$ $.001, \eta_{p}{ }^{2}=.11$. See Figure 1 for means and SEs. Additional independent samples t-tests indicated that ED patients were significantly slower than controls at detecting body related target words, $t(123)=2.69, p<.01, d=.62$, and neutral target words, $t(123)=$ $4.62, p<.001, d=.83$. Even though ED patients were slower than controls on both types of trials, the significant Group X Target type interaction shows that ED patients, relative to controls, did show a benefit in the speed with which they detected a body related target word as compared to a neutral target word. In other words, the difference in detection speed between ED patients and controls was less pronounced for body target words than for neutral target words, proving the relative benefit for body related words in ED. 


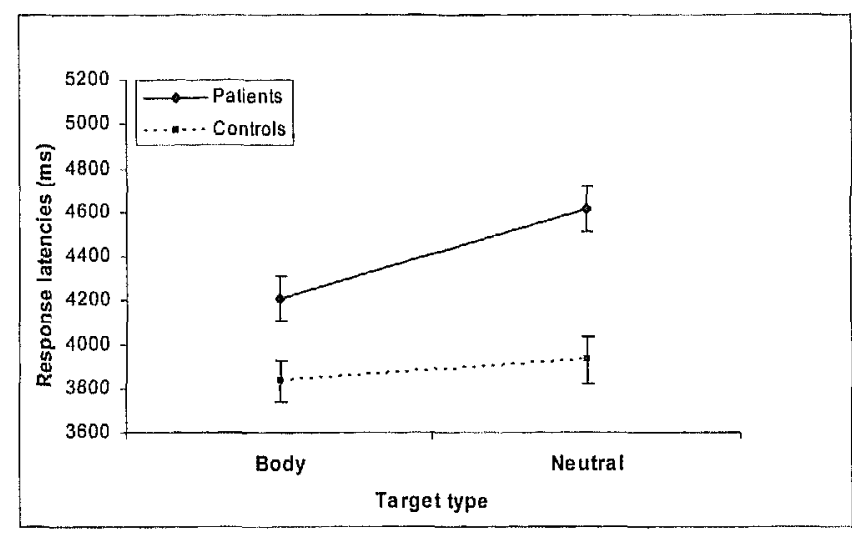

Figure 1a. Mean response latencies for trials in which participants searched for 1 body target-word among 19 neutral words (target type $=$ body), and for trials in which participants searched for 1 neutral target-word of one category among 19 neutral words of another category (target type = neutral). Results are presented separately for ED patients and healthy controls. Error bars represent one standard error. This graph shows that ED patients show evidence of speeded detectlon of body-related information, compared to controls.

Hypothesis 2: ED patients show evidence of increased distraction by body related information in comparison to controls.

Results were analysed in a 2 (Group: ED vs. controls) $\times 2$ (Distractor type: body vs. neutral) repeated measures ANOVA. Of main interest to our hypothesis, a significan Group $x$ Distractor type interaction, $F(1,123)=15.81, p<.001, \eta_{p}{ }^{2}=.11$, was found qualifying main effects of Distractor type, $F(1,123)=60.17, p<.001, \eta_{p}{ }^{2}=.33$, and of Group, $F(1,123)=13.51, p<.001, \eta_{p}^{2}=.10$. See Figure 2 for means and SEs. Additional independent samples t-tests indicated that ED patients were significantly slower than controls with neutral distractors, $t(123)=4.62, p<.001, d=.83$, and with body related distractors, $t(123)=2.31, p<.05, d=.42$. Even though ED patients were slower than controls on both types of trials, the significant Group $X$ Distractor type interaction shows that, relative to controls, they did show a benefit for the body related distractors as compared to the neutral distractors. In contrast to our hypothesis, the difference in distraction between ED patients and controls was less pronounced for body distractor words than for neutral distractor words. 


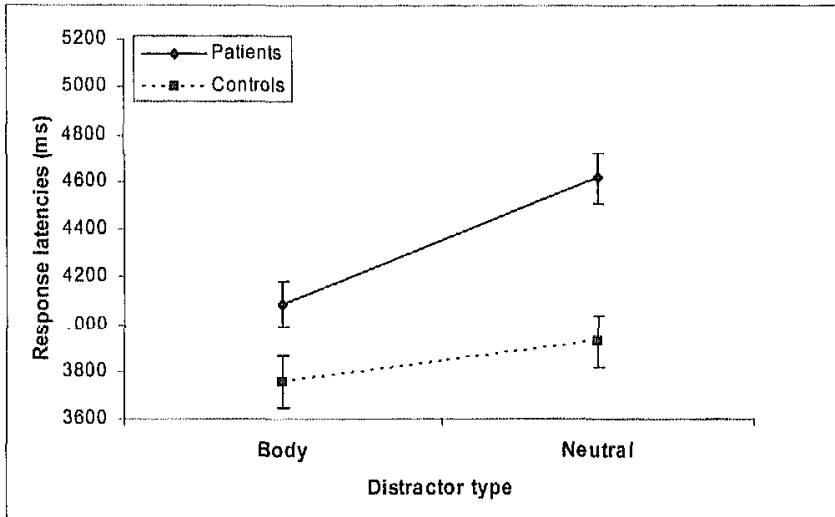

Figure 1b. Mean response latencies for trials in which participants searched for 1 neutral target-word among 19 body related distractor-words (distractor type $=$ body), and for trials in which participants searched for 1 neutral target-word of one category among 19 neutral distractor-words of another category (distractor type $=$ neutral). Results are presented separately for ED patients and healthy controls. Error bars represent one standard error. This graph shows that ED patients are not more controls. Error bars represent one standard error. This graph

Hypothesis 3: ED patients show evidence of speeded detection of high caloric food information in comparison to controls.

Results were analysed in a 2 (Group: ED vs. controls) $\times 3$ (Target type: high caloric food vs. low caloric food vs. neutral) repeated measures ANOVA, which yielded a significant main effect of Group, $F(1,1.23)=5.71, p<.05, \eta_{p}{ }^{2}=.05$, and a marginal significant effect of Target type, $F(1.9,231.24)=2.64, p=.07, \eta_{p}{ }^{2}=.02$. However, the Group $x$ Target type interaction, $F(1.9,231.24)=0.77$, ns, was not significant. See Figure 3 for means and SEs. Taken together, no evidence was found for speeded detection of high caloric food words in ED. 


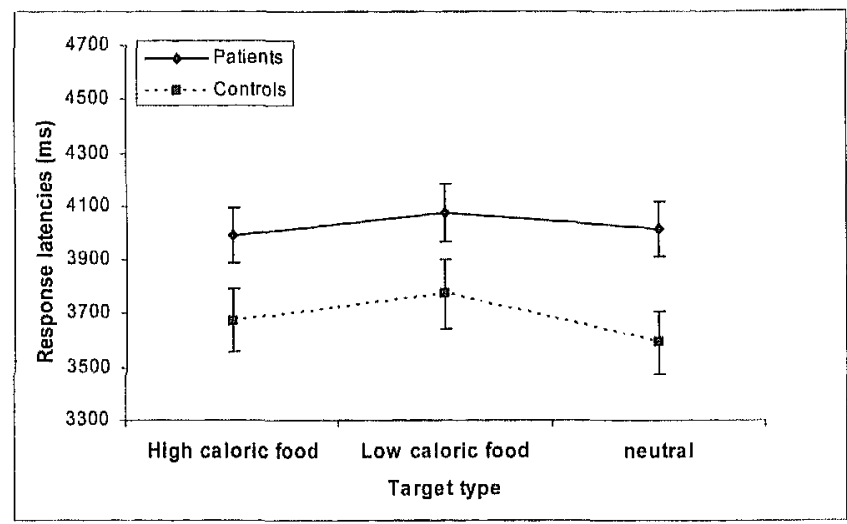

Figure 2a. Mean response latencies for trials in which participants searched for 1 high caloric food target-word among 19 neutral words (target type = high caloric food), for 1 low caloric food target-word among 19 neutral words (target type = low caloric food), and for trials in which participants searched for 1 neutral target-word of one category among 19 neutral words of another category (target type = neutral). Results are presented separately for ED patients and healthy controls. Error bars represent one standard error.

Hypothesis 4: ED patients show evidence of increased distraction by high caloric food information in comparison to controls.

Results were analysed in a 2 (Group: ED vs. controls) $\times 3$ (Distractor type: high caloric food vs. low caloric food vs. neutral) repeated measures ANOVA. Of main interest to our hypothesis, a marginally significant Group $\times$ Distractor type interaction was found, $F$ $\left(2.0,243.50^{1}\right)=2.91, p=.06, \eta_{p}{ }^{2}=.02$, qualifying main effects of Distractor type, $F(2.0$, $\left.243.50^{1}\right)=2919, p<.001, \eta_{\mathrm{p}}{ }^{2}=.19$, and of Group, $F(1,123)=7.27, p<.001, \eta_{\mathrm{p}}{ }^{2}=.06$. See Figure 4 for means and SEs. Additional independent samples t-tests indicated that ED patients were significantly slower than controls at detecting neutral target words among high caloric food distractors, $t(123)=3.25, p<.01, d=.64$, and among neutral distractors of another category, $t(123)=2.20, p<.05, d=.40$. In contrast, both groups were equally slow at detecting a neutral target word among low caloric food distractors, $t(123)=1.75, p=.08$.

To test whether the difference between ED patients and controls was larger for high caloric foods than for neutral distractors, an additional 2 (Group: ED vs. controls) $x$ 2 (Distractor type: high caloric food, vs. neutral) repeated measures ANOVA was con-

${ }^{1}$ Greenhouse Geisser degrees of freedom were reported. 
ducted. Importantly, we found a significant Group $\times$ Distractor type interaction, $F$ (1 $123)=4.94, p=.03, \eta_{p}^{2}=.04$, qualifying main effects of Distractor type, $F(1,123)=$ $30.51, p<.001, \eta_{p}{ }^{2}=.20$, and of Group, $F(1,123)=9.08, p<.001, \eta_{p}{ }^{2}=.07$. The Group $x$ Distractor type interaction shows that the difference between ED patients and controls was more pronounced for high caloric food distractors than for neutral distractors. These results provide clear evidence for increased distraction by high caloric food words in eating disorder patients.

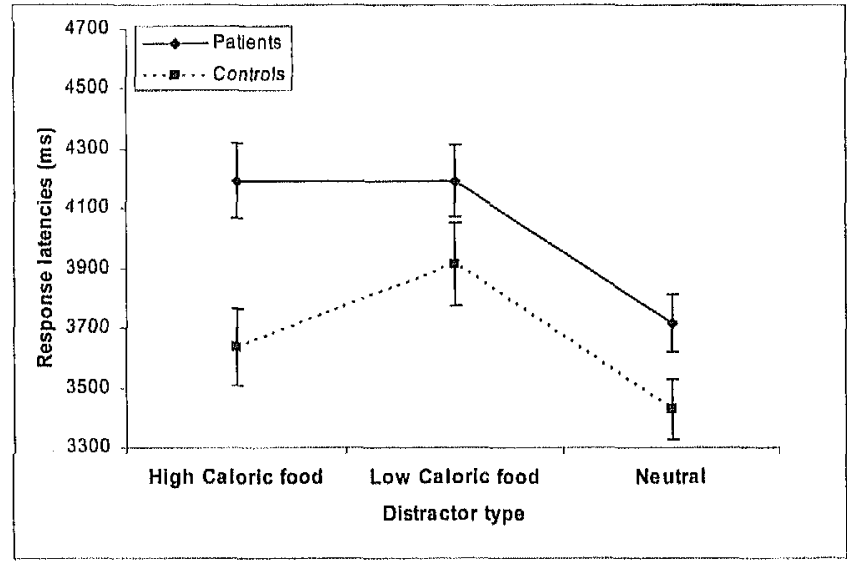

Figure $2 b$. Mean response latencies for trials in which participants searched for 1 neutral target-word among 19 high caloric food distractor-words (distractor type = high caloric food), for 1 neutral targetword among 19 low caloric food distractor-words (distractor type = low caloric food) and for trials in which participants searched for 1 neutral target-word of one category among 19 neutral distractor words of another category (distractor type $=$ neutral). Results are presented separately for ED patients and healthy controls. Error bars represent one standard error. This graph shows that ED patients are more distracted by high caloric food information, compared to controls. Error bar represents one standard error.

\section{Discussion}

The present study sought to confirm the assumed existence of an attentional bias for body and food stimuli, and to investigate how the attentional bias can be understood in terms of speeded detection of or increased distraction by the disorder-relevant information. Compared to controls, ED patients showed evidence of speeded detection of body-related information. However, our hypothesis of increased distraction by bodyrelated information was not confirmed; the ED patients were not more distracted by 
body-related information. Considering the food-related information, it was found that compared to controls ED patients showed evidence of increased distraction by high caloric food words, but there was no evidence of a speeded detection of high caloric food words.

Taken together, speeded detection accounted for the attentional favouring of body related information whereas increased distraction accounted for the attentional favouring of food related information in ED. Elaborating on the findings of Shafran et al., (2007), these findings suggest that the exact nature of the attentional bias in eating disorder patients is dependent upon the type of information they are presented with.

The current findings support cognitive-behavioural theories of ED, in that they underline the importance of attentional biases in ED psychopathology. By establishing the presence and exact nature of the attentional bias in eating disorder patients, our findings help illuminate the general nature of biased cognitive processes which are involved in ED. If the attentional bias acts as a maintaining factor in ED pathology, it would be worthwhile to investigate in future research whether reducing the attentional bias for body and food related information might lead to a reduction in ED pathology. Reducing biases by e.g. cognitive therapy or retraining might be different for biases related to speeded detection (body) and biases related to increased distraction (food). If body information is threatening and therefore elicits an attentional bias, behavioural experiments and cognitive restructuring might be focused on the extinction of anxiety and anxiety-related cognitions. If food information elicits a craving response, and therefore an attentional bias, behavioural experiments and cognitive restructuring might be focused on the extinction of craving and craving-related cognitions.

Our idea that body cues might elicit an attentional bias because they are threatening stems from anxiety studies. The results of the body visual search task in the present study are in line with several studies using the odd-one-out visual search task in spiderfearful individuals, and individuals suffering from social phobia (Gilbao-Schechtman, Foa, \& Amir, 1999; Öhman, Flykt, \& Esteves; 2001; Rinck \& Becker, 2006). More specifically, these studies on anxiety showed speeded detection of threatening information in the absence of increased distraction. In the present study, a same pattern was found: ED patients were faster at detecting body related information (i.e., speeded detection) whereas they were not more distracted by this type of information (i.e., no increased distraction), relative to neutral information. Quite the opposite, ED patients were more distracted by neutral distractors than by body related distractors. This is particularly interesting because it suggests that ED patients exhibit vigilance for body information (speeded detection) but are not more distracted by it, which may point to an avoidance response. In this line, one might speculate as to why ED patients exhibit this particular attentional bias for body related information in their environment. One possibility is 
that ED patients experience body related information as highly negative or even threatening, since they suffer from intense body concerns (Cash \& Deagle, 1997). Consequently, it can be hypothesized that the confrontation with negative stimuli in the body visual search task might have accounted for the present pattern of results.

Nonetheless, other studies from the field of anxiety seem to contradict this line of reasoning. Using the visual search task, Rinck and colleagues (2003; 2005) showed that the confrontation with threatening information does not only attract attention (i.e. speeded detection), but might also hold attention (i.e., increased distraction) in spider phobics. Given this inconsistency, the question as to whether an attentional bias for body related information reflects increased anxiety remains intriguing and warrants further investigation. Also of interest is to test whether decreased levels of body dissatisfaction (e.g., after treatment) are related to a slower detection of body cues, suggesting that the visual search paradigm might be a useful and implicit index of body image change

Our idea that food cues elicit an attentional bias because they elicit an appetitive or craving response stems from appetitive studies. With regard to the food visual search task, we found evidence for increased distraction by high caloric food words in ED patients without speeded detection. In other words, ED patients do not search for food information in the environment, but are distracted by these cues when they are confronted with an environment that is filled with high caloric food items. One might interpret this food attentional bias in two ways. On the one hand, one can hypothesize that food related information is experienced as highly negative by ED patients, because they suffer from an intense fear of gaining weight, In this line, the observed increased distraction effects might have been the consequence of a fear response, as has been documented in anxiety research (Rinck, Becker, Kellermann, \& Roth, 2003; Rinck et al., 2005). On the other hand, one can hypothesize that in an early stage of information processing, food related information might be experienced as positive instead of negative by ED patients. In this line, increased distraction might resemble a craving response for food. Research from the field of addiction seems to support this link. Mogg, Field, and Bradley (2005) found that greater maintained attention, which may resemble the distraction component in the visual search task, for smoking cues in smokers was associated with higher levels of craving. In the present study we did not measure levels of craving or anxiety; it would be of interest to further study whether the increased distraction by high caloric food cues in ED is anxiety- or craving-driven.

In the present study, the slower detection of a neutral target word among high caloric food distractors is interpreted as a difficulty to withdraw attention away from the food distractors, as we compare our findings to those of Mogg, Field, and Bradley (2005). It might however also be possible that it was not a difficulty to shift attention 
away from distracting stimuli (increased distraction), but successive attraction of the participants' attention by the diverse food stimuli. It is of great theoretical interest to find out in further studies, for example by using methods of eye tracking, whether the slower detection of a neutral target word among high caloric food distractors points to this difficulty to shift attention away from the high caloric food distractors or to distractors successively attracting the participants' attention.

In sum, this study investigated the mechanisms underlying the preferential processing of body and food related information in ED. It is concluded that the attentional biases in ED can be explained by two different components: speeded detection and increased distraction. The type of information with which ED patients are presented determines which of both components is involved in the bias. The attentional favouring of body related words can be explained by speeded detection of body-related information, whereas the attentional favouring of high caloric food related information can be explained by the difficulty to shift attention away from high calorie foods once detected. 


\section{Chapter 3}

Selective attention for unattractive body parts causes body dissatisfaction 


\section{Abstract}

Body dissatisfaction plays a key role in the maintenance of eating disorders and selective attention might be crucial for the origin of body dissatisfaction. Jansen et al., (2005) showed that eating disorder patients attend relatively more to their own unattractive body parts, whereas healthy controls attend relatively more to their own attractive body parts. In the current study, it was investigated whether this bias in selective attention is causal to body dissatisfaction. To test this hypothesis, we trained attention to either one's self-defined unattractive body parts (i.e., negative bias training) or one's self-defined attractive body parts (i.e., positive bias training) in 47 healthy female participants while registering eye-movements. The results show that inducing a temporary attentional bias for self-defined unattractive body parts led to a significant decrease in body satisfaction. The positive bias training did lead to a significant increase in body satisfaction but only when it followed the negative bias training. Registration of eye-movements showed that the bias inductions did not lead to long-lasting changes in visual attention. In conclusion, the current study supports the causal role of selective attention for unattractive body parts in the development of body dissatisfaction.

Keywords: Body dissatisfaction, Attentional bias, Eye-movements, Eating disorders, Attentional retraining

\section{Introduction}

Body dissatisfaction has been classified as one of the main diagnostic characteristics of eating disorders (APA, 1994). Individuals with eating disorders suffer from severe feelings of fatness and unattractiveness, and are characterised by intense body loathing (Cash \& Deagle, 1997). Cognitive models attribute an important role to cognitive biases in explaining the aetiology and maintenance of eating disorders psychopathology (Faunce, 2002; Lee \& Shafran, 2004; Williamson, White, York-Crowe, \& Stewart, 2004). More specifically, these models explain eating disorder symptoms (i.e., negative body image) in terms of maladaptive knowledge structures (e.g., schemas) that bias the processing of disorder-relevant information (Williamson et al., 2004). One type of cognitive bias that has been studied extensively is the attentional bias. An attentional bias $(A B)$ refers to the tendency to selectively attend to and give priority to disorderrelevant information (e.g., Mathews and MacLeod, 2005; Williamson et al. 2004). Ove the last two decades, much support has been found for the existence of an attentional bias in eating disorders (for reviews see: Faunce, 2002; Lee \& Shafran, 2004). More 
specifically, previous research using the modified Stroop paradigm (e.g., see Dobson \& Dozois, 2004), the visual probe paradigm (Rieger et al., 1998, Shafran et al., 2006), and the visual search paradigm (Smeets, Roefs, van Furth, \& Jansen, 2008) have indicated the existence of attentional biases for body and food related information in eating disorder patients.

Recent research from our laboratory shows that eating disorder patients not only show an attentional bias for body and food related information (i.e., words), but also for specific body parts (Jansen, Nederkoorn \& Mulkens, 2005). Jansen and colleague studied the attentional bias in eating disorders in a direct way, by exposing participants to pictures of their own and a control body while simultaneously registering eyemovements. Results indicated that eating disorder patients show a dysfunctional way of looking at their own and a control body, which might maintain eating disorders psychopathology. More specifically, results showed that when attending to their own body eating disorder patients attended more to their self-defined unattractive body parts than to their self-defined attractive body parts, whereas healthy controls attended more to their own attractive body parts than to their unattractive body parts. The pattern of results was reversed when participants were exposed to the control body: eating disorder patients attended relatively more to the attractive body parts (i.e. downward comparison), whereas healthy controis attended relatively more to the unattractive body parts (i.e., upward comparison; Jansen et al., 2005).

These data suggest that a selective tendency for attending to one's own unattractive body parts may maintain or even causes severe feelings of body dissatisfaction. The results of Jansen et al., (2005) are however correlational in nature, which precludes drawing conclusions about the causal status of an attentional bias for unattractive body parts in explaining body dissatisfaction. In the present study, this causal status is tested experimentally. A negative or a positive body image bias is temporarily induced, by presenting participants with a picture of their own body and training them to selectively attend to either their three self-defined most unattractive (i.e., negative bias training) or their three self-defined most attractive body parts (i.e., positive bias training). All participants who are assigned to the negative bias training receive an additional positive bias training afterwards. This is done not only for ethical reasons, but also to test whether temporarily induced feelings of body dissatisfaction can be repaired by means of a positive bias training. To investigate whether not only subjective feelings of (dis)satisfaction but also the participant's pattern of visual attention changes as a result of the training, participants are exposed to a picture of their own body for 30 seconds, before and after the training, while eye-movements are registered. In addition, the effects of the bias training on mood are assessed, to test whether mood changes parallel changes in body satisfaction. 
CHAPTER 3

In sum, the following hypotheses are tested: (1a) The negative bias training will induce a decrease in body and weight satisfaction, whereas the positive bias training will induce an increase in body and weight satisfaction. (1b) The positive counter induction training will repair body and weight satisfaction. (2) After a negative bias training, participants will look more (number of fixations and dwell time) at their unattractive body parts whereas after a positive bias training participants will look more at their attractive body parts, compared to before training.

\section{Method}

\section{Participants}

A total of 47 female undergraduate students were invited to participate in a study ostensibly testing the relation between perception and concentration, to disguise the real purpose of the experiment. All participants were randomly assigned to either the positive bias training ( $n=24)$, or the negative bias training $(n=23)$. Inclusion criteria were: no current or past history of eating disorders as assessed during recruitment, and a moderate score on the Body Shape Questionnaire (BSQ, score between 21-41), which measures overall body dissatisfaction. BSQ data were obtained through an undergraduate screening session at the beginning of the academic year. Participants had an average $B M I$ of $20.7(S D=1.9 ; 16.73-26.2)$, were on average $19.5(S D=1.3 ; 18-24)$ years old, and scored on average $29.3(S D=5.49 ; 21-41)$ on the BSQ. All participants received either a gift voucher or course credits for their participation. The present study was approved by the local committee for research ethics.

\section{Materials \& assessment}

Pictures. Participants were told that they would have their picture taken in their own underclothes in the lab, and were asked to wear neutral-coloured underwear at the day of testing. Pictures were taken with a Nikon D70 SLR camera. The front side of the participant's body was photographed from neck to toes (i.e., without the head being visible), against a white background. Participants stood in a standard position with their arms hanging loosely besides the body.

Individual stimulus selection. To select the body parts for the individually tailored bias training, participants were asked to fill out a so-called perception and concentration ranking questionnaire. As part of this fake questionnaire, with items on for example artworks, colors, and hobbies, participants received a black-and-white printed 
picture of their own body on which the experimenter had marked 12 body parts. They were asked to name and rank all marked body parts from most attractive to least attractive, and to give a grade (1: very negative - 10: very positive) for every body part. In a similar way they were asked to rank and give ratings for the distractor categories (e.g., artworks, colors, and hobbies). Furthermore, participants were asked to indicate how satisfied they were with their body overall (0: not satisfied at all - 10: very satisfied). The three most attractive or unattractive ranked body parts were selected as stimuli for the bias training.

Apparatus. During the attentional bias induction, participant's eye- movements were registered binocularly by the EyeLink I eye-tracking system distributed by SensoMotoric Instruments (SMI, Germany) and SR Research (Canada). The Eyelink I eye tracker is an infrared, head-mounted, video-based tracking system (two cameras), with a $250 \mathrm{~Hz}$ temporal resolution, a $0.005^{\circ}$ gaze and eye position resolution, and gaze position accuracy with $0.5-1.0^{\circ}$ average error. An additional infrared head-tracking camera positioned on the center of the headband detects and compensates for possible head motions ( $>1 \%$ over the acceptable range of head motion). The participant was seated at an approximate distance of $57 \mathrm{~cm}$ of a computer monitor (1024*768), with her head resting on a chin-rest. Eye-movement registration was done before, during, and after the attentional training. A Dell Optiplex GX110 Pentium III computer controlled the stimulus presentation, which was programmed in Presentation.

Satisfaction and mood. The Body Shape Questionnaire (BSQ; Cooper, Taylor, Cooper, \& Fairburn, 1987) was used to select participants with a moderate level of body dissatisfaction. The BSQ is a psychometrically sound 16- item self-report measure, assessing shape and weight concerns (Rosen, Jones, Ramirez, \& Waxman, 1996). Furthermore, state body satisfaction, state weight satisfaction, and state mood were each assessed before and after the attentional bias induction training, using $100 \mathrm{~mm}$ Visual Analogue Scales (VAS) asking "how do you feel at this very moment", and ranging from 0 - "extremely dissatisfied" to 100 - "extremely satisfied" and 0 - "depressed" to 100 - "happy". Participants in the negative bias condition received the VAS scales once more after the positive counter induction training.

\section{Attentional bias induction.}

To induce a temporary attentional bias for the participant's self-defined attractive or unattractive body parts, an individually tailored attentional bias induction training was developed. The first part of the program enabled us to insert the participants selfdefined attractive and unattractive body parts in the training procedure by indicating the body parts on the picture, and to select the condition participants were assigned to 
(e.g., negative or positive bias training). The second part of the program consisted of the attentional bias induction training itself. During the training, participants were instructed to detect and identify the nature of probes appearing at different locations on a fuzzy background picture of the participant's body and three neutral objects in the periphery. In half of the trials, participants had to discriminate the shape of the probe, and in the other half of the trials they had to discriminate the color of the probe. The task for the participant was varied (color and shape) to reduce boredom. During the training, the eye-tracker was connected to the stimulus presentation computer to monitor the illumination of the stimuli. As soon as the participant's gaze matched the location of the probe (as measured by the eye tracker), the underlying body part or neutral object lightened up while the rest of the body picture remained fuzzy. The illuminated part remained bright during four seconds to ensure that the participant could have a good look at it. Also, the participant was instructed to keep looking at the illuminated part until the start of the next trial (i.e., the full four seconds). This procedure ensured that the overt attention of the participant was directed at the stimulus.

Manipulations. In both conditions the probe appeared on $10 \%$ of the trials on one of three neutral objects located outside the body. In the negative bias training, the probe appeared on $90 \%$ of the trials on one of the three most unattractive body parts, whereas in the positive bias training, it appeared on $90 \%$ of the trials on one of the three most attractive body parts. The $90 \%$ was divided into $40 \%$ for the most (un)attractive body part, $30 \%$ for the second most (un)attractive body part, and $20 \%$ for the third most (un)attractive body part. The training lasted 20 minutes, consisting of 4 blocks of 40 trials. Participants who were assigned to the negative bias condition were given an additional positive bias training of 10 minutes (i.e., 2 blocks of 40 trials), which served as a positive counter induction training.

\section{Procedure}

All participants were tested individually. In the first session, the participant was invited to the lab to have her picture taken wearing neutral underwear. After signing the informed consent, she was asked to change into her own neutral underwear and her picture was taken. Then, the participants were given the perception and concentration ranking questionnaire, to select the body parts for the bias training.

The second session took place approximately one week later. Before the participant entered the lab, the experimenter inserted the participants self-defined attractive and unattractive body parts in the computer program. During the second session, the participant was given a range of VAS measuring body satisfaction, weight satisfaction, and mood among irrelevant filler items. After this, the participant was asked to take 
place in front of the computer. Then, the eye-tracker was placed on her head, and she was asked to rest her head on a chin-rest during the entire experiment. Furthermore, she was told that the size of her pupils would be registered throughout the session, as a measure of concentration. Nothing was told about the eye-movements. After the eyetracker had been calibrated, the experiment began. Participants were told that they were taking part in a visual discrimination task and that they would be presented with one of the pictures of the perception and concentration ranking questionnaire of the first session. In all cases this picture was the picture of the participant's own body of course. When the picture appeared on screen, participants were asked to look at it during 30 seconds while eye-movements were registered. After this, the picture turned fuzzy and the attentional bias induction training began. Participants were instructed to detect and discriminate the shape (square/circle) or color (red/green) of the probes appearing on the picture as quickly and accurately as possible. At the end of the training, the participant was again instructed to concentrate for 30 seconds on the picture of her own body, while eye-movements were registered, followed by the VAS measuring body and weight satisfaction and mood. Participants who were assigned to the negative bias training received an additional positive bias training. After completing the positive counter induction training the particjpant was again asked to concentrate on the picture of her own body for 30 seconds. Finally, she was asked to fill out the VAS measuring body and weight satisfaction, and mood. All participants were debriefed in writing after the experiment was completed.

\section{Results}

\section{Design and statistical analysis}

To measure whether the attentional bias training caused changes in body and weight satisfaction and mood, results were analysed in three 2 (Condition: negative bias training vs. positive bias training) $\times 2$ (Time: pre-training vs. post-training) mixed model ANOVAs with the VAS measures of body and weight satisfaction, and mood as the main dependent variables. In addition, to assess whether the positive counter induction was successful at restoring levels of state body and weight satisfaction, and mood, paired samples t-tests comparing post-training and post-counter induction training levels of body and weight satisfaction, and mood were conducted. Furthermore, eyemovements were analysed in a 2 (Condition: negative bias training vs. positive bias training) $\times 2$ (Time: pre-measurement vs. post-measurement) $\times 2$ (Body part: attractive vs. unattractive) mixed model ANOVA, to test whether dwell time and the number of 
fixations in the areas of interest (i.e., most attractive and unattractive body parts) changed after the training. Dwell time was defined as the total duration (in $\mathrm{ms}$ ) of time that was spent looking in the pre-defined areas of interest. The fixation duration threshold was set to $50 \mathrm{~ms}$. Both dwell time and number of fixations were measured during the 30 seconds exposure to the picture,

\section{Participant characteristics}

ANOVAs revealed that the two conditions did not differ significantly in age (positive bias training: $M=19.5, S D=1.3$; negative bias training $M=19.4, S D=1.4$ ), Body Mass Index (BMI = weight/height ${ }^{2}$; positive bias training: $M=20.6, S D=1.8$; negative bias training: $M=20.9, S D=1.9$ ), and BSQ (positive bias training: $M=28.8, S D=5.6$; negative bias training: $M=29.7, S D=5.4)$, all $F^{\prime} s(1,45)<1.0$, ns. Furthermore, the conditions did not differ significantly on pre-test measures of state body and weight satisfaction, and mood as measured by the VAS, both $F^{\prime} s(1,45)<1.0$, both $p^{\prime} s>.05$.

Hypothesis 1. (a) The negative bias training will induce a decrease in body and weight satisfaction, whereas the positive bias training will induce an increase in body and weight satisfaction. (b) The positive counter induction training will repair body and weight satisfaction.

Consistent with our hypothesis, a significant Time $x$ Condition interaction was found for body satisfaction, $F(1,45)=14.03, p<.01$, and for weight satisfaction, $F(1,45)=6.36$ $p<.05$, qualifying main effects of Time for both body satisfaction, $F(1,45)=8.59, p<$ .01 , and weight satisfaction, $F(1,45)=9.71, p<.01$. Additional paired samples t-tests for the negative bias condition revealed that participants in the negative bias condition showed a significant decrease in body satisfaction, $t(22)=4.51, p<.01$, and weight satisfaction, $t(22)=3.79, p<.01$, at post-measurement as compared to premeasurement (see Figure 1a and 1b). Additional paired samples t-tests for the positive bias condition revealed that participants in the positive bias condition did neither show a significant increase in body satisfaction, $t<1$, nor in weight satisfaction, $t<1$, at postmeasurement as compared to pre-measurement.

The positive counter induction training, which was given to the participants of the negative bias condition, did however lead to a significant increase in state body satisfaction, $t(22)=3.74, p<.01$, and weight satisfaction, $t(22)=2.12, p<.05$, from posttraining to post counter induction training. Additional paired samples t-tests comparing pre-training and post-training levels of body and weight satisfaction, showed that the positive counter induction training was effective at restoring levels of state body 
satisfaction, $t(23)=1.44, n s$, and weight satisfaction, $t<1$, to pre-measurement levels See Figure 1 for means and SEs on state body and weight satisfaction.

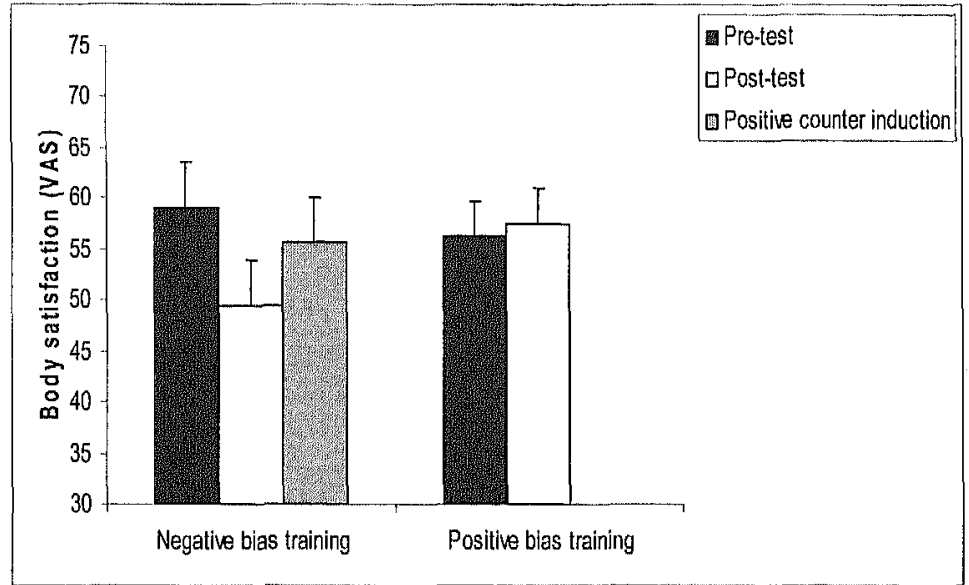

Figure 1a. Levels of state body satisfaction as measured by a visual analogue scale 10 "extremely dissatisfied" to 100 - "extremely satisfied") for the positive and negative training condition, before training (pre-test), after training (post-test), and after the tralning condition, before training (pre-test), after training (post-test), and after the
positive counter induction (negative bias training only). Error bars represent one standard error

Hypothesis 2. After a negative bias training, participants will look more at their unattractive body parts whereas after a positive bias training participants will look more at their attractive body parts, compared to before training.

Most importantly, the crucial Body part $x$ Time $x$ Condition interaction, which was of main interest to our hypothesis, failed to reach significance, for both dwell time, and number of fixations, $F^{\prime} s<1$. See Table 1 for means and SEs. Nevertheless, a significant Body Part $x$ Time interaction was found for dwell time, $F(1,45)=7.43, p<.01$, and for number of fixations, $F(1,43)=22.53, p<.001$. This interaction qualified main effects of Body part, for dwell time, $F(1,45)=26.76, p<.001$, and number of fixations, $F(1,43)=$ $25.29, p<.001$, and of Time, for dwell time, $F(1,45)=14.36, p<.001$, and number of fixations, $F(1,43)=81.41, p<.001$. 


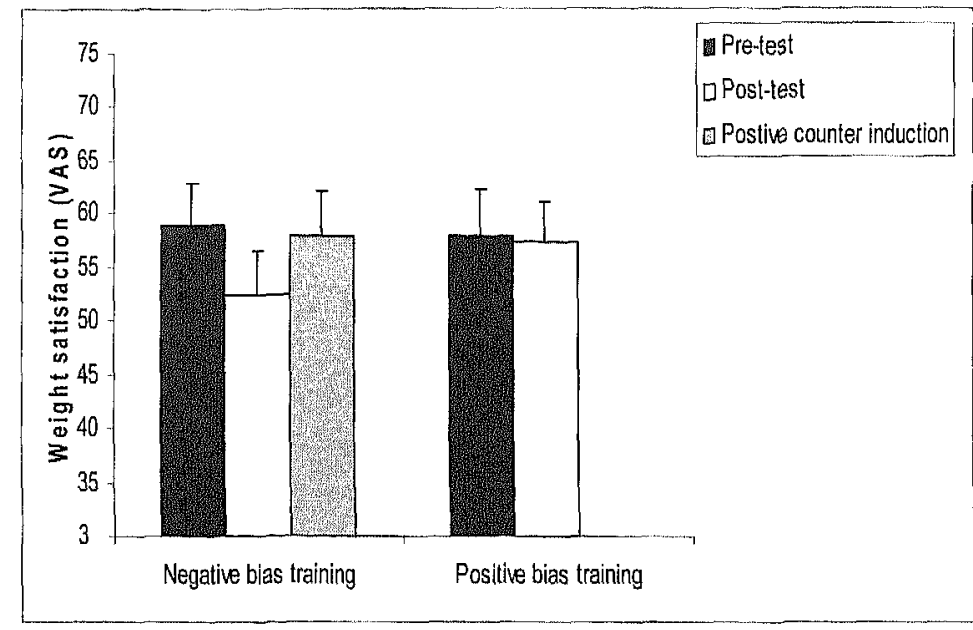

Figure $1 b$. Levels of state weight satisfaction, as measured by a visual analogue scale (0 - "extremely dissatisfied" to 100 - "extremely satisfied") for the positive and negative training condition, before training (pre-test), after training (post-test), and after the positive counter induction (negative bias training only). Error bars represent one standard error.

Table 1.

\begin{tabular}{lllll}
\hline & $\begin{array}{l}\text { Positive bias training } \\
n=24\end{array}$ & $\begin{array}{l}\text { Negative bias training } \\
n=23\end{array}$ \\
\hline & $\begin{array}{l}\text { Unattractive body } \\
\text { parts }\end{array}$ & Attractive body parts Unattractive body & $\begin{array}{l}\text { Attractive body } \\
\text { parts }\end{array}$ & \\
\hline & $M(5 D)$ & $M(S D)$ & $M(S D)$ & $M(S D)$ \\
\hline $\begin{array}{l}\text { Measure } \\
\text { Dwell time }\end{array}$ & $5124(3069)$ & $2566(2378)$ & $5740(2862)$ & $2992(2656)$ \\
$\begin{array}{l}\text { Pre-training } \\
\text { Post-training }\end{array}$ & $3299(3593)$ & $2178(1887)$ & $3083(1285)$ & $2088(1427)$ \\
\hline $\begin{array}{l}\text { Number of Fixations } \\
\text { Pre-training }\end{array}$ & $18.21(11.96)$ & $7.90(5.69)$ & $19.27(11.47)$ & $8.43(6.86)$ \\
Post-training & $7.75(4.75)$ & $4.51(3.22)$ & $7.44(2.86)$ & $5.52(3.86)$ \\
\hline
\end{tabular}

Note. In the positive bias training participants were trained to attend to their three self-defined most attractive body parts. In the negative bias training partlcipants were trained to attend to their three selfdefined most unattractive body parts. Dwell time was defined as the total duration (in ms) of time that was spent looking in the pre-defined areas of interest. The fixation duration threshold was set to $50 \mathrm{~ms}$. Both dwell time and number of fixations were measured during the 30 seconds exposure to the picture 
To better understand the body part $x$ time interaction, two sets of paired-samples $t$-tests were conducted. A first set of paired samples t-tests showed, that all participants dwelled less and fixated less often on both their attractive (dwell time: $t(46)=2.57$, $<.05$; fixations: $t(46)=4.89, p<001$ ) and unattractive (dwell time: $t(46)=4.36, p$ $<.001$; fixations: $t(46)=7.06, p<.001$ ) body parts at post-training than at pre-training So visual attention for trained body parts decreased from pre to post training, but, as is apparent from the interaction, this effect was strongest for the unattractive body parts.

A second set of paired samples t-tests showed that all participants dwelled longer and fixated more often on unattractive body parts than on attractive body parts at both pre-training (dwell time: $t(46)=4.21, p<.001$; fixations: $t(45)=5.04, p<.001$ ), and post-training (dwell time: $t(46)=2.17, p<.05$; fixations: $t(45)=3.65, p<.001$. So generally more visual attention was paid to unattractive than attractive body parts, but, as is apparent from the interaction, this effect was strongest at pre-training.

So, in contrast to our hypothesis, participant's pattern of visual attention did not change in the expected direction as a result of the training.

\section{Mood}

A trend significant Time $\times$ Condition interaction was found, $F(1,45)=3.31, p=.08$ which qualified a main effect of Time, $F(1,45)=18.05, p<.01$. Post-hoc paired samples $\mathrm{t}$-tests show a significant decrease in mood at post-training compared to pre-training in the negative training condition, $t(22)=4.02, p<.01$, and trend significantly in the positive training condition, $t(23)=1.90, p=.07$. An additional paired samples t-test showed no significant increase in mood after the positive counter induction compared to post-training, $t(22)=1.02$, ns.

See figure $1 \mathrm{c}$ for means and SEs on state mood. In sum, results show that all participants showed a decrease in mood after the training, but this decrease was less pronounced for participants in the positive training condition. 


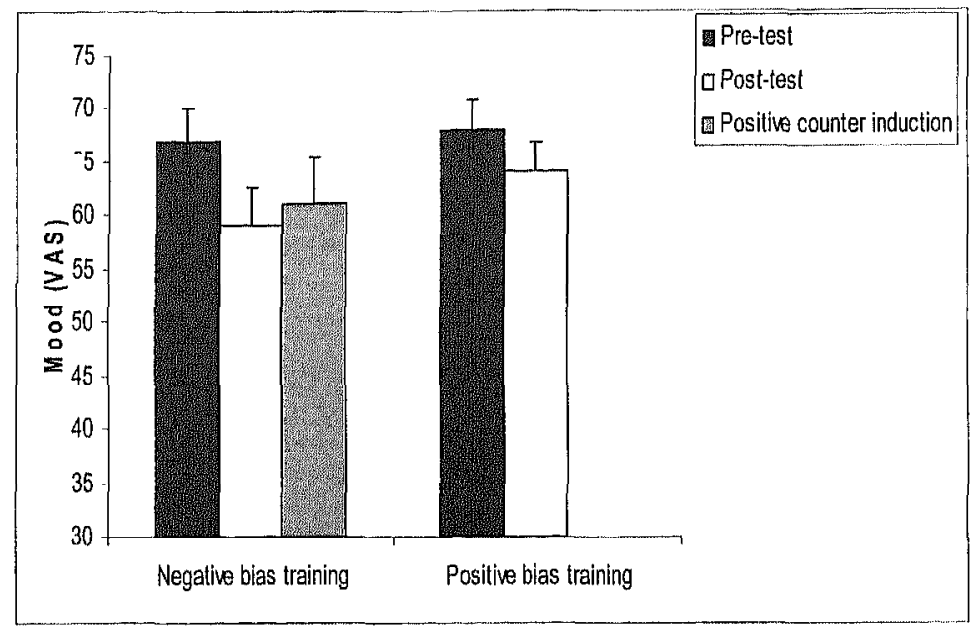

Figure 3. Levels of state mood as measured by a visual analogue scale (0 - "depressed" to 100 - "happy") for the positive and negative training condition, before training (pretest), after training (post-test), and after the positive counter induction (negatlve bias training only). Error bars represent one standard error.

\section{Discussion}

The aim of the present study was to test the causal role of selective attention for (un)attractive body parts in the induction of body (dis)satisfaction. More specifically, it was investigated whether training healthy participants to selectively attend to their three most unattractive body parts would lead to increased feelings of body/weight dissatisfaction, and whether training participants to selectively attend to their three most attractive body parts would lead to increased feelings of body/weight satisfaction. With respect to the negative bias induction training, the present results support the hypothesis that training participants to selectively attend their own self-defined unattractive body parts induces decreased feelings of body satisfaction. Contrary to our expectations, training participants to selectively attend to their own self-defined attractive body parts did not result in increased feelings of body satisfaction. Interestingly, though, the positive counter induction training did increase body satisfaction in participants who were first assigned to the negative bias induction training. With respect to the eye-movement data, results show that the induced negative or positive bias training did not have the expected influence on the amount of visual attention (i.e., dwell time and the number of fixations) for the trained body parts at post-training. The 
amount of visual attention for the trained body parts decreased from pre to post training, an effect that occurred for all body parts but was most pronounced for the unattractive body parts. Furthermore, results showed that all participants had a preference for looking at their self-defined unattractive body parts, although this effect was stronger at pre-training than at post-training. With respect to the analysis of mood, results show that all participants showed a decrease in mood after the bias training. Interestingly, however, this decrease was smaller for participants in the positive bias condition than for participants in the negative bias condition. These results show that inspecting a picture of one's own body for 20 minutes negatively affects one's mood, however when being trained to attend to one's attractive body parts this effect is less severe than after an attention training in unattractive body parts.

Taken together, the present findings provide support for the aetiological significance of biased attentional processes in body dissatisfaction. Elaborating on the findings of Jansen et al., (2005), it was shown that training healthy participants to view their bodies in a dysfunctional or biased way results in increased feelings of body dissatisfaction. More specifically, only a brief 20-minute negative bias training made healthy participants feel worse about their body. As eating disorder patients have been shown to selectively attend to their own unattractive body parts (Jansen, et al., 2005), it can be suggested that repeatedly attending to these parts might not only cause but also maintain intense feelings of body dissatisfaction. In this line, it would be worthwhile to investigate in future research whether reducing the attentional bias for unattractive body parts in eating disorder patients might lead to a reduction in body dissatisfaction.

Moreover, the present findings are in line with recent research by Smith and Rieger (2006) and Engel and colleagues (2006) supporting the causality of selective attention for body-related words in body dissatisfaction and eating concerns. Smith and Rieger (2006) used an attentional probe task to train healthy participant's attention toward or away from negative shape/weight related words, neutral words, or negatively valenced emotion words. After the training, participants were presented with a body image challenge (i.e., exposure to advertisements of slender models) to assess their levels of body dissatisfaction. As expected, results indicated that training an attentional bias toward shape/weight related words, in comparison to both control groups, led to increased levels of body dissatisfaction in healthy participants.

Engel and colleagues (2006) also used an attentional probe task, and trained healthy participant's attention toward or away from body/shape related words after which their concerns about eating and body were assessed. In contrast to the findings of Smith and Rieger (2006), Engel and colleagues (2006) found that training attention away from body/shape related words resulted in greater concerns about body and eating, than training attention towards body/shape related words. Although it is un- 
clear why these studies show opposite results, both studies confirm a causal relation between disturbed attentional processes and the development of eating disorder symptoms which nicely dovetails with the findings of the present study.

Eye-movements were registered before and after the training to check whether temporarily training participants to look at their body in a biased way would translate in a persisting attentional bias for the trained body parts, in addition to a change in body satisfaction. Results indicated that the bias training did not have a persisting effect on visual attention. The data show that a relatively short bias training that results in temporarily decreased body satisfaction in healthy participants is not automatically followed by a change in the pattern of visual attention for body parts. Considering that the training was short, it might not have been intensive or long enough to induce the expected changes in the pattern of visual attention. The data show that the overall dwelling time and number of fixations in all selected body parts decreased after the training, which might be an indication of tiredness or boredom. Moreover, the repetitive nature of the training might have led participants to shift their attention to novel stimuli during free looking at post measurement. Even though the bias training did not lead to a long-lasting change in visual attention, it should be noted that participant's attention had been successfully manipulated during the training, due to the gazedependent illumination of the trained body-parts. It would be of interest to find out under what circumstances a trained attentional bias might be more persistent.

With respect to the positive bias induction training, the hypothesis that temporary inducing selective attention for self-defined attractive body parts would lead to increased feelings of body satisfaction was only partly supported. The positive bias training in healthy women did not induce more satisfaction, although we had selected a group that had some room for improvement because of their scores in the middle range of the $\mathrm{BSO}$. It might not only be more difficult to induce a positive body image bias in reasonably satisfied women, it might in general be more difficult to induce positive biases than negative biases.

We could, however, find some support for the idea that a positive bias training leads to increased body satisfaction: the positive training did work for the group that first received a negative body image bias induction and, as a consequence of that training, showed a recent significant decrease in body satisfaction. These women had of course more room for improvement than the women who were assigned to the positive bias training without preceding negative bias induction, but another crucial difference is that their relative dissatisfaction was recently induced and thus not that tenacious.

The finding that a temporarily decrease in body and weight satisfaction could be reversed by training participants to selectively attend to their three most attractive body parts (i.e., positive counter induction training), shows that changes in a positive 
direction are possible. It would be a promising avenue for future research to find out under which conditions an attentional retraining might lead to a more positive body image in body dissatisfied people, and for example whether a more intensive and repetitive positive bias training might be of benefit for an increase in body satisfaction.

Finally, our findings may have some implications for the widespread use of body exposure therapy in clinical practice. In the light of the current findings, caution is warranted when exposing eating disorder patients to their own body in a mirror Specifically, because eating disorder patients have the natural tendency to attend to their unattractive body parts (Jansen et al., 2005), the present data show that unguided exposure might aggravate body image concerns because of this 'natural' self-imposed negative bias induction. 


\section{Chapter 4}

Self-activation in high restrained eaters causes body dissatisfaction 


\section{Abstract}

The present study sought to investigate the influence of self-activation on body and weight satisfaction in restrained and unrestrained eaters, after exposure to thin-ideal images. Restrained eaters $(n=39)$ and unrestrained eaters $(n=40)$ were randomly assigned to a self-activation manipulation versus a control manipulation. After the manipulation, all participants were exposed to eight thin-ideal images. Measures of state body- and weight satisfaction and of social comparison tendencies were assessed throughout the experiment. Self-activated restrained eaters showed a significant decrease in body and weight satisfaction after exposure to thin-ideal images, compared to restrained eaters who were not self-activated. In unrestrained eaters, the selfactivation manipulation did not have any effect on body or weight dissatisfaction. These results underline that it is not mere exposure to thin-ideal images that increases women's body dissatisfaction. Exposure to beauty models only had a negative influence on women's self-evaluations when two conditions were met: (1) the participant was 'self-activated', and (2) the participant classified as a restrained eater.

Keywords: Self-activation, social comparison, body dissatisfaction, restrained eaters, media exposure

\section{Introduction}

It is a commonly held belief that the media's focus on slenderness and beauty affects women adversely. By setting an unrealistic beauty standard, which most women desire but only few can meet, the media has been considered to promote feelings of body dissatisfaction in many women. Indeed, this belief seems to be supported by numerous correlational studies showing reliable relations between exposure to thin-ideal images in the media and negative self-evaluations (e.g., Harrison \& Cantor, 1997; Stice, Schupak-Neuberg, Shaw, \& Stein, 1994; Tiggemann, \& Pickering, 1996). Moreover, a plethora of experimental studies underline the detrimental effects of watching idealised music videos (Tiggemann \& Slater, 2004), television images (Lavine, Sweeney, \& Wagner, 1999), and advertisements (Stice \&. Shaw, 1994) on women's body image. Nevertheless an equal number of studies failed to find any significant effect of thin-idea images on body dissatisfaction (Barzekowski, Robinson, \& Killen, 2000; Champion \& Furnham, 1999; Irving, 1990; Seddon \& Berry, 1996; Martin \& Kennedy, 1993; Waller, Hamilton, \& Shaw, 1992). To complicate matters further, other studies have shown that a specific group of women (i.e., restrained eaters) feel more confident about their 
appearance after being exposed to pictures of thin and attractive models (Joshi, Herman, \& Polivy, 2004; Mills, Polivy, Herman, \& Tiggemann, 2002). In sum, the media's role in the development of body dissatisfaction seems not as straightforward as generally assumed.

One explanation for the clearly mixed findings might be that previous research has often ignored the importance of individual differences in explaining the effects of thinideal images on women's body image. Research suggests that not all women react in the same negative way to media-portrayed idealized body images. More specifically it has been shown that women who have higher dispositional levels of body dissatisfaction (Posavac, Posavac, \& Posavac, 1998; Trampe, Stapel, \& Siero, 2007), and women who invest more in beauty and thinness (e.g., thin-ideal internalisation; Dittmar \& Howard, 2004; Stice \& Whitenton, 2002) are more likely to be affected adversely than other women. Another individual difference variable that has been found to make women more vulnerable to the adverse effects of the media, is the tendency to compare one's appearance to that of other women (Cattarin, Thompson, Thomas, \& Williams, 2005; Dittmar \& Howard, 2004; Tiggemann \& McGill, 2004). Indeed social comparison (Festinger, 1954) has been generally considered an important variable in explaining women's adverse reactions to thin-ideal images. Women who regularly make self-comparisons to images of idealised women's bodies have been found to feel less attractive and more dissatisfied with their own body (Stice, Schupak-Neuberg, Shaw, \& Stein, 1994; Stormer \& Thompson, 1996) than other women. In addition, Corning Krumm, and Smitham (2006) indicated that a greater tendency to engage in upward social comparison (i.e., in which the comparison target is perceived as better looking) predicts the presence of eating disorder symptoms.

Even though it is clear that the increased tendency to engage in social comparison is associated with feelings of body dissatisfaction, it is unclear where this tendency stems from in the first place. As yet, there has been very little research to address why some women have a higher need for social comparison than others. Investigating the mechanisms that drive women to compare their own appearance with that of others, Trampe, Stapel, and Siero (2007) showed that body dissatisfaction is an important determinant in the occurrence of social comparison effects. In explaining this finding the authors hypothesize that body dissatisfied women are more likely to engage in social comparison as their self-related cognitions and feelings are more accessible (i.e., higher levels of self-activation) and as they consider a wider range of comparison targets as relevant (i.e., peers and fashion models). In this perspective, recent research from the field of social psychology has shown that self-activation is an important prerequisite for promoting social comparison tendencies (Stapel \& Tesser, 2001). Selfactivation refers to a state in which one is more aware of one's self-related cognitions, 
feelings, behaviour and goals (like for example the goal of losing weight). Stapel and Tesser (2001) manipulated self-activation by instructing participants to name eithe four defining things about themselves (i.e., self-activation condition) or about a movie (i.e., control condition). Results indicated that participants in the self-activation condition showed higher social comparison tendencies than participants in the contro condition.

Given that self-activation has been found to increase people's interest in social comparison, the current study sought to investigate which effects it might have on women's vulnerability to media exposure. More specifically, it was examined whethe manipulating levels of self-activation would make women feel less satisfied with their body after having been exposed to thin-ideal pictures. Both restrained and unrestrained eaters were randomly assigned to either a self-activation condition or a control condition (i.e., no self-activation). It is expected that restrained eaters in a state of selfactivation will be more prone to the adverse effects of the media, as being aware of their present goals to meet a thin beauty standard will increase their tendency to compare themselves to other women. Therefore we hypothesize that self-activated restrained eaters will show a decrease in body and weight satisfaction after exposure to thin-ideal pictures compared to restrained eaters in the control condition. With regard to self-activated unrestrained eaters we expect no changes in body and weight satisfaction after thin-ideal exposure, as compared to unrestrained eaters in the contro condition. Finally, it is hypothesized that participants in the self-activation condition will engage more in social comparison than participants in the control condition.

\section{Method}

\section{Participants}

A total of 79 female undergraduate students of Maastricht University between the ages of 18 and $28(M=19.4, S D=1.74)$ participated in a study ostensibly testing the link between information processing and memory. Participants were selected for either a high (i.e., a score above 15) or a low score (i.e., a score below 14) on the Restraint Scale (RS; Herman \& Polivy, 1975). Restraint scores were obtained through an undergraduate screening session at the beginning of the academic year. Restrained eaters scored on average $18.45(S D=2,62)$ on the RS, whereas unrestrained eaters scored on average $7.54(S D=2.57)$ on the RS. All participants (restrained and unrestrained) were randomly assigned to either the self-activation condition $(n=39)$ or the control condition $(n=40)$. 
All participants received a gift voucher or course credit for their participation. The present study was approved by the local committee for research ethics.

\section{Manipulation}

Self-activation manipulation. In order to induce self-activation, participants were given an essay-assignment (Swinghammer \& Stapel, 2006), which was presented as an application letter for a future employer. Participants were told that their application letter should enable their future employer to get an accurate impression of who they are and what they are capable of. In the essay-assignment participants were asked to describe three positive and three negative character traits of themselves in detail by (1) naming the traits and (2) referring to real-life situations illustrating these personal traits. In every sentence they had to use one of the following words: ' $l$ ', 'me', 'myself', or 'mine'. Control participants were given a neutral essay-assignment in which they had to write a short story (e.g., 7-10 sentences) about a chair and a table. They were instructed to use the following words in their description: 'chair', 'material', 'armrests', 'chair legs', 'table', and 'round'. To maintain self-activation throughout the experiment, scrambled sentences were used. After the presentation of each thin-ideal picture, participants were instructed to complete a scrambled sentence exercise (five scrambled sentences in total). This exercise consisted of constructing a grammatically correct fourword sentence out of a five-word scrambled sentence. In the self-activation condition the scrambled sentences always contained the first-person pronoun ' 1 ' (e.g., black I shoes like for), whereas the scrambled sentences in the control condition always contained third-person pronouns (i.e., names; e.g., black Billie shoes likes for).

Self-activation manipulation check. In order to check whether our self-activation manipulation had been effective, participants were asked to complete a self-activation measure. Participants were presented with a short story in a non-existent language, in which 15 pronouns were underlined. They were told that the story they were presented with was written in Wezwe (i.e., a language only spoken in New Guinea), and they were instructed to guess the correct translation of each of the 15 pronouns (see Dijksterhuis \& Van Knippenberg, 2000 for previous use of this task). For the translation, participants could choose from the following pronouns: 'he', 'his', 'she', 'her', 'you', 'yours', 'l', 'me', ' $m y^{\prime}$. The level of self-activation is indicated by the number of selected first-person pronouns. Previous research has shown that heightened self-activation leads participants to translate more pronouns as first-person pronouns (Dijksterhuis \& Van Knippenberg, 2000; Stapel \& Tesser, 2001). To reassess the level of self-activation afte participants were presented with the thin-ideal pictures (see procedure) and to avoid 
learning effects, we designed a Chinese symbol variant of the Wezwe task. The idea behind the Chinese symbol task was equal to the Wezwe task. The only difference was that in this task participants had to correctly guess the translation of 15 underlined Chinese symbols.

\section{Materials}

Thin-ideal pictures. In a pilot study a panel of 15 undergraduate students were asked to judge the attractiveness and slenderness $10=$ least attractive -10 ; most attractive) of 17 thin-ideal pictures, which were obtained from a Dutch modeling agency. Based on their judgments, 8 full-body pictures with an average score of 9 on attractiveness and slenderness were selected. All women on the thin-ideal pictures were models, wearing casual clothes. Next to each picture, information was given about the model (i.e., name, age, modeling agency). Participants were led to believe that they would get a memory test at the end of the experiment, and were instructed to carefully attend to the picture and description of every model.

Questionnaires. Participants filled out Dutch versions of five questionnaires. (1) The Restraint Scale (RS; Herman \& Polivy, 1980) is an 11-item scale, which measures the extent to which participants try to restrain their food intake and show weight fluctuations. Higher scores reflect increased intention to restrain food intake. (2) State body satisfaction and state weight satisfaction were assessed using $100 \mathrm{~mm}$ Visual Analogue Scales (VAS) asking "how do you feel at this very moment about your body / weight", and ranged from 0 - "extremely dissatisfied" to 100 - "extremely satisfied". These two items were presented among a range of VAS filler items, to disguise the purpose of the study. (3)The Body dissatisfaction subscale of the Eating Disorders Inventory (EDI-II BD Gardner, 1991) was used to measure overall satisfaction with body and shape. Nine items are scored on 6-point scales, and are summed to a total score. Higher scores indicate more body dissatisfaction. The psychometric qualities of the EDI-II have been well established (Espelage et al., 2003; Schoemaker, Verbraak, Breteler, \& van der Staak, 1997). (4) The Body Image States Scale (BISS; Cash, Fleming, Alindogan, Stead man, \& Whitehead, 2002) was used to measure participant's evaluative/ affective body image states, and is a psychometrically sound six-item self-report measure (Cash et al. 2002). Items of the BISS were scored on 9-point likert-scales, with higher scores indicating more body dissatisfaction. (5) The Sociocultural Attitudes to Appearance Questionnaire (SATAQ; Heinberg, Thompson, \& Stormer, 1995) is a 14-item questionnaire measuring internalisation of the thin-ideal and awareness of sociocultural pressures to be thin. All items were scored on 5-point likert scales. (6) All participants were weighed and their height was measured to calculate their BMI. (7) Social comparison. Partici- 
pants had to indicate on a $100 \mathrm{~mm}$ VAS to what extent $(0=$ not at all, $100=$ very much) they had compared themselves with the models on the pictures while they were exposed to them (i.e., during the previous task, I compared myself (not at all - very much) with the models on the pictures. These items were presented among filler items to disguise the true purpose of the experiment.

\section{Procedure}

Participants were invited to participate in a study ostensibly testing the link between information processing and memory. All participants were tested individually. After signing the informed consent, participants completed a pre-measurement of state body- and weight satisfaction. Hereafter, participants were randomly assigned to either the self-activation condition or the control condition. In the self-activation condition, participants had to complete the self-activation essay-assignment. In the control condition participants had to complete the control essay-assignment. After this, all participants were given the Wezwe task (manipulation check). Subsequently, participants were exposed to eight thin-ideal pictures on a computer screen, which were presented as representing fashion models ( 8 pictures). Each picture was shown for 7 seconds. After each picture a scrambled sentence exercise was presented to maintain self-activation (or control). Participants were instructed to construct a four-word grammatically correct sentence out of five-word sequence, and were subsequently asked to read the sentence out loud. After the exposure, participants completed a postmeasurement of state body-and weight satisfaction. Furthermore, participants completed the social comparison manipulation check, in which they had to indicate to what extent they had compared themselves to the models during the exposure. After this, al participants completed the Chinese symbol task as a second manipulation check of selfactivation. Then, participants were asked to fill out the EDI-BD, the BISS, and the SATAQ. Then they were presented with five multiple choice memory questions about the thin-ideal pictures to disguise the true purpose of the study. Finally, height and weight of all participants were recorded. All participants were debriefed in writing after the experiment was completed. 


\section{Results}

\section{Design and statistical analysis}

Results were analysed in a 2 (Condition: experimental vs. control) $\times 2$ (Group: restrained eaters vs. unrestrained eaters) $\times 2$ (Time: pre-measurement vs. post-measurement) repeated measures ANOVA with the VAS measures of body and weight satisfaction as the main dependent variables. Furthermore, a 2 (Condition: self-activation vs. control) $x$ 2 (Group: restrained eaters vs. unrestrained eaters) repeated measures ANOVA of the level of social comparison was conducted to determine whether the self-activation manipulation led to increased social comparison tendencies.

\section{Participant characteristics}

We conducted 2 (Group: restrained eaters vs. unrestrained eaters) $\times 2$ (condition: selfactivation vs. control) analyses of Variance (ANOVA) to check for differences on age, BMI, EDI, BISS, and SATAQ. There were no significant condition effects, all $F^{\prime} s<2.4$, all $p^{\prime} s<.05$. However, we did find significant group effects for all variables, but age. Restrained and unrestrained eaters did not differ significantly on age but they did differ significantly with respect to BMI. Restrained eaters had a significantly higher BMI than unrestrained eaters. Furthermore, restrained eaters scored higher on the body dissatisfaction subscale of the EDI, the BISS, and the thin-ideal internalization subscale of the SATAQ compared to unrestrained eaters. See Table 1 for means, F-values, and post-hoc comparisons.

Taken together, restrained eaters were more dissatisfied with their body, had a higher BMI, less favourable body image states, and a greater internalization of thinideal compared to unrestrained eaters.

\section{Manipulation check self-activation}

To check whether the self-activation manipulation was successful, the use of firstperson pronouns was counted. An independent samples t-test indicated that participants in the self-activation condition used more first-person pronouns in the Wezwe task $(M=6.21, S D=1.72)$ than participants in the control condition $(M=5.23, S D=1.9)$, $t(77)=2.39, p<.05$. Furthermore, participants in the self-activation condition also used more first-person pronouns in the Chinese symbol variant of the Wezwe task $(M=6.15$, $S D=1.25)$ than participants in the control condition $(M=5.33, S D=1.23), t(77)=2.98$, $p<.01$. 


\begin{tabular}{|c|c|c|c|c|c|}
\hline & \multicolumn{2}{|l|}{ Self-activation } & \multicolumn{3}{|l|}{ Control } \\
\hline & $\begin{array}{l}\text { Restrained } \\
\text { eaters }\end{array}$ & $\begin{array}{l}\text { Unrestrained } \\
\text { eaters }\end{array}$ & $\begin{array}{l}\text { Restrained } \\
\text { eaters }\end{array}$ & $\begin{array}{l}\text { Unrestrained } \\
\text { eaters }\end{array}$ & $\begin{array}{l}F \\
(1,77)\end{array}$ \\
\hline Measure & $M(S D)$ & $M(S D)$ & $M(S D)$ & $M(S D)$ & \\
\hline Age (years) & $19.44_{\mathrm{d}}(1.04)$ & $19.20_{\mathrm{a}}(2.50)$ & $19.95_{\mathrm{a}}\langle 1.70\rangle$ & $19.00_{a}(1.33)$ & 2.22 \\
\hline Restraint (RS) & $18.16_{\mathrm{a}}(2.54)$ & $7.80_{b}(2.94)$ & $18.71_{\mathrm{a}}(2.72)$ & $7.26_{\mathrm{v}}(2.16)$ & 342.28 \\
\hline BMI & $23.02_{\mathrm{a}}(1.97)$ & $20.26_{b}(1.88)$ & $23.11_{\mathrm{a}}(3.14)$ & $20.31_{b}(1.92)$ & 27.99 \\
\hline Body dissatisfaction (EDI-\|I BD) & $34.44 a(7.16)$ & $24.80_{b}(9.33)$ & $35.55_{\mathrm{a}}(7.49)$ & $21.16_{b}(7.27)$ & 44.61 \\
\hline Body image states (BISS) & $32.85_{b}(4.38)$ & $26.61_{a}(6.99)$ & $35.84_{b}(4.37)$ & $26.55_{a}(7.64)$ & 31.91 \\
\hline $\begin{array}{l}\text { Thin-ideal internalisation } \\
\text { (SATAQ) }\end{array}$ & $25.50_{\mathrm{a}}(4.44)$ & $21.00_{b}(7.08)$ & 23.95 a $(7.01)$ & $18.32_{\mathrm{b}}(4.63)$ & 13.81 \\
\hline
\end{tabular}

Note. BMI = Body Mass Index = weight in kilograms/height in meters²; RS = Restraint Scale; EDI-II BD Eating Disorders Inventory, Body Dissatisfaction Subscale; BISS = Body Image States Scale; SATAQ = Sociocultural Attitudes to Appearance Questionnalre. Means with different subscripts differ significantly at $p<, 001$. $F$-values are for the group effects.

Taken together, these results indicate that the self-activation manipulation was successful at increasing levels of self-activation in the self-activation condition, as was apparent in both the Wezwe task and the Chinese symbol task.

\section{Social comparison}

A 2 (Condition: self-activation vs, control) $\times 2$ (Group: restrained eaters vs. unrestrained eaters) ANOVA of the level of social comparison, yielded a significant main effect of Condition, $F(1,75)=5.05, p<.05$, indicating that participants in the self-activation condition showed higher levels of social comparison $(M=4.93, S D=2.52)$ than participants in the control condition $(M=3.69, S D=3.95)$. Furthermore, a significant main effect of Group, $F(1,75)=12.38, p<.01$ was found. Restrained eaters compared themselves significantly more with the models $(M=5.20 ; S D=2.35)$ than unrestrained eaters did $(M=3.65 ; S D=1.74)$. The Group $\times$ Condition interaction was non-significant, $F(1,75)=1.96, p=.16$

Taken together, these results indicate that participants in the self-activation condition had higher tendencies to socially compare themselves than participants in the control condition and that restrained eaters compared themselves more to the models than unrestrained eaters did. 
Hypothesis 1: Self-activated restrained eaters will show a decrease in body and weight satisfaction after exposure to thin-ideal images as compared to restrained eaters in the control condition, whereas self-activated unrestrained eaters will show no changes in body and weight satisfaction as compared to unrestrained eaters in the control condition.

A 2 (Condition: self-activation vs. control) $\times 2$ (Group: restrained eaters vs. unrestrained eaters) $\times 2$ (Time: pre-measurement body satisfaction vs. post-measurement body satisfaction) repeated measures ANOVA of body and weight satisfaction yielded significant main effect of Time for body satisfaction, $F(1,75)=12.24, p<.01$, and a significant main effect of Group for both body satisfaction, $F(1,75)=40.12, p<.001$, and weight satisfaction, $F(1,75)=61.30, p<.001$. Of main interest to our hypotheses, these main effects were qualified by a significant Time $\times$ Condition $\times$ Group interaction, for body satisfaction, $F(1,75)=9.81, p<.01$, and weight satisfaction, $F(1,75)=7.30, p$ $<$.01. Follow-up ANOVA's were conducted separately for the restrained and unrestrained eaters. In line with our hypothesis, for restrained eaters, a significant Time $x$ Condition interaction effect was found, for body satisfaction, $F(1,38)=13.04, p<.01$ and weight satisfaction, $F(1,38)=16.24, p<.001$. Additional paired samples t-tests, separately for each condition, indicated that restrained eaters in the self-activation condition showed a significant decrease in body satisfaction, $t(18)=6.08, p<.001$, and weight satisfaction, $t(18)=5.21, p<.001$, whereas restrained eaters in the control condition did not, both $t^{\prime} s<1$. Furthermore, no significant Time $x$ Condition interaction effect was found for the unrestrained eaters, $F(1,37)=0.48$, ns (body satisfaction), $F$ $(1,37)=0.007, n s$, (weight satisfaction). See Figure 1a for mean scores of body satisfaction and Figure $1 \mathrm{~b}$ for mean scores of weight satisfaction, for the different groups and conditions.

In sum, in accordance with our hypothesis, we found that self-activated restrained eaters showed a decrease in body and weight satisfaction as compared to restrained eaters in the control condition, whereas self-activated unrestrained eaters showed no changes in body and weight satisfaction as compared to unrestrained eaters in the control condition. 
SELF-ACTIVATION AND BOBY DISSATISFACTION

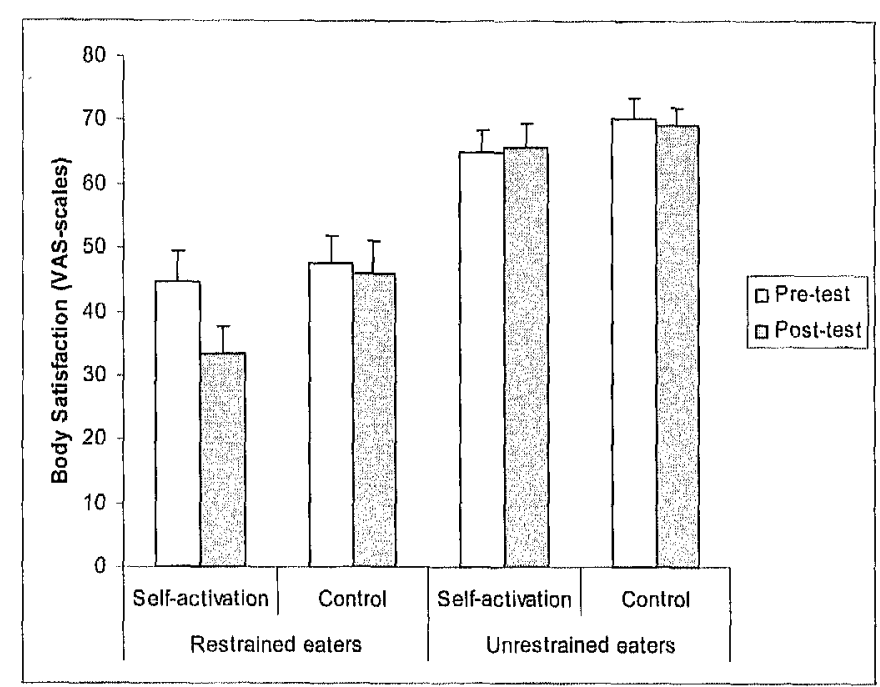

Figure 1a. Mean scores of body dissatisfaction at pre- and post measurement for restrained and unrestrained eaters in the experimental and control condition.

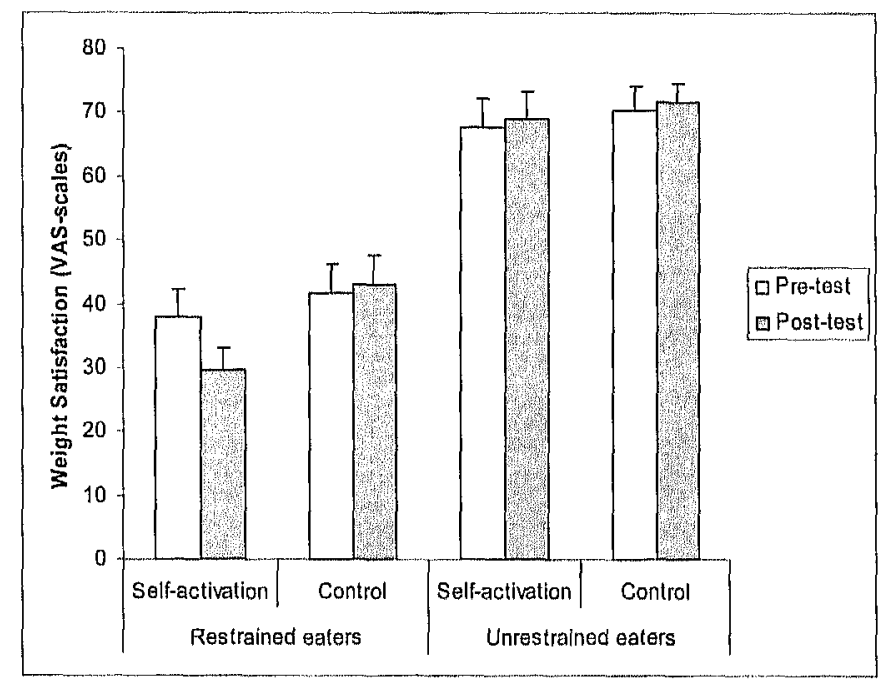

Figure $1 b$. Mean scores of weight dissatisfaction at pre- and post measurement for restrained and unrestrained eaters in the experimental and control condition. 


\section{Discussion}

It was found that restrained eaters in the self-activation condition felt less satisfied with their body and weight after exposure to thin-ideal pictures, as compared to restrained eaters in the control condition. Unrestrained eaters in the self-activation condition, however, did not experience any change in their body and weight satisfaction after exposure to the pictures, as compared to unrestrained eaters in the control condition. Taken together, these findings provide support for the potential negative influence of self-activation on body and weight satisfaction. Interestingly, the current data underline that exposure to thin-ideal images only had a negative influence on self-evaluation when two conditions were met: (1) when the participant was 'self-activated', and (2) when the participant classified as a restrained eater.

Results showed that our self-activation manipulation was successful at increasing levels of self-activation. Participants in the self-activation condition used more firstperson pronouns in the Wezwe and Chinese symbol task than participants in the contro condition. Furthermore, in addition to increasing levels of self-activation, our selfactivation manipulation also led to increased social comparison tendencies. Participants in the self-activation condition compared themselves significantly more with the thinideal pictures than participants in the control condition. From this pattern of results it can be postulated that the effect of self-activation in restrained eaters may be mediated by social comparison. In other words, as their current goals and feelings were made more accessible by the self-activation manipulation, they experienced an in creased tendency to compare themselves with the skinny models on the pictures, in turn causing them to feel less satisfied with their own body. The body image of restrained eaters in the control condition, however, was left unaffected. This last findin is in line with findings from Jansen et al. (1995), who found that the subliminal presentation of the thin-ideal does not have a negative effect on women's body image.

This pattern of results fits with research on social anxiety that has shown that selffocused attention can have negative effects for individuals with low self-confidence, whereas it has no or positive effects for individuals with high self-confidence (e.g., Brockner \& Hulton, 1978; Duval \& Wicklund, 1972). As for self-activated unrestrained eaters, we found no changes in body and weight satisfaction after thin-ideal exposure compared with unrestrained eaters in the control condition. Even though self-activated unrestrained eaters did show increased tendencies to engage in social comparison, they were not at all influenced by the thin-ideal pictures that had been presented to them. These findings show that self-activation only has an adverse effect on restrained eaters.

Not only do the present results dovetail with previous research showing that not al women are equally vulnerable to the adverse effects of the media (Posavac, Posavac, \& 
Posavac, 1998; Tiggemann \& McGill, 2004; Trampe, Stapel, \& Siero, 2007), they also extend previous knowledge on the factors that influence women's vulnerability to thinideal media images. Previous research has shown that women with high social comparison tendencles are more adversely influenced by thin-ideal images than other women. In the present study, however, higher social comparison tendencies alone could not account for the negative effects of exposure thin-ideal images. Even though the selfactivation manipulation led to social comparison in both restrained and unrestrained eaters, only the restrained eaters were adversely affected by the thin-ideal images. The current data imply that exposure to thin-ideal images is not as detrimental as assumed before. Only a combination of a restrained eating style and an elevated state of self activation made women feel less dissatisfied with their body and weight after being exposed to thin-ideal images.

The self-activation manipulation that was adopted in the current study provides a new and strictly implicit method for inducing social comparison tendencies in studies investigating the effects of thin-ideal images on body image. In line with Stapel and Tesser (2001), we showed that making people more aware of themselves by activating their self-related cognitions increases their interest in social comparison. Moreover, as none of the participants was able to guess the actual purpose of the study, it can be concluded that our self-activation manipulation was successful at preventing demand characteristics. In sum, this method might be valuable for future experimental research addressing the influence of social comparison on women's self-evaluations.

in conclusion, the present study shows that exposure to thin women in the media does not invariably affect all women in the same negative way. Oniy restrained eaters who were more aware of themselves and who consequently engaged in more socia comparison, showed a decrease in body and weight satisfaction after exposure to idealised images. These results are the first to draw attention to the importance of selfawareness and restraint status in explaining women's adverse reactions to idealise media images. As a combination of heightened self-awareness and restraint status might make women more vulnerable to the effects of the media, future research on body dissatisfaction prevention programs might benefit from experimentally testing strategles in which women are taught to focus less on themselves. 


\section{Chapter 5}

Body checking induces an attentional bias for body-related cues 


\section{Abstract}

Theoretical models suggest that body checking contributes to the maintenance of eating disorders, and that it is linked to biased cognitive processing. However, as yet, the link between body checking and cognitive biases has not been investigated in any systematic way. In the current study, the influence of body checking on attentional bias for body-related cues was examined by manipulating body checking behaviours in nonclinical participants. A sample of 66 women was randomly assigned to one of three conditions: body checking, body exposure, or control. To measure attentional bias, a body visual search task was used. It was found that participants in the body checking condition showed speeded detection of body-related information in comparison to participants in the exposure and control conditions. No evidence was found for increased distraction by body-related information. Furthermore, participants in the body checking condition reported feeling more dissatisfied with their body after the manipulation than participants in the body exposure and control condition. These results are the first to experimentally establish the link between body checking and attentional bias toward body-related cues in the environment.

Keywords: body checking, attentional bias, body image, speeded detection

\section{Introduction}

Body checking is an important component of eating disorders and has been considered to be a behavioural manifestation of the over-evaluation of shape and weight in eating disorder individuals (Fairburn, Shafran, Cooper, 1999). Body checking can be defined as the repeated and ritualistic monitoring of several aspects of the body (Rosen, 1997). More specifically, examples of body checking include scrutinizing specific body parts in the mirror, frequent weighing, pinching certain body parts to measure fatness, and using the fit of clothes to carefully check for any changes in shape or weight (Reas, Whisenhunt, Netemeyer, \& Williamson, 2002).

Although body checking behaviours have been frequently observed in clinical settings, it has not been until the last decade that researchers have given the concept of body checking empirical attention. Research focussing on the phenomenology of body checking has shown that eating disorder individuals engage in body checking significantly more often than do normal controls (Shafran, Fairburn, Robinson, \& Lask, 2004; Reas et al., 2002). In addition, a positive association between the severity of the eating disorder and the frequency of body checking behaviours has been found (Shafran et al., 
2004). In support of the notion that body checking is indeed a behavioural expression of the core psychopathology of eating disorders, body checking has been shown to be associated with increased shape and weight concerns in individuals with anorexia nervosa and bulimia nervosa (Shafran et al., 2004), and in overweight individuals with binge eating disorders (Latner, 2008). Furthermore, Mountford, Haase, and Waller (2006) have identified a range of dysfunctional beliefs related to body checking behavlours in women with eating disorders such as the belief that body checking serves to maintain control over eating and weight, decreases anxiety and helps one to feel better.

Cognitive-behavioural theoretical accounts suggest that body checking might contribute to the maintenance of eating disorders (Fairburn, et al., 1999; Williamson, Muller, Reas, \& Thaw, 1999). More specifically, Fairburn et al. (1999) hypothesized that the constant monitoring of weight and shape as a manifestation of extreme body concerns will serve to intensify patients' efforts to restrict eating. As individuals with eating disorders use the information they obtain from body checking as a measure of self-control, even the slightest perceived negative change in weight or shape is interpreted as a failure in self-control, thereby enhancing dietary restraint, shape concerns, and drive for thinness. In the first study to explicitly address the maintenance role of body checking in eating disorder psychopathology, Shafran, Lee, Payne, and Fairburn (2007) experimentally investigated the impact of body checking behaviours on body dissatisfaction. Healthy participants standing in front of a mirror were randomly assigned to a "high body checking condition", in which they were instructed to focus on and scrutinise their most disliked body parts, or to a "low body checking condition", in which they were instructed to look at all parts of their body, and to describe each part in a neutral way. Results showed that participants in the "high body checking condition" experienced an increase in body dissatisfaction, self-critical thought, and feelings of fatness, immediately after the manipulation, in comparison to participants in the low body checking condition. These findings support the role of body checking in body dissatisfaction.

A somewhat different account by Williamson attributes the maintenance role of body checking in eating disorder psychopathology to cognitive biases, such as selective attention for body-related information (Williamson, 1996; Williamson, Muller, Reas, \& Thaw, 1999). Indeed, a large number of studies using either the modified Stroop paradigm (for reviews see: Faunce, 2002; Lee \& Shafran, 2004), the dot-probe paradigm (Rieger et al., 1998, Shafran et al., 2006), or the visual search paradigm (Smeets, Roefs, van Furth, \& Jansen, 2008) have consistently demonstrated that individuals with eating disorders show an attentional bias for body-related information in their environment, but these biases were never studied in relation to body checking. Recent research from our laboratory did however show that body checking individuals with eating disorders 
have an attentional bias for their disliked body parts (Jansen, Nederkoorn \& Mulkens, 2005). In a similar vein, it was demonstrated that individuals with eating disorders (Shafran et al., 2004) and women with high levels of body shape concern (Farrell, Shafran, \& Fairburn, 2004) report attending more to their self-defined problem zones (i.e., stomach, thighs) than normal controls, while body checking.

Even though the existence of an attentional bias in eating disorders has been wellestablished, as yet there has been no research investigating whether the act of body checking itself biases the attentional processing of body-and shape-related information as hypothesized by Williamson (Williamson, 1996; Williamson et al., 1999). Therefore, the current study aimed to investigate the impact of experimentally induced body checking behaviours on the attentional processing of body-related information. We used the body visual search paradigm (Smeets et al., 2008) which is able to distinguish two subcomponents of attention: speeded detection (i.e., hyper vigilance for relevant stimuli) and distraction (i.e., increased distraction by relevant stimuli). Previously Smeets et al., (2008) studied the nature of attentional bias for body-related information in individuals with eating disorders using the body visual search paradigm. Results indicated that individuals with eating disorders showed evidence of speeded detection, but not increased distraction by body-related information in comparison to normal controls.

Given that body checking is a naturally occurring phenomenon in individuals with eating disorders, manipulating it in a clinical group is not a direct test of its causal effect on attentional processing. Preferably, if one wants to test experimentally whether body checking is a possible mechanism in explaining an attentional bias one needs to first manipulate it in non-clinical participants. The current study examined an experimental analogue of body checking and its effects on attention to body cues in the environment specifically our aim was to induce one particular aspect of body checking (i.e., focusing on and inspecting the size of different parts of the body) in a sample of non-clinical participants and to examine the direct impact of this manipulation on the attentional processing of body-related information in the body visual search paradigm. Participants were randomly assigned to one of three conditions: a body checking condition, a body exposure condition, and a control condition. The body exposure condition was added to our design to investigate whether it is the active act of body checking or merely passive exposure to the body which influences the attentional processing of body-related information. In line with our previous findings on the attentional processing of bodyrelated information in individuals with eating disorders (Smeets et al., 2008), it was hypothesized that participants who were assigned to the body checking condition would show evidence of speeded detection but not increased distraction by bodyrelated information in comparison to participants assigned to the exposure or control 
condition. This result would signify hypervigilance to body-related information as a result of body checking. We expected no differences in attentional processing between the body exposure and control condition, as it was hypothesized that passive exposure would not lead to an attentional bias for body-related information.

\section{Method}

\section{Participants}

A total of 66 female undergraduate students from Flinders University, Australia, were invited to participate in a study ostensibly investigating the relationship between personality, cognition, and female perception. All participants were randomly assigned (subject to equal numbers per cell) to either a body checking condition ( $n=22$ ), a body exposure condition $(n=22)$, or a control condition $(n=22)$. Participants had an average $\mathrm{BMI}\left(\mathrm{BMI}=\right.$ weight $\left./ \mathrm{height}^{2}\right)$ of $23.1(S D=4.5)$, and were on average $20.45(S D=3.3)$ years old. One control participant was excluded from the analyses due to a high percentage of outlier responses and errors on the body visual search task $>M+35 D=25$ $\%)$. This left a total of 21 control participants in the control condition. All participants received course credits for their participation. The present study was approved by the local committee for research ethics.

\section{Materials}

Body-related Visual Search Task. Each trial started with a brief tone, after which the participant was shown a fixation cross for $500 \mathrm{~ms}$ in the middle of the computer screen. Then she was presented with a $5 \times 4$ matrix of 20 words and was instructed to indicate whether the matrix contained 20 words of the same category or whether it contained one word from a different category (the odd-one-out). If the matrix contained an oddone-out word (henceforth called the target word), she was instructed to press the right button of a response-box. If the matrix did not contain an odd-one-out word, she was instructed to press the left button. The matrix remained on screen until response or for a maximum of 20 seconds upon which the next trial began. The location of each word in each matrix was chosen randomly for each trial and for each participant. However, the target word never appeared directly above or below the location of the fixation cross in order to avoid facilitated detection. Participants were informed about the three categories stimuli could come from. 
Word stimuli from three categories (translated into English from Smeets et al., (2008) were used: body, countries (neutral), and musical instruments (neutral). Stimulus words of the three categories did not differ significantly in length, all $t$ 's $=0.00$, all $p^{\prime} s>05$. Matrices on target present trials consisted of one body-related word among 19 countries or 19 musical instruments, one musical instrument or country among 19 body-related words, one musical instrument among 19 countries, or one country among 19 musical instruments. Each of these six types of matrices was shown 19 times to each participant. Matrices on target absent trials consisted of 20 countries, 20 musical instruments, or 20 body-related words. There were 114 target present trials, 30 target absent trials and 12 practice trials. In line with Smeets et al., (2008) the majority of the trials were target present trials because this type of trial is relevant for testing speeded detection and increased distraction. Speeded detection of body-related words is calculated by comparing response latencies to detect a body-related target word vs. a neutral target word among neutral distractor words from one other category. Increased distraction is calculated by comparing response latencies to detect a neutral target word among body-related words vs. neutral distractor words from one other category.

The visual search task lasted approximately 15 minutes, divided over two blocks of trials of 7.5 minutes. The participant was given a brief break between blocks. The distance between the participant and the monitor was approximately $90 \mathrm{~cm}$. Within the frame of the matrix, words were horizontally separated by $6.76 \mathrm{~cm}$ and vertically by 6.5 $\mathrm{cm}$ (measured from the middle point of the stimulus word). All words were displayed on a light-grey background on a 17-inch monitor with a resolution of $1280 \times 1024$ pixels.

Trait body checking. The Body Checking Questionnaire ( $\mathrm{BCQ}$ ) was used to measure habitual body checking behaviours (Reas et al., 2002). This self-report measure consists of 23 items, e.g., "I look to see if I have cellulite on my thighs when I am sitting ", "I pinch my stomach to measure fatness". Items are rated on a 5-point likert scale, ranging from $1=$ never to $5=$ very often. The $B C Q$ has good test-retest reliability (.94) and internal consistency (.87) (Reas et al., 2002).

\section{Manipulations}

As we hypothesized that attentional processing could be susceptible to demand characteristics we chose to use a more subtle body checking manipulation than Shafran and colleagues (2007) did. For the current study, we developed a manipulation for inducing one particular aspect of body checking behavior (i.e., focusing on and inspecting the size of different body parts). To disguise the purpose of the manipulation, participants were asked to complete a perceptual estimation task in which they had to make a series of length estimations (i.e., in centimetres). They were told that the experimenter would 
indicate the objects of which they had to estimate the length. For the first part of the task, participants in all conditions were asked to estimate the length of three different parts of a table. For the second part of the task participants in the body exposure and control condition were asked to estimate the length of three different parts of a chair. In contrast, participants in the body checking condition were asked to estimate the length of three different parts of their body. The body parts of which the body checking participants had to estimate the length were indicated by the experimenter on the participant's body. The three body parts were respectively: (1) collarbone to waist, (2) hips to knees, and (3) shoulder to elbow. None of the indicated parts was mentioned out loud, to avoid the facilitated detection of these words in the body visual search task. In the body exposure and the body checking condition participants performed the perceptual estimation tasks in front of a mirror, and were positioned at a specific point in the room (which was indicated by a white cross) to ensure that all participants were facing the mirror from the same distance and to maximize body exposure. Participants in the body checking and body exposure condition were both instructed to look in the mirror when performing the perceptual estimation task. They were told that using the mirror would help them make an accurate perceptual judgment. However, participants in the body exposure condition were not instructed to estimate the length of several body parts. Participants in the body checking condition were told to carefully focus on and inspect the size of the body parts they had to estimate the length of. During the task the experimenter monitored that the participants complied with the instruction to look in the mirror. In the control condition there was no mirror in the laboratory. After the manipulation the experimenter moved the mirror out of sight (i.e., body checking and body exposure condition) in order to ensure that participants would not be distracted by it while completing the body visual search task.

Manipulation check. To check whether our manipulation was successful, particpants were asked to think back to the thoughts and feelings they had during the perceptual estimation task (i.e., the manipulation). Specifically participants rated their response to the question "To what extent did you focus on and inspect the size of your body parts during the perceptual estimation task" on a $10 \mathrm{~cm}$ scale ranging from 0 "not at all" to 10 - "very much". In order to mask our research question, we formulated our manipulation check as implicit as possible. So rather than asking participants explicitly to what extent they checked out their body, we decided to ask participants to what extent they focused on their body during the perceptual estimation task.

Body dissatisfaction. Even though the main focus of the present study was not on the influence of body checking on body dissatisfaction, we did add an additional measure to find out whether our manipulation had any effect on body dissatisfaction. Participants were asked to think back to the thoughts and feelings they had during the 
perceptual estimation task (i.e., the manipulation), and rated their response to the question "To what extent were you satisfied with your body during the perceptua estimation task" on a $10 \mathrm{~cm}$ scale ranging from 0 - "not at all" to 10 - "very much". Furthermore, to measure whether our groups differed in trait body dissatisfaction we used the Body Shape Questionnaire (BSQ; Cooper, Taylor, Cooper, \& Fairburn, 1987) The BSQ is a psychometrically sound 16-item self-report measure, assessing shape and weight concerns over a period of four weeks (Rosen, Jones, Ramirez, \& Waxman, 1996). Items, e.g., "In the past four weeks have you felt so bad about your shape that you have cried", are rated on a 6-point likert scale ranging from $1=$ never to $6=$ always.

\section{Procedure}

All participants were tested individually. Upon entering the experimental room, participants were told that the study consisted of a perceptual estimation task, a computer task and some questionnaires. After signing the informed consent form, participants completed the perceptual estimation task. After this, participants completed the body visual search task. Upon finishing the body visual search task, they were given a questionnaire assessing body focus (i.e., serving as a manipulation check) during the perceptual estimation task and state body dissatisfaction. Finally, they were asked to fill out the trait Body Checking Questionnaire, the Body Shape Questionnaire, and to report their height, weight, and age. Self-reported height and weight are reasonably accurate in a non-clinical sample (McCabe, McFarlane, Polivy, \& Olmsted, 2001). It was chosen to administer the trait measures after the visual search task to make sure that the experimental manipulation and the visual search task would not be affected by it. All participants were debriefed in writing after the experiment was completed.

\section{Results}

\section{Participant characteristics}

ANOVAs revealed that participants in the three conditions did not differ significantly on age (body checking: $M=20.05, S D=3.11$; body exposure: $M=20.68, S D=3.37$; control: $M=20.62, S D=3.57$ ), Body Mass Index (body checking: $M=23.39, S D=4.80$; body exposure: $M=21.98, S D=3.27$; control: $M=23.80, S D=5.31$ ), trait body dissatisfaction (i.e., BSQ; body checking: $M=49.68, S D=18.61$; body exposure: $M=44.32, S D=16.25$; control: $M=43.48, S D=16.91$ ), or on the trait measure of body checking (i.e., $B C Q$ 
body checking: $M=56.04, S D=15.89$; body exposure: $M=51.77, S D=16.90$; control: $M$ $=49.57, S D=13 \cdot 12)$. All $F^{\prime} s(2,62)<1.00$, ns

\section{Manipulation check}

Analysis of Variance (ANOVA) revealed that participants in the body checking condition $(M=5.70, S D=2.80$ ) reported focussing (i.e., focussing on and inspecting the size) significantly more on their body during the perceptual estimation task, $F(2,62)=27.56$, $p<.001$, than did participants in the exposure condition $(M=1.00, S D=1.60)$ or the control condition $(M=1.70, S D=2.20)$. Additional post-hoc analyses with bonferoni correction $(\alpha=0.017)$ revealed that participants in the body checking condition differed significantly from both participants in the body exposure condition, $t(42)=6.82, p<$ .001 , and participants in the control condition $t(41)=5.18, p<.001$. There were no significant differences between participants in the body exposure condition and participants in the control condition, $t(41)=1.20, n s$. It was concluded that the manipulation was successful.

\section{Body dissatisfaction}

Analysis of Variance (ANOVA) showed that participants in the body checking condition $(M=4.06, S D=2.15$ ) reported feeling significantly less satisfied with their body, $F(2$, $62)=5.05, p<.01$, than did participants in the body exposure condition $(M=5.86, S D=$ 2.51) and control condition $(M=6.03, S D=2.11)$. Additional follow-up analyses with bonferoni correction $(\alpha=0.017)$ showed that participants in the body checking condition differed significantly from both participants in the body exposure condition, $t(42)=$ $2.55, p=.014$, and participants in the control condition $t(41)=3.02, p=.004$. There were no significant differences between participants in the body exposure condition and participants in the control condition, $t(41)=0.24$, ns.

\section{Data reduction and target-absent trials}

The main analyses were conducted on the target-present trials. Errors (i.e., misses: 8.35 $\%$ of the target-present trials) and responses faster than $200 \mathrm{~ms}$ and slower than 20.000 $\mathrm{ms}$ were discarded, as were response latencies higher than three standard deviations (SD) above the overall mean of all participants of the remaining response latencies $(0.86$ $\%$ of the target-present trials). None of the response latencies were lower than three SD below the mean. 
False alarm rates to the target-absent trials in the body visual search task were low (body: $6.77 \%$; country: $6.46 \%$; music: $4.92 \%$ ). A 3 (Stimulus category: body vs. music vs. country) $\times 3$ (Group: body checking vs. body exposure vs. control) repeated measures ANOVA of false alarms, revealed that the Stimulus category $x$ Group interaction was not significant, $F(4,124)=1.50, n s$, indicating that there were no significant differences between participants in the three conditions on the false alarm rates for body, country, and music target-absent trials. Main effects of Stimulus category, $F$ $(2,124)=1.04, n s$, and Group, $F(2,62)=0.15, n s$, were also non-significant.

\section{Effects of condition on speeded detection of body-related information}

Results were analysed in a 3 (Condition: body checking vs. body exposure vs. control) $x$ 2 (Target type: body vs. neutral) repeated measures ANOVA of the response latencies on the target-present trials in the body visual search task. Consistent with our expectations, a significant Condition $\times$ Target type interaction was found, $F(2,62)=7.29, p=$ 001, qualifying a main effect of Target Type, $F(1,62)=14.54, p<.001$, and a trend significant main effect of Condition, $F(2,62)=2.95, p=.06$. See Figure 1a for means and SEs. Additional post-hoc analyses with Bonferoni correction $(\alpha=0.017)$ revealed that participants in the body checking condition were significantly faster at detecting a body-related target word among neutral distractors, than a neutral target word among neutral distractors from another category, $t(21)=4.57, p<.001$.

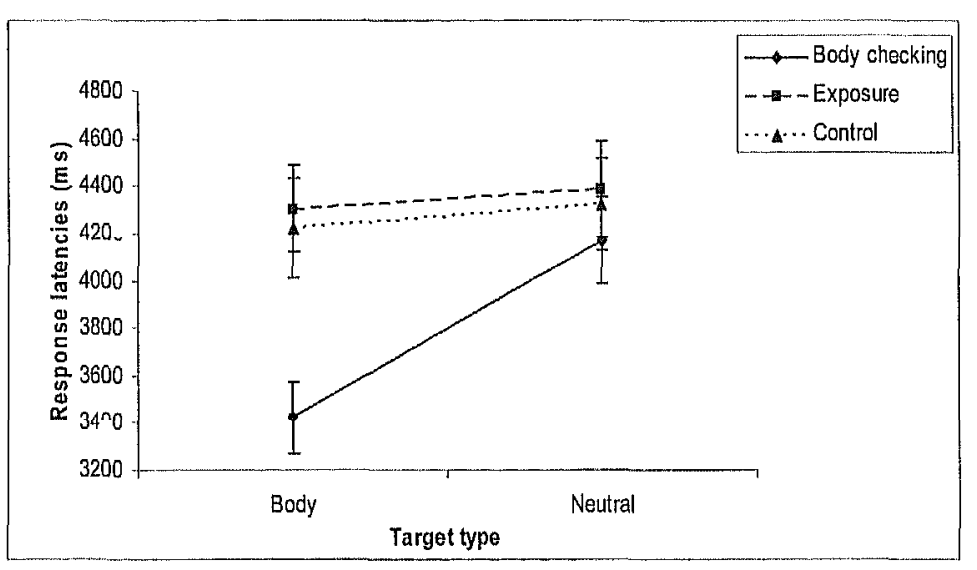

Figure 1a. Mean response latencies for trials in which participants searched for 1 body target-word or one neutral target word among 19 neutral words of one other category. Error bars represent one standard error. 
This difference was not significant for participants in the body exposure condition, $t$ (21) $=0.68, n s$, or the control condition, $t(20)=0.75$, ns. Thus, participants in the body checking condition showed speeded detection of body-related information in the body visual search task, whereas participants in the body exposure and control condition did not. Interestingly, attentional bias (i.e., mean response latencies body target among neutral distractors minus mean response latencies neutral target among neutral distractors of another category) was correlated with state body dissatisfaction as experienced during the perceptual estimation task, $r=.31, p=.01$. So, our manipulation led to correlated changes in both attentional bias and state body dissatisfaction.

\section{Effects of condition on increased distraction by body-related information}

Results were analysed in a 3 (Condition: body checking vs. body exposure vs. control) $x$ 2 (Distractor type: body vs. neutral) repeated measures ANOVA of the response latencies on the target-present trials in the body visual search task. In line with our expectations, no significant Condition $\times$ Distractor type interaction was found, $F(2,62)=0.25$, $n s$. Moreover, no significant main effects of Distractor type, $F(1,62)=1.65, p=.20$, or Condition, $F(2,62)=0.23$, ns, were found. Thus, participants who were assigned to the body checking condition were not significantly more distracted by body-related information than participants who were assigned to the body exposure or the control condition. See Figure $1 \mathrm{~b}$ for means and SEs.

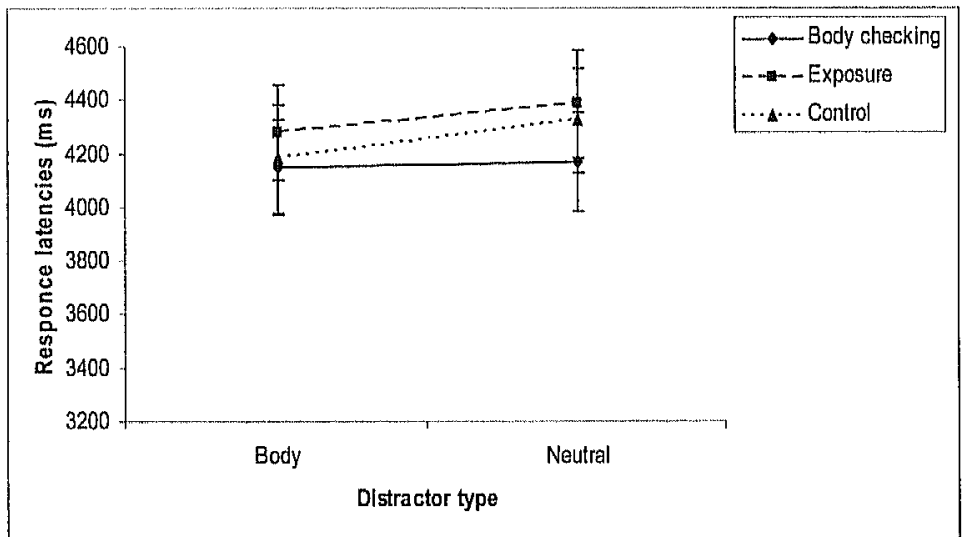

Figure $1 b$. Mean response latencies for trials in which participants searched for 1 neutral target-word among 19 body related distractor-words or 19 neutral distractorwords of one other category. Error bars represent one standard error 
The present study aimed to experimentally examine the impact of induced body checking behaviours on the attentional processing of body-related information in non-clinical participants. In line with our hypothesis, it was found that experimentally induced body checking behaviours led to an attentional bias for body-related information in the environment. In particular, participants in the body checking condition were faster at detecting body-related target words (i.e. speeded detection) than neutral target words among neutral distractors of one other category, relative to participants in the exposure condition and control condition. Interestingly, the attentional bias for body-related information was correlated with body dissatisfaction. There was no evidence of increased distraction; participants in the body checking condition were not more distracted by body-related distractors as compared to neutral distractors, when searching for a neutral target word, relative to participants in the body exposure condition and control condition.

Results confirm that the experimental manipulation was successful, as participants in the body checking condition reported focussing significantly more on their body during the perceptual estimation task than participants in the body exposure or control conditions. Also, participants in the body checking condition reported to feel less satisfied with their body than participants in the body exposure or control conditions. As no pre-existing differences were found between groups on trait measures of body checking and body dissatisfaction, it can be assumed that any effect on attentional bias and body dissatisfaction can be ascribed to our manipulation.

Taken together, these results experimentally show that the act of body checking biases the attentional processing of body-related information. Moreover, they show that body checking over and above mere exposure to one's body in the mirror (i.e., body exposure condition) is necessary to produce an attentional bias. The present findings parallel previous findings from our laboratory, showing evidence of speeded detection of, but not increased distraction by, body-related information in eating disorder individuals (Smeets et al., 2008). Thus it appears that, experimentally inducing one of the central characteristics of eating disorders, namely body checking, in nonclinical participants results in a pattern of information processing that generally resembles that of eating disorder individuals. In addition to inducing an attentional bias for body-related information, our body checking manipulation led to increased feelings of body dissatisfaction (see Shafran, et al., 2007) which were correlated with the attentional bias for body-related information. This suggests an interesting yet complex relationship between body checking, body dissatisfaction, and attentional bias. From the current study we know that body checking induced both an attentional bias and 
body dissatisfaction. Nevertheless, at this point no conclusions can be drawn about the direction of the relationship between body dissatisfaction and attentional bias. One possibility could be that body checking leads to an attentional bias which then leads to body dissatisfaction. This possibility is in accordance with recent research supporting the causal role of attentional biases in the development of body dissatisfaction. Smith and Rieger (2006) and Engel and colleagues (2006) showed that training an attentional bias for body-related information in healthy participants results in more body dissatisfaction. Moreover, elaborating on these findings, Smeets, Jansen, Lindelauf, and Roefs (submitted for publication) showed that inducing selective attention for self-defined unattractive body parts in healthy participants also causes increased feelings of body dissatisfaction. Another possibility could be that body checking leads to body dissatisfaction which then leads to an attentional bias, and yet another possibility could be that body checking leads to both body dissatisfaction and attentional bias independently. Future research is necessary to unravel the direction of this relationship.

The pattern of results is consistent with some research from the field of anxiety, indicating that the confrontation with threatening information is associated with speeded detection in the absence of increased distraction, in spider-fearful individuals and individuals suffering from social phobia (Gilbao-Schechtman, Foa, \& Amir, 1999; Öhman, Flykt, \& Esteves; 2001; Rinck \& Becker, 2006). As participants in the body checking condition were faster at detecting body-related information (i.e., speeded detection), but were not more distracted by this type of information (i.e., no increased distraction), it is possible that the confrontation with body-related information in the body visual search task might have led them to experience fear of being or becoming fat. Nevertheless, as levels of anxiety were not measured in the present study, the current explanation warrants further investigation.

The present findings strongly support the theoretical account of Williamson (1996; 1999). More specifically, by establishing that body checking leads to an attentional bias for body-related information, the present study provides experimental support for the hypothesized link between body checking and cognitive biases. Future research should determine whether such "body checking induced" attentional biases actually maintain eating disorder psychopathology.

One limitation of the current study is that we only induced one particular aspect of body checking (i.e., focusing on and inspecting the size of different body parts) whereas the clinical definition of body checking is more elaborate. Nevertheless, even though one might contend that the current body checking manipulation differs from clinically observed body checking behaviours, this kind of manipulation is necessary to draw conclusions about the causality of body checking in attentional processing. If even a subtle body checking manipulation leads to biased information processing, it is very 
likely that clinically observed body checking behaviours will lead to even stronger effects.

Apart from empirically demonstrating the causal link between body checking and the attentional bias for body-related information, our findings have clinical implications. As poorer treatment outcomes have been associated with remaining body checking behaviours (Latner, 2008) and negative body image at the end of treatment (Garner \& Garfinkel, 1997), the present findings further articulate the importance of targeting body checking in treatment programs. Given that body checking might maintain eating disorder psychopathology through an attentional bias for body-related information, the present findings underline the importance of addressing the attentional bias, and the body checking behaviours during body exposure therapy with response prevention.

In sum, the present study represents the first experimental investigation of the impact of induced body checking behaviours on the attentional processing of bodyrelated information in the environment. It is concluded that the active act of body checking, in contrast to passive body exposure, leads to an attentional bias for bodyrelated information, through the speeded detection of this type of information. 


\section{Chapter 6}

Experimentally induced chocolate craving leads to increased distraction 


\section{Abstract}

In the present study, the causal influence of chocolate craving on attentional bias for chocolate-related information was examined by experimentally inducing chocolate craving in a sample of high trait chocolate cravers versus low trait chocolate cravers. A sample of 35 high trait chocoholics and 33 low trait chocolate cravers were randomly assigned to either the exposure condition in which craving was manipulated or the nonexposure condition. To measure attentional bias, a pictorial version of the visual search paradigm (Smeets et al, 2008) was used, assessing two components: distraction and detection. It was found that experimentally induced chocolate craving led to increased distraction by chocolate pictures in the high trait chocolate cravers, in comparison to the low trait chocolate cravers. Moreover, this measure of distraction correlated strongly with self-reported craving, but only in the chocoholics and in the exposure condition. in the non-exposure condition, high trait chocolate cravers showed speeded detection of chocolate pictures relative to non-chocoholics, but this component did not correlate with self-reported craving. It is concluded that experimentally induced craving for chocolate causes a bias in, specifically the increased distraction component of attention in high trait chocolate cravers.

Keywords: Attentional bias, craving, chocoholics, speeded detection, increased distraction

\section{Introduction}

Over the past decades, ample research has demonstrated attentional biases for cravingrelated stimuli (e.g., alcohol, drugs, and cigarettes) in individuals for whom these stimuli are of particular concern. An attentional bias is defined as the tendency to selectively attend to personally-relevant information over neutral information (Mathews \& Macleod, 2005). Using the emotional Stroop paradigm, research from the field of addiction has consistently shown that alcoholics (Bauer and Cox, 1998; Cox et al., 1999, 2002; Stormark et al., 2000), smokers (Gross et al., 1993; Waters \& Feyerabend, 2000) and drug addicts (Franken et al., 2000) show increased interference when naming the colour of craving-related stimuli as compared to neutral stimuli. In addition, findings from studies using the dot-probe paradigm also support the presence of attentional biases in these individuals (Ehrman et al., 2002; Lubman et al., 2000).

In explaining the occurrence of these attentional biases, a link has been proposed between selective attentional processing and craving (Franken, 2003; Robinson \& 
Berridge, 1993). Indeed, a substantial number of studies have found significant correlations between attentional bias for craving-related stimuli and levels of subjective craving (e.g., Field et al., 2005b, 2007a; Franken et al., 2000; Rosse et al., 1993, 1997). Other studies suggest that this relationship only holds true for a specific component of the attentional bias. In general, two subcomponents of attention have been distin guished by attentional bias researchers using paradigms like the dot-probe paradigm (i.e., Mogg, Field, \& Bradley, 2005; Macleod, Mathews, \& Tata, 1986), the exogenous cueing paradigm (Fox, Russo, Bowles, \& Dutton, 2001) and the odd-one-out visual search paradigm (Hansen \& Hansen, 1988; Rinck, Reinecke, Ellwart, Heuer, \& Becker, 2005). The first subcomponent is involved in the early attentional processing of information whereas the second subcomponent is specifically involved in late attentiona processing. Depending on the attentional bias paradigm that is used, the first subcomponent is referred to as increased initial orienting (i.e., Mogg, Field, \& Bradley, 2005), engagement (i.e., Fox, Russo, Bowles, \& Dutton, 2001), or speeded detection (i.e. Rinck, Reinecke, Ellwart, Heuer, \& Becker, 2005) while the second subcomponent is referred to as greater maintained attention (i.e., Mogg, Field, \& Bradley, 2005), slowed disengagement (i.e., Fox, Russo, Bowles, \& Dutton, 2001), or increased distraction (i.e., Rinck, Reinecke, Ellwart, Heuer, \& Becker, 2005). Using eye-tracking, Mogg, Field, and Bradley (2005) showed that higher levels of craving are correlated specifically with greater maintained attention for smoking cues in smokers. Likewise, Field and colleagues (2004) only found a correlation between craving and the attentional bias for alcohol cues in the maintenance component of attention.

Apart from addiction-related stimuli, attentional biases have also been reported for food-related stimuli. More specifically, these biases have been demonstrated in restrained eaters (Francis, Stewart, \& Hounsell, 1997), dieters (Cooper \& Fairburn, 1992) eating disorder individuals (for reviews see: Faunce, 2002; Lee \& Shafran, 2004), people who are food deprived (Placanica, Faunce, \& Soames Job, 2005), hungry (Mogg, Bradley, Hyare, \& See, 1998), or in people who have just finished an appetizer (Overduin Jansen, \& Louwerse, 1995). In a recent study from our laboratory we used an odd-oneout variant of the visual search paradigm (Hansen \& Hansen, 1998; Rinck, Reinecke, Ellwart, Heuer, \& Becker, 2005) to investigate two subcomponents of attention (i.e. speeded detection and increased distraction) that might underlie the attentional bias in eating disorder patients (Smeets, Roefs, van Furth, \& Jansen, 2008). Speeded detection refers to the faster detection of relevant stimuli in the environment, whereas increased distraction refers to the heightened distraction which can be brought about by these relevant stimuli. Results indicated that eating disorder patients showed evidence of increased distraction by food-related information, but not of the speeded detection of this kind of information (Smeets, et al., 2008). In line with Mogg and colleagues (2005), 
we concluded that this increased distraction by food, might reflect a craving response, In other words, experiencing food cravings might have led eating disorder patients to be more distracted by food-related information while searching for neutral information. Nevertheless, as measuring or experimentally inducing craving was neither the goal of our study or of other previous studies, no conclusions can be drawn about the link between food cravings and the attentional bias for food. In this perspective, the purpose of the present study was to unravel the nature of this link in more detail in a nonclinical group of trait chocolate cravers experiencing intense and frequent cravings for chocolate (Benton, Greenfield, \& Morgan, 1998). Specifically our aim was to induce chocolate craving in samples of high and low trait chocolate cravers and to examine the direct impact of this manipulation on the attentional processing of chocolate-related pictures in a visual search paradigm. A pictorial chocolate variant of the visual search paradigm as used by Smeets, Roefs, van Furth, \& Jansen, 2008 was developed. Participants were randomly assigned to one of two conditions: the exposure condition, in which chocolate craving was induced, or the non-exposure condition.

It was hypothesized that high trait chocolate cravers in the non-exposure condition would show speeded detection of chocolate pictures, in comparison to low trait chocolate cravers. Based on previous addiction studies in which a craving-related bias was specifically found in maintained attention, we expected our craving induction to cause an attentional bias effect in the distraction component (which may resemble maintained attention). In this line, it was hypothesized that the craving induction (i.e. exposure) would lead to increased distraction by chocolate pictures in trait chocolate cravers, in comparison to the low-trait cravers and the non-exposure condition. Finally, self-reported craving was expected to correlate with the distraction component of the attentional bias.

\section{Method}

\section{Participants}

A total of 68 female undergraduate students were invited to participate in a study ostensibly investigating the relationship between perception and cognition. Inclusion criteria were either a high (highest $25 \%$ ) or a low (lowest $25 \%$ ) score on the chocolate craving subscale of the Attitudes to Chocolate Questionnaire (Benton, Greenfield, \& Morgan, 1998) which was assessed two weeks before the experiment. Participants with a high score (i.e., a score above 10) on the chocolate craving subscale were classified as high trait chocolate cravers (henceforth called chocoholics), and participants with a low 
score (i.e., a score below -10 ) were classified as low trait chocolate cravers (henceforth called non-chocoholics). Both chocoholics $(n=35)$ and non-chocoholics $(n=33)$ were randomly assigned to either the exposure condition or the non-exposure condition. In total 18 chocoholics and 17 non-chocoholics were assigned to the exposure condition, and 17 chocoholics and 16 non-chocoholics were assigned to the non-exposure condition. All participants received course credits for their participation. The present study was approved by the local committee for research ethics.

\section{Materials}

Pictorial chocolate Visual Search Task. Each trial started with a brief tone, after which the participant was shown a fixation cross for $500 \mathrm{~ms}$ in the middle of the computer screen. Then she was presented with a $5 \times 4$ matrix of 20 pictures and was instructed to indicate whether the matrix contained 20 pictures of the same category or whether it contained one picture from a different category (the odd-one-out). If the matrix contained an odd-one-out picture (henceforth called the target picture), she was instructed to press the right button of a response-box. If the matrix did not contain an odd-oneout picture, she was instructed to press the left button. Note that the counterbalancing of right and left button is not necessary as only the target-present trials are relevant for testing our hypotheses. The matrix remained on screen until response or for a maximum of 20 seconds upon which the next trial began. The location of each picture in each matrix was chosen randomly for each trial and for each participant. However, the target picture never appeared directly above or below the location of the fixation cross in order to avoid facilitated detection. Participants were informed about the three categories stimuli could come from.

Pictorial stimuli from four categories were used: chocolate, candy, couches (neutral), and handbags (neutral). The function (i.e., target or distractor) of the neutral categories (couches and handbags) was counterbalanced over participants. Matrices on target present trials consisted of one chocolate-related picture among 19 couches/handbags, one candy related picture among 19 couches/handbags, one handbag among 19 couches, one couch/handbag among 19 chocolate related pictures, one couch/handbag among 19 candy related pictures, or of one couch among 19 handbags. Each of the six types of matrices was shown 19 times to each participant. Matrices on target absent trials consisted of 20 chocolate-related pictures, 20 candyrelated pictures, 20 handbags, or of 20 couches. There were 114 target present trials, 40 target absent trials, and 12 practice trials. Trials with candy-related pictures were included as an additional control category to check whether the attentional bias effects are specific for chocolate or whether they generalize to other sweets. 
In line with Smeets et al. (2008), the majority of the trials were target present trials because this type of trial is relevant for testing our hypotheses. Speeded detection of chocolate-related pictures is calculated by comparing response latencies to detect a chocolate-related target picture vs. a neutral target picture (e.g., handbags) among neutral distractor pictures from one other category (e.g., couches). Increased distraction is calculated by comparing response latencies to detect a neutral target picture (e.g., a handbag) among chocolate-related pictures vs. neutral distractor pictures from one other category (e.g., couches).

The visual search task lasted approximately 20 minutes, divided over two blocks of trials of 10 minutes. The participant was given a brief break between blocks. The distance between the participant and the monitor was approximately $90 \mathrm{~cm}$. Within the frame of the matrix, pictures were horizontally separated by $6.76 \mathrm{~cm}$ and vertically by $6.5 \mathrm{~cm}$ (measured from the middle point of the stimulus picture). All pictures were displayed on a light-grey background on a 17-inch monitor with a resolution of $1.280 \mathrm{x}$ 1024 pixels.

Stimulus material. Out of a pool of 250 pictures taken from the internet, 80 pictures were selected to create 20-item lists for four categories (i.e., chocolate, candy, couches, and handbags). Pictures were matched as closely as possible on shape, color and on the number of items present in a picture.

Manipulation check: State chocolate craving. State chocolate craving was assessed using a $100 \mathrm{~mm}$ Visual Analogue Scale (VAS) asking "how much do you crave chocolate at this very moment", ranging from 0 - "not at all" to 100 - "very much".

Trait chocolate craving. The chocolate craving subscale of the Attitudes to Chocolate Questionnaire (Benton, Greenfield, \& Benton, 1998) was used to select participants with a high and a low score on chocolate craving. This subscale consists of 16 statements about chocolate, such as, "My desire for chocolate often seems overpowering" "I eat chocolate to cheer me up when I'm down", and measures the amount of chocolate craving. Items are rated on a 7-point likert scale, ranging from $-3=$ strongly disagree to $3=$ strongly agree. Total scores range from -48 to 48 .

Restraint scale. The Restraint Scale (RS; Herman \& Polivy, 1980) is a 11-item scale, which measures the extent to which participants try to restrain their food intake. Higher scores reflect increased intention to restrain food intake.

Manipulations.

To induce chocolate craving, participants in the exposure condition were exposed to 11 different kinds of chocolate on a table individually. Each participant was instructed to select the chocolates that appeared the most appealing to her, and was instructed to 
closely smell, touch, and feel these chocolates without eating them for three minutes. After the first part of the visual search task, the participant was exposed to the chocolates again, but this time for one minute. The experimenter monitored whether participants complied with the instructions. Participants in the non-exposure condition were instructed to fill out a perception and concentration ranking questionnaire (i.e., control questionnaire) with items on artworks and colours. At the beginning of the experiment, each participant in the non-exposure condition was instructed to rank and give ratings for the artworks, while after the first part of the visual search task the participant was instructed to rank and give ratings for the colours.

\section{Procedure}

All participants were tested individually. Before entering the laboratory, participants signed the informed consent form and completed the state chocolate craving VAS (i.e., craving 1). Then participants were invited to the laboratory. Participants in the exposure condition were exposed to chocolates for three minutes while participants in the non-exposure condition completed the first part of the control questionnaire. State chocolate craving was measured subsequently (i.e., craving 2). Thereafter, all participants took place behind the computer and completed the first part of the visual search task. The computer was located behind a big screen to prevent participants in the exposure condition from seeing the chocolates which were presented on a table at the other side of the screen. Upon finishing the first part of the task, participants rated their levels of state chocolate craving (i.e., craving 3). Then, participants in the exposure condition received an additional 1-minute lasting craving-induction while participants in the non-exposure condition filled out a second part of the control questionnaire. State chocolate craving was measured (i.e., craving 4) and all participants completed the second part of the visual search task. Thereafter, state chocolate craving was measured one last time (i.e., craving 5) after which participants filled out a brief demographics questionnaire and the restraint scale. Finally, participants' height and weight were assessed.

Results

\section{Participant characteristics}

Analyses of variances were conducted to check for differences in age, BMI, restraint and trait chocolate craving between the groups. Four 2 (Group: chocoholics vs. non- 
chocoholics) $\times 2$ (Condition: exposure vs. non-exposure) ANOVAs with respectively age, $B M I$, Restraint, and trait chocolate craving as the dependent variables, revealed no significant Group $\times$ Condition interactions, all $F^{\prime} s<1.19$, all $p^{\prime} s>.28$, no significant main effects of Condition, all $F^{\prime} s<2.51$, all $p^{\prime} s>.12$, and no effects of group for age (Chocoholics exposure condition: $M=21.17, S D=2.01$; Chocoholics non-exposure condition: $M=21.06, S D=1.52$; non-chocoholics exposure condition: $M=21.41, S D=2.85$; nonchocoholics non-exposure condition: $M=21.19, S D=1.79$ ), BMI (Chocoholics exposure condition: $M=21.93, S D=2.72$; Chocoholics non-exposure condition: $M=21.58, S D=$ 2.83; non-chocoholics exposure condition: $M=21.79, S D=3.52$; non-chocoholics nonexposure condition: $M=19.95, S D=2.01$ ), and Restraint score (Chocoholics exposure condition: $M=10.94, S D=4.02$; Chocoholics non-exposure condition: $M=11.53, S D=$ 3.43; non-chocoholics exposure condition: $M=9.35, S D=4.46$; non-chocoholics nonexposure condition: $M=10.43,5 D=4.38$ ), all $F^{\prime} S<1.82$, all $p$ 's $>$. 18. A significant main effect of Group was found for trait chocolate craving, $F(1,67)=7.44, p<.05$, chocoholics (chocoholics exposure condition: $M=17.12, S D=6.97$; chocoholics non-exposure condition: $M=18.35, S D=6.43$ ) scored significantly higher on trait chocolate craving than non-chocoholics (non-chocoholics exposure condition: $M=-28.45, S D=7.76$, nonchocoholics non-exposure condition: $M=-27.10, S D=6.74$ ).

\section{Manipulation check}

Two paired samples t-tests were conducted to investigate whether our manipulation was successful at increasing levels of state chocolate craving in the exposure condition. Analyses show that state chocolate craving levels at pre-measurement $(M=5.49 ; S D=$ 2.65) increased significantly after the first $(M=6.60, S D=2.79), t(34)=3.47, p<.01$ and the second chocolate exposure $(M=6.42, S D=2.81), t(34)=3.23, p<.01$. Furthermore, an additional paired samples t-test showed that the level of chocolate craving after the first chocolate exposure was equal to the level of chocolate craving after the second chocolate exposure, $t(34)=1.06, p=.29$.

It can be concluded that our chocolate craving induction was successful at increasing levels of state chocolate craving in both chocoholics and non-chocoholics.

\section{Attentional bias scores}

We calculated bias scores (i.e., attentional bias difference scores) for both speeded detection and increased distraction. For investigating speeded detection effects, mean response latencies of trials in which a neutral target was presented among neutral distractors was subtracted from mean response latencies of trials in which a chocolate 
target was presented among neutral distractors. For investigating increased distraction effects, mean response latencies of trials in which a neutral target was presented among neutral distractors was subtracted from mean response latencies of trials in which a neutral target was presented among chocolate distractors.

Speeded detection. Bias scores were analyzed in a 2 (Condition: exposure vs. nonexposure) $\times 2$ (Group: chocoholics vs. non-chocoholics) ANOVA. Consistent with our expectations, a significant Condition $\times$ Group interaction was found, $F(1,64)=9.98, p$ $<.01$, qualifying a trend significant main effect of Group, $F(1,64)=3.34, p=.07$. The effect of Condition was not significant, $F(1,64)=0.86, p=35$. See Figure 1a for means and SEs.

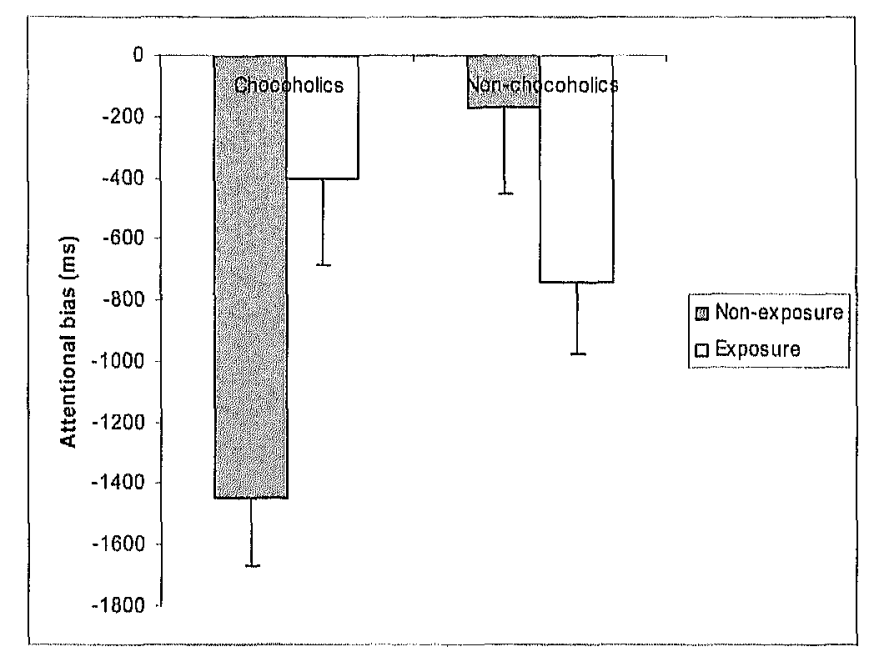

Figure 1a. Mean blas scores of speeded detection ( $y$-axis) for chocoholics and nonchacoholics in the exposure and non-exposure condition ( $x$-axis). Error bars represent one standard error.

Follow-up t-tests comparing exposure and non-exposure conditions separately for chocoholics and non-chocoholics were conducted. Chocoholics in the non-exposure condition were significantly faster at detecting a chocolate target than a neutral target in comparison to chocoholics in the exposure condition, $t(33)=2.93, p<.01$. For nonchocoholics, no effect of condition was found, $t(31)=1.56, p=.129$. In addition, t-tests comparing chocoholics and non-chocoholics within each condition were conducted. In the non-exposure condition, chocoholics were significantly faster at detecting chocolate targets than neutral targets in comparison to non-chocoholics, $t(31)=3.61, p<.01$. No 
difference between chocoholics and non-chocoholics was found in the exposure condition, $t(33)=0.93$, ns.

Taken together, chocoholics in the non-exposure condition showed speeded detection of chocolate targets, relative to chocoholics in the exposure condition and non-chocoholics in either the exposure or the non-exposure condition.

Increased distraction. Bias scores were analyzed in a 2 (Condition: exposure vs. non-exposure) $\times 2$ (Group: chocoholics vs. non-chocoholics) ANOVA. In accordance with our hypothesis, a significant Condition $\times$ Group interaction was found, $F(1,64)=7.62$, $<.01$, qualifying main effects of Condition, $F(1,64)=4.47, p<.05$, and Group, $F(1,64)$ $=4.44, p<.05$. See Figure $1 b$ for means and SEs.

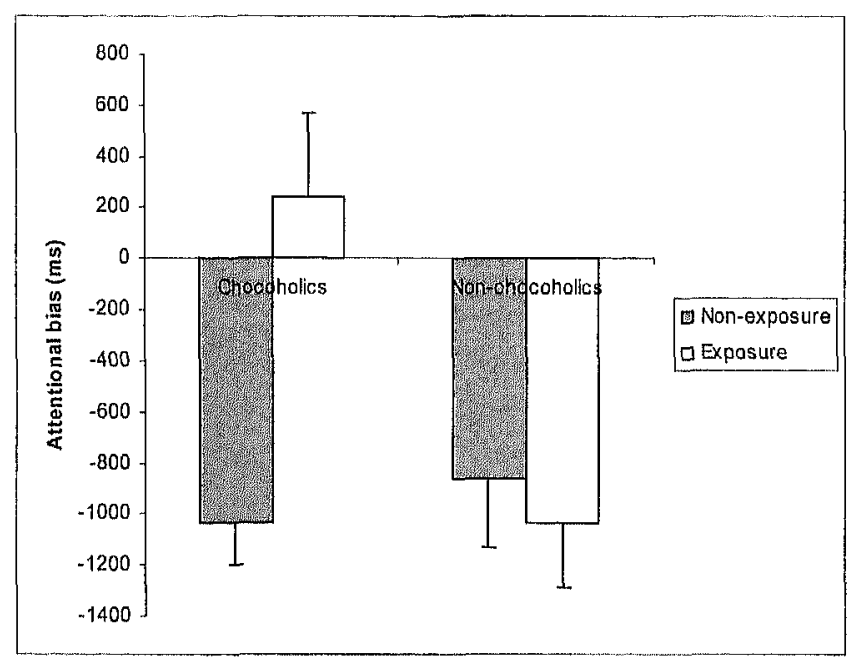

Figure 1b. Mean bias scores of increased distraction ( $y$-axis) for chocoholics and non chocoholics in the exposure and non-exposure condition ( $\mathrm{x}$-axis). Error bars represent one standard error.

Follow-up t-tests comparing exposure and non-exposure conditions separately for chocoholics and non-chocoholics were conducted. In line with our expectations, chocoholics in the exposure condition showed significantly higher distraction bias scores in comparison to chocoholics in the non-exposure condition, $t(33)=3.44, p<.01$. In the non-chocoholics group, distraction bias scores did not differ between conditions, $t$ (31) $=0.46$, ns. In addition, t-tests comparing chocoholics and non-chocoholics within each condition were conducted. Within the exposure condition, chocoholics showed significantly higher distraction bias scores than non-chocoholics, $t(33)=3.06, p<.01$. Within 
the non-exposure condition, distraction bias scores did not differ between groups, $t$ (31) $=0.55, n s$.

In conclusion, experimentally induced craving (i.e., exposure condition) caused increased distraction by chocolate targets in chocoholics, but not in non-chocoholics, as compared to a non-exposure control condition.

\section{Craving and attentional bias for candy}

To test whether either experimentally induced craving or trait levels of chocolate craving would also be related to an attentional bias for candy, two 2 (Condition: exposure vs. non-exposure) $\times 2$ (Group: chocoholics vs. non-chocoholics) ANOVAs of the attentional bias scores were conducted to investigate both speeded detection and increased distraction effects. These analyses showed that all interaction and main effects were non-significant, all $F^{\prime} s<2.02$, all $p^{\prime} s>16$. Taken together, these analyses show that our chocolate attentional bias effects did not generalize to candy.

\section{Correlations}

Pearson correlations were used to examine the relationship between the attentional bias measures (i.e., speeded detection, and increased distraction) and the craving measures. To increase power, the measure of craving was calculated by taking the mean of the craving measurements after the first (i.e., craving 2) and the second chocolate exposure (i.e., craving 4). Increased distraction and craving were positively correlated, $r=.28, p<.05$. Interestingly, this correlation was significant in the exposure condition, $r=.38, p<.05$, and in the chocoholics, $r=.36, p<.05$, but not in the nonexposure condition or in the non-chocoholics, all $r$ 's $<.01$, all $p>.95$. Speeded detection on the other hand was not correlated with craving, $r=.001, p=.99$.

\section{Discussion}

It was found that chocoholics who did not receive a chocolate craving induction were faster to detect chocolate-targets than neutral targets, relative to non-chocoholics and chocoholics in the exposure condition. Chocoholics who did receive a chocolate craving induction (i.e., exposure condition) were significantly more distracted by chocolatedistractors when looking for a neutral target than chocoholics in the non-exposure condition or non-chocoholics in the exposure condition. Interestingly, self-reported craving was positively correlated with increased distraction, in the chocoholics and in 
the exposure condition, but not in the non-chocoholics and non-exposure condition. Speeded detection, on the other hand, was not correlated with self-reported craving. Attentional bias effects were specific to chocolate-targets; no attentional bias effects were found for candy-targets as compared to neutral targets, in none of the groups or conditions.

The present study clearly shows a causal link between chocolate craving and a bias in the distraction component of attention. More specifically, when brought in an elevated state of craving, chocoholics showed more distraction by chocolate than when they were not brought in this elevated state. This finding sheds more light on the factors that might cause or maintain a food-related attentional bias. In a similar vein, research from the field of addiction, in which heavy drinkers were given a low dose of alcohol, also showed that increased feelings of craving lead to a bias in maintained attention (e.g., Schoenmakers, Wiers, \& Field, 2008).

Apart from a causal link between chocolate craving and increased distraction, we also found a positive correlation between self-reported levels of craving and a bias in increased distraction. These data build on addiction studies that have found larger associations between craving and attentional bias for measures of maintained attention than for measures of initial orienting of attention (Field, Mogg, Zetteler, and Bradley, 2004; Mogg, Field, \& Bradley; 2005). Adding further to this line of reasoning, in the current study no correlations were found between craving and measures of speeded detection. Theoretical models by Kavanagh and colleagues (2005), and Laberge (1995) respectively explain this finding by hypothesizing that craving is linked to the extent of rumination on, or greater maintained attention on craving-related stimuli, and that motivational factors are most likely to be evident in maintained attention rather than in the engagement of attention. In the same line, it can be hypothesized that the in creased distraction in chocoholics who were assigned to the exposure condition might reflect their motivation to consume chocolate as a result of the experimentally induced craving.

This brings us to the question as to whether a chocolate-related attentional bias in the distraction component might lead to overeating. Previous research has repeatedly shown that restrained eaters as well as bingers tend to overeat as a result of food cravings that were brought about by exposure to cues predicting food intake (e.g. Jansen, 1998). Therefore, it would be of great interest to investigate in future research whether an attentional bias might be the missing link in explaining the relation between food cravings and overeating.

With regard to the chocoholics who were not exposed to chocolates, we found evidence for speeded detection. This finding fits with predictions of the incentive sensitization theory (Robinson \& Berridge, 1993). In this perspective, it can be hypothe- 
sized that the bias in speeded detection in this group results from the fact that chocolate cues have acquired incentive salience (i.e., appetitive motivational characteristics) making them more salient and attention-grabbing than other stimuli. Another related explanation as to why trait chocoholics were faster to detect chocolate targets is that this group might exhibit a natural tendency to search for chocolate cues in their environment when they are not in an elevated state of craving. This rationale seems to be supported by the fact that the tendency to search for chocolate cues seems to disappear when craving levels are experimentally increased, as shown by the absence of speeded detection in the chocoholics in the exposure condition. For future research, it would be worthwhile to find out whether the speeded detection of chocolate is also associated with an approach bias.

It is concluded that chocoholics who have been exposed to chocolates show a bias in increased distraction, whereas chocoholics who have not been exposed to chocolates show a bias in speeded detection. Taken together, the present findings further articulate the importance of craving in explaining attentional biases for craving-related stimuli. 


\section{Chapter 7}

General Discussion 
The goal of the present dissertation was to gain a better understanding of the role of attentional biases in the origin and maintenance of eating disorder psychopathology, and in particular body dissatisfaction. In this section the findings of the present dissertation are discussed and a cognitive model of body dissatisfaction is proposed. Suggestions for future research are given and implications for the treatment of eating disorders and body dissatisfaction are discussed. Finally, some concluding remarks are made.

\section{The nature of the attentional bias in eating disorders}

The findings of the present dissertation underline the importance of attentional biases in eating disorders. By establishing the presence and nature of the attentional bias in eating disorder patients, our findings shed more light on the general nature of the biased cognitive processes that are involved in eating disorders. In this respect, the use of the visual search paradigm enabled us to explain the attentional bias effects in terms of speeded detection and increased distraction. The attentional favouring of bodyrelated information was reflected in speeded detection of body-related information, whereas the attentional favouring of food-related information was reflected in the difficulty to shift attention away from this type of information once detected (i.e., increased distraction). Given that the nature of the attentional bias in eating disorder patients differs with the type of information they are presented with, it is of great interest to unravel the meaning of these biases.

Attentional bias for body. In line with findings from anxiety studies (GilboaSchechtman, Foa \& Amir, 1999; Öhman, Flykt, \& Esteves, 2001; Rinck \& Becker, 2006), it was hypothesized that anxiety leads to a faster detection of body-related information. As eating disorder patients suffer from intense body concerns (Cash \& Deagle, 1997), it was contended that they might have experienced the body-related information as highly threatening, which in turn led to the present pattern of results. However since anxiety levels were not measured, alternative explanations for the speeded detection of body-related information could not be ruled out. Indeed, other studies from the field of anxiety (Rinck et al., 2003, 2005) show that the confrontation with threatening information does not only attract attention (i.e., speeded detection), but might also hold attention (i.e., increased distraction). Therefore, the question as to whether the present body-related attentional bias indeed reflects increased anxiety warrants further investigation. In addition, it would be of interest to test whether decreasing levels of body concerns by means of treatment will lead to a slower detection of body cues, and the other way around, whether a training in the slower detection of body cues, will lead to higher levels of body esteem. 
Attentional bias for food. With regard to the food-related attentional bias, results showed no faster detection of food cues, but increased distraction by food items in eating disorder patients. Two explanations for the increased distraction by food-related information in eating disorder patients can be put forward. One explanation is that in the light of their intense fear of gaining weight, eating disorder patients might have experienced the food-related information as threatening. This line of reasoning seems to be supported by research from the field of anxiety in which increased distraction by threatening stimuli was found (Rinck et al., 2003; 2005). However, another explanation is that in an early stage of information processing, food-related information might have been experienced as positive rather than negative by eating disorder patients. In this respect, it was hypothesized that the increased distraction by food cues might reflect craving response. In support of this explanation, research from the field of addiction (Mogg, Field, \& Bradley, 2005) showed that greater maintained attention, which may resemble the distraction component in the visual search task, for smoking cues in smokers was associated with higher levels of craving.

Given that craving- or anxiety-levels were not measured in previous studies on the attentional processing of eating disorder patients, it would be worthwhile to investigate whether the increased distraction by food-related information is anxiety- or cravingdriven. The present dissertation addressed the hypothesis that craving elicits increased distraction by food-related stimuli. Craving was manipulated in a group of chocoholics and non-chocoholics, and support was found for the craving-related explanation of the increased distraction effect. Chocoholics who were brought in an elevated state of craving had more difficulty to shift their attention away from chocolate-related distractors when searching for a neutral target (i.e., increased distraction), than did chocoholics in the control condition. These findings provide support for the causal role of craving in the development of food-related attentional biases. Furthermore, in line with studies from the field of addiction (Field, Mogg, Zetteler, \& Bradley, 2004; Mogg, Field, \& Bradley, 2005) self-reported levels of craving were found to be positively correlated with a bias in increased distraction in chocoholics and in the exposure condition.

\section{Future research: Attentional bias for food and craving}

The findings on the attentional bias for food give rise to interesting research questions. First of all, one could investigate whether an attentional bias for food-related information might lead to overeating. Previous research has shown that restrained eaters as well as bingers tend to overeat as a result of food cravings (e.g., Jansen, 1998). Therefore, it would be worthwhile to address whether an attentional bias might be the 
CHAPTER 7

missing link between food cravings and overeating. One possible way of addressing this suggestion is to randomly assign a group of healthy participants to one of two conditions; an attentional bias training condition and a control condition. In the attentional bias training condition participants will be trained to selectively attend to high-caloric food items, whereas in the control condition participants will receive a neutral training. The dependent variable will be the amount of calories that were consumed during a taste test before and after the attentional bias training. If participants who had received the attentional bias training would consume relatively more calories after the training than control participants, one could conclude that food-related attentional biases might induce overeating. This type of research would be extremely helpful in the light of the current "obesogenic" environment (Jeffrey \& Utter, 2003) with its abundance of high caloric palatable food cues. If it were true that an attentional bias for high caloric food might cause people to overeat, future research should focus on developing an attentional re-training for high-caloric foods and investigate it's effects on people's food intake.

A second question for future research would be to investigate whether the link between attentional bias and craving is indeed bi-directional as has been proposed by addiction theorists (Franken, 2003). It was shown that experimentally inducing chocolate cravings in chocoholics led to an attentional bias in the increased distraction component. However, so far the question whether an attentional bias for food also increases the extent to which people crave food has not been addressed. This could be done by testing in future studies the effect of an experimentally induced food-related attentional bias on craving in a sample of healthy participants.

The cognitive theory of eating disorders (e.g., Williamson, Muller, Reas, \& Thaw, 1999) states that cognitive biases, like the attentional bias have a maintaining role in eating disorder psychopathology. Based on this theory, it would be worthwhile to investigate in future research whether reducing the attentional bias for body-and foodrelated information might lead to a reduction in eating disorder psychopathology. Furthermore, given that the underlying mechanisms involved in the biased attentional processing of eating disorder patients are different for body-related biases than for food-related biases, future research should determine whether a specific approach is required for tackling each of these biases. More precisely, reducing biases by for example cognitive therapy or re-training might be different for biases related to speeded detection (body) and biases related to increased distraction (food). If the speeded detection of body-related information is indeed anxiety-driven, behavioural experiments and cognitive restructuring might be focused on the extinction of anxiety and anxiety-related cognitions. With regard to increased distraction by food-related information, it was shown that a food-related attentional bias is craving-driven. Therefore, 
behavioural experiments and cognitive restructuring might be focused on the extinction of craving and craving-related cognitions.

\section{Attention and body dissatisfaction}

\section{Cognitive model of body dissatisfaction}

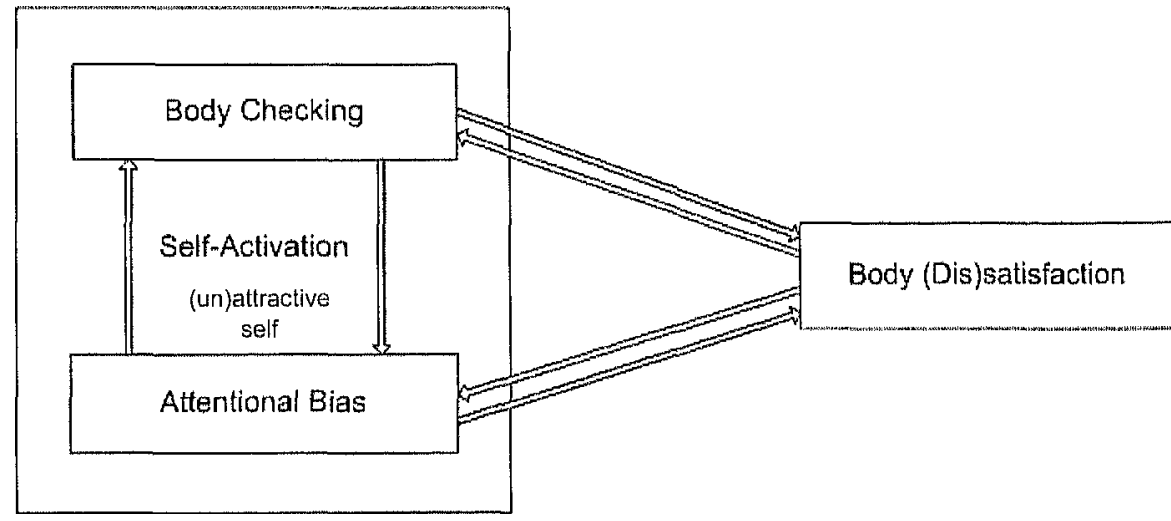

Figure 1. The attentional bias for the (un)attractive self and its effect on body (dis)satisfaction. (The gre lines represent findings of the present dissertation; the white lines represent directions for future research).

In the present section a new theoretical model that offers a cognitive explanation of body dissatisfaction is proposed (see Figure 1). This model states that selective attention for the unattractive self plays a crucial part in causing body dissatisfaction. It is hypothesized that the activation of the self manifests itself in body checking (on a behavioural level) as well as in a body-related attentional bias (on a cognitive level). Self-activation is regarded as general attention for the self, which increases the accessibility of self-related cognitions and feelings. Depending on whether the "unattractive self" or the "attractive self" is activated, body image will be influenced in a negative or in a positive way. In vulnerable groups (e.g. restrained eaters, body dissatisfied individuals) self-activation is hypothesized to automatically increase the individuals' awareness of their unattractive self, whereas in a normal group it is expected to increase the individuals' awareness of their attractive self. The activation of the unattractive self is believed to cause body dissatisfaction, given that body checking and selective attention will be directed at unattractive body parts. The activation of the attractive self is be- 
lieved to cause body satisfaction, given that body checking and selective attention will be directed at attractive body parts. A bi-directional relationship between body checking and attentional bias is proposed, because they are both regarded as manifestation of the same underlying construct (i.e. self-activation). More precisely, body checking is hypothesized to cause an attentional bias and vice versa. Finally, body dissatisfaction is hypothesized to have a maintaining effect on both body checking and attentional bias.

\section{Findings in support of the cognitive model of body dissatisfaction}

The findings of the present dissertation provide empirical support for the assumption that selective attention for the unattractive self causes body dissatisfaction. Using three different manipulations, the findings show that training participants to focus on their own unattractiveness caused them to feel body dissatisfied. Firstly, it was shown that training healthy participants to selectively attend to their three most unattractive body parts caused them to feel dissatisfied with their bodies. Secondly, it was shown that training healthy participants to engage in body checking behaviours led to increased feelings of body dissatisfaction. Thirdly, it was shown that experimentally inducing selfactivation caused restrained eaters but not unrestrained eaters to feel body dissatisfied after they were exposed to thin-ideal pictures. This finding underlines the potential negative influence of self-activation on body satisfaction and shows that exposure to thin-ideal images does not invariably affect all women in the same negative way. A combination of a restrained eating style and an elevated state of self-activation was necessary to make women feel less satisfied with their body after being confronted with images of beautiful women. Being in a state of self-activation led both restrained and unrestrained eaters to compare themselves more with the skinny looking models on the pictures, however only restrained eaters experienced a negative change in the way they felt about their bodies. This latter finding can be explained by the cognitive model of body dissatisfaction that states that self-activation in a vulnerable group will automatically increase the individuals' awareness of their "unattractive self". In that regard, it can be contended that the self-activation manipulation made restrained eaters more aware of their feelings of body dissatisfaction and their current goals to lose weight, which in turn made them feel even more dissatisfied when presented with pictures of beautiful women. As for unrestrained eaters, the self-activation manipulation did not have a negative effect on body image, given that the increased awareness of the self did not activate "unattractive" body schemes. Taken together, the findings of these three manipulations show that body dissatisfaction can be caused by one and the same mechanism, namely the activation of the unattractive self. 
Also in line with the cognitive model of body dissatisfaction, it was shown that body checking caused an attentional bias for body-related information. More precisely, experimentally inducing body checking in healthy participants led to an attentional bias for body-related information and more specifically speeded detection of this type of information in the absence of increased distraction. These findings are in line with the hypothesized link between body checking and cognitive biases (Williamson et al., 2004 Williamson, 1996) and parallel findings from the present dissertation, showing evidence of speeded detection of, but not increased distraction by, body-related information in eating disorder individuals. This suggests that, experimentally inducing one of the central characteristics of eating disorders (i.e., body checking) in a non-clinical group results in a pattern of information processing that generally resembles that of eating disorder patients. Future research should establish whether "body checking induced" attentional biases actually maintain eating disorder psychopathology

\section{Future research}

The cognitive model of body dissatisfaction and the findings outlined above give rise to interesting avenues for future research

Positive bias training. Firstly, it would be worthwhile to find out whether changing the way eating disorder patients attend to their bodies leads to positive changes in the way they feel about their bodies. Recent research findings seem to suggest that this is possible. Hilbert, Tushen-Caffier, and Vögele (2002), found that binge eating disorder individuals experienced an increase in body satisfaction when they were trained to describe their body as neutrally as possible during mirror exposure therapy. In a similar vein, Jansen and colleagues (2008) showed that describing one's body in neutral terms in addition to guided body exposure was a promising strategy for decreasing anxiety and increasing body satisfaction in a sample of obese adolescents. Given that increases in body satisfaction were already found with a neutral body image training, it can be hypothesized that a positive body image bias training might produce even stronger increases in body satisfaction.

Research from the present dissertation indicates that it is indeed possible to change the evaluation of the body in a positive direction by training participants to focus on their attractive body parts rather than on their unattractive ones. However, a significant increase in body satisfaction was only found for participants who had received a negative bias training before they were trained to selectively attend to their beautiful body parts. Participants who had only received the positive bias training did not show an increase in body satisfaction. One explanation for this effect might be that 
healthy participants had less room for improving their feelings of body satisfaction because they were already fairly satisfied with their bodies. In this respect, one could hypothesize that a positive bias training will have stronger effects in a clinical eating disorders group or in body dissatisfied individuals.

Even though the present finding is only preliminary and in need of replication, there is some reason to believe that treatment programs might benefit from incorporating procedures to teach eating disordered and other body dissatisfied patients to focus more on their beautiful body parts. Future research should find out under which conditions an attentional training might lead to a more positive body image, and whether a more intensive and repetitive positive bias training might be of benefit for an increase in body satisfaction. In conclusion, a main empirical question that remains for future research is whether training eating disorder patients to selectively attend to their most beautiful body parts leads to an increase in body satisfaction. Essentially, one would want to address this hypothesis in a group of patients that are at the end of their treatment program. Given the likelihood that eating disorder patients who are at the beginning of their treatment would rank their most skinny-looking body parts as the most beautiful, training them to focus even more on these parts could increase their reluctance to gain weight, and even reinforce the glorification of their skinny body. Therefore, it is necessary to restrict the investigation of the effect of a positive body training to patients who have or approach a healthy body weight. In this perspective, it can be hypothesized that the clinical implications of the positive bias training might be predominantly in relapse prevention rather than in the acute treatment of eating disorder psychopathology.

\section{Clinical implications}

The use of body exposure therapy. Nowadays body exposure therapy is a commonly used technique in clinical settings (Hilbert, Tuschen-Caffier, \& Vogele, 2002; Key, George, Beattie, Stammers, Lacey, \& Waller, 2002; Rushford \& Ostermeyer, 1997; Tuschen-Caffier, Vogele, Bracht, \& Hilbert, 2003). However, as of yet little is known about the mechanisms or the effects of exposure therapy. Clinicians confront their patients with their bodies in a mirror, but so far there is no empirical data on what exactly happens during that exposure. Jansen and colleagues (2005) exposed a group of eating symptomatic and control participants to pictures of their own and somebody else's body, while measuring eye-movements. Results demonstrated that exposing participants to a picture of their own body lowered the mood of eating symptomatic participants, whereas it did not alter the mood of healthy controls. Furthermore it was 
shown that when attending to a picture of their own body, eating symptomatic participants attend more to their own unattractive body parts than to their attractive body parts, whereas controls attend more to their own attractive body parts than to their unattractive body parts. These findings, together with the data from the present dissertation that show that the selective tendency to attend to unattractive body parts can cause body dissatisfaction, underline that caution is warranted when exposing eating disorder patients to their own body in a mirror. In this perspective, the present findings suggest that unguided body exposure might aggravate instead of improve body image concerns as eating disorder patients might continue to selectively look at their most unattractive body parts and in that way "reinforce their "ugly" body schemes" ( $p$. 12; Jansen et al., 2005)

Consequently, a cognitive training that tackles the selective processing of unattractive body parts and the related negative feelings, along with the traditional body exposure therapy might be necessary for the treatment to be successful in reducin body image concerns. Future research should find out whether a change in information processing, for example away from unattractive body parts is needed for recovery. Preliminary data indicate that habituation takes place during body exposure therapy (Hilbert et al., 2002; Key et al., 2002; Rushford \& Ostermeyer, 1997; Tuschen-Caffier et al., 2003), however future research is needed to determine whether this habituation also changes the way patients direct attention.

Addressing body checking during treatment. Given that poorer treatment outcomes have been associated with remaining body checking behaviours (Latner, in press) and negative body image at the end of treatment (Garner, 1997), the finding that body checking causes a body-related attentional bias further emphasizes the importance of targeting body checking in treatment programs. As body checking might maintain eating disorder psychopathology through an attentional bias for body-related information, it might be important to address the attentional bias and the body checking behaviours during guided body exposure therapy with response prevention.

Attentional bias: epiphenomenon or independent mechanism. There is currently some debate on whether attentional biases act as independent maintaining mechanisms in eating disorder psychopathology or whether they are merely an expression of this pathology which disappears with effective treatment (Shafran, Lee, Cooper, Palmer, \& Fairburn, 2008). Recently Shafran and colleagues (2008) conducted a study that suggests that attentional biases might be an epiphenomenon of eating disorder psychopathology. They showed that attentional blases in eating disorder patients diminished after they had received 20 weeks of standardised cognitive behaviour therapy. Nevertheless, as the authors did not include a control treatment group in which the cognitive component of the treatment was left out, it remains unclear whether the 
same pattern of results would have occurred for a treatment in which self-focused attention to disliked body parts was not addressed. In conclusion, a promising avenue for future research would be to find out whether or not specific methods to tackle attentional biases are necessary, and possibly sufficient, for a successful eating disorders treatment.

\section{Concluding remarks}

In the present dissertation a cognitive experimental approach was used to gain more understanding of the role of attentional biases in eating disorders. Three main themes were investigated. First, the nature of the attentional bias in eating disorder patients was addressed. It was demonstrated that the components that are involved in the biased attentional processing of eating disorder patients are dependent upon the type of information patients are presented with. The attentional bias for body-related information consisted of speeded detection of body-related information and the attentional bias for food-related information consisted of the difficulty to shift attention away from food-related information (i.e., increased distraction). Second, the causal influence of an attentional bias on body dissatisfaction was investigated. Using three different manipulations, it was demonstrated that training participants to focus on their own unattractiveness caused them to feel dissatisfied with their bodies. These findings support the causal role of an attentional bias in the development of body dissatisfaction. Third, two factors that were proposed to have a causal impact on the development of attentional biases were examined. It was demonstrated that experimentally inducing craving caused an attentional bias for food-related information in the increased distraction component whereas experimentally inducing body checking caused an attentional bias for body-related information in the speeded detection component. Taken together, the findings of the present dissertation underline the importance of attentional biases in understanding eating disorders and emphasize the causal role of these biases in the development of body dissatisfaction. 


\section{Chapter 8}

References 
American Psychiatric Association (1994). Diagnostic and statistical manual of mental disorders (4th ed.) Washington, DC.

Bauer, D., Cox, W.M. (1998). Alcohol-related words are distracting to both alcohol abusers and nonalcohol abusers in the Stroop colour-naming task. Addiction, 93, 1539-1542.

Bearman, S.K., Presnell, K., Martinez, E., Stice, E. (2006).The skinny on body dissatisfaction: A longitudinal study of adolescent girls and boys. Journal of Youth and Adolescence, 35, 229-241.

Beck, A.T., Ward, C.H., Mendelson, M., Mock, J., \& Erbaugh, J. (1961). An inventory for measuring depression. Archives of General Psychiatry, 4, 561-571.

Beck, A.T., Steer, R.A., Garbin, M.G. (1988). Psychometric properties of the Beck Depression Inventory Twenty-five years of evaluation. Clinical Psychology Review, 8, 77-100.

Benton, D., Greenfield, K., \& Morgan, M. (1998). The development of the attitudes to chocolate questionnaire. Personality and Individual Differences, 24, 513-520.

Borzekowski, D. L.G., Robinson, T.N., Killen, J.D. (2000). Does the camera add 10 pounds? Media use, perceived importance of appearance, and weight concerns among teenage girls. Journal of Adolescent Health, 26, 36-41.

Brockner J., \& Hulton, A.J., (1978). How to reverse the vicious cycle of low self esteem: The importance of attentional focus. Journal of Experimental Social Psychology 14, 564-578.

Cash, T.F., \& Deagle, E.A. (1997). The nature and extent of body image disturbances in anorexia nervos and bulimia nervosa: A meta-analysis. International Journal of Eating Disorders, 22, 107-125.

Cash, T.F., Fleming, E.C., Alindogan, J., Steadman, L., \& Whitehead, A. (2002). Beyond body image as a trait: The development and validation of the Body Image States Scale. The Journal of Treatment and Prevention, 10, 103-113.

Cattarin, J.A., Thompson, J.K., Thomas, C., \& Williams, R. (2000). Body image, mood, and televised images of attractiveness: The role of social comparison. Journal of Social and Clinical Psychology, 19, $220-239$.

Champion, H., \& Furnam, A. (1999). The effect of the media on body satisfaction in adolescent girls. European Eating disorders Review, 213-228.

Cooper, M.J., \& Fairburn, C.G. (1992). Selective processing of eating, weight, and shape related words in patients with eating disorders and dieters. Britlsh Journal of Clinical Psychology, 31, 363-365.

Cooper, P. J., Taylor, M. J., Cooper, Z., \& Fairburn, C. G. (1987). The development and validation of the Body Shape Questionnaire. International Journal of Eating Disorders, 6, 485-494.

Corning, A.F., Krumm, A.J., \& Smitham, L. A. (2006). Differential social comparison processes in women

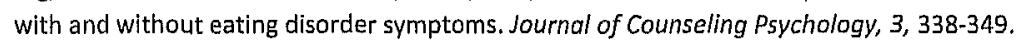

Cox, W.M., Yeates, G.N., \& Regan, C.M. (1999). Effects of alcohol cues on cognitive processing in heavy and light drinkers. Drug Alcohol Dependence, 55, 85-89.

Cox, W.M., Hogan, L.M., Kristian, M.R., \& Race, J.H. (2002). Alcohol attentional bias as a predictor of alcohol abusers' treatment outcome. Drug Alcohol Dependence, 68, 237- 243. 
De Ruiter, C., \& Brosschot, J.F. (1994). The emotional stroop interference effect in anxiety: Attentional bias or cognitive avoidance? Behaviour Research and Therapy, 32, 315-319.

Dijksterhuis, A., \& van Knippenberg, A. (2000). Behavioral indecision: Effects of self focus on automatic behavior. Social Cognition, 18, 55-74.

Dittmar, H., \& Howard, S. (2004). Thin-Ideal internalization and social comparison tendency as moderators of media models' impact on women's body-focused anxiety, Journal of Social and Clinical Psychology, 23, 768-791.

Dobson, K. S., \& Dozois, D. J. A. (2004). Attentional biases in eating disorders: A meta-analytic review of Stroop performance. Clinical Psychology Review, 23, 1001-1022.

Duval, S., \& Wicklund, R.A., (1972). A theory of objective self-awareness, Academic Press, New York.

Ehrman, R.N., Robbins, S.J., Bromwell, M.A., Lankford, M.E., Monterrosso, J.R., \& O'Brien, C.P. (2002). Comparing attentional bias to smoking cues in current smokers, former smokers, and non-smokers using a dot-probe task. Drug Alcohol Dependence, 67, 185-191.

Engel, S.G., Robinson, M.D., Wonderlich, S.J, Meier, B., Wonderlich, S.A.,

Crosby, R.D., Steffen, K.J. \& Mitchell, J.E. (2006). Does the avoidance of body and shape concerns reinforce eating disordered attitudes? Evidence from a manipulation study. Eating Behaviors, 7 , 368-374.

Espelage, D.L., Mazzeo, S.E., Aggen, S.H., \& Quittner, A.L. (2003). Examining the construct validity of the Eating Disorder Inventory. Psychological Assessment, 15, 71-80.

Eysenck, M. W. (1992). Anxiety: The cognitive perspective. Hillsdale, NJ: Erlbaum.

Fairburn, C.G. (2008). Cognitive behaviour therapy and eating disorders. New York: Guilford Press.

Fairburn, C.G., \& Beglin, S.J. (1994). Assessment of eating disorders: Interview or self-report questionnaire? International Journal of Eating Disorders, 16, 363-370.

Fairburn, C.G., \& Cooper, Z. (1993). The Eating Disorder Examination (12 ${ }^{\text {th }}$ ed.). In C.G. Fairburn \& G.T. Wilson (Eds.), Binge eating: Nature, assessment and treatment (pp. 317-360). New York: Guilford Press.

Fairburn, C.G., Cooper, Z., \& Shafran, R. (2003). Cognitive behaviour therapy for eating disorders: a "transdiagnostic" theory and treatment. Behaviour Research and Therapy, 41, 509-528.

Fairburn, C.G., \& Harrison, P.J. (2003). Eating disorders, Lancet, 361, 401-416.

Fairburn, C.G., Shafran, R., \& Cooper, Z. (1999). A cognitive behavioural theory of anorexia nervosa. Behaviour Research and Therapy, 37, 1-13.

Farrell, C., Shafran, R., \& Fairburn, C.G. (2004). Mirror cognitions and behaviours in people concerned about their body shape. Behavioural and Cognitive Psychotherapy, 32, 225-229.

Faunce, G.J. (2002). Eating disorders and attentional disorders: A review. Eating Disarders, 10, 125-139.

Festinger, L. (1954). A theory of social comparison processes. Human Relations, 7, 117-140. 
Field, M., Mogg, K., Zetteler, J., \& Bradley, B.P. (2004b). Attentional biases for alcohol cues in heavy and light social drinkers: the roles of initial orienting and maintained attention. Psychopharmacology, $176,88-93$.

Field, M., Mogg, K., \& Bradley, B.P (2005b). Craving and cognitive biases for alcohol cues in socia drinkers. Alcohol and Alcoholism, 40, 504-510.

Field, M., Duka, T., Eastwood, B., Child, R., Santarcangelo, M., \& Gayton, M. (2007a). Experimental manipulation of attentional biases in heavy drinkers: do the effects generalize? $P_{\text {sychopharmacol- }}$ ogy, 192, 593-608

Francis, J.A., Stewart, S.H., \& Hounsell, S. (1997). Dietary restraint and the selective processing of forbidden and nonforbidden food words. Cognitive Therapy and Research, 21, 633-646.

Franken, I.H.A. (2003). Drug craving and addiction: integrating psychological and neuropsychopharmacological approaches. Progress in Neuro-Psychopharmacology \& Biological Psychiatry, 27, 563 579.

Franken, I.H.A., Kroon, L.Y., Wiers, R.W., \& Jansen, A. (2000b). Selective cognitive processing of drus cues in heroin dependence, Journal of Psychopharmacology, 14, 395-400.

Freeman, R., Touyz, S., Sara, G., Rennie, C., Gordon, E., \& Beumont, P. (1991). In the eye of the beholder: Processing body shape information in anorexic and bulimic patients. International Journal of Eating Disorders, 6, 709-714.

Gardner, D.M. (1991). Eating Disorder Inventory-2 Manual. Odessa: Psychological Assessment Resources, Inc.

Garner, D.M., \& Bemis, K.M. (1982). A cognitive-behavioral approach to anorexia nervosa. Cognitive Therapy and Research, 6, 123-150.

Garner, D.M., \& Bemis, K.M. (1985). A cognitive-behavioral approach to anorexia nervosa. In D.M. Garner, \& P.E. Garfinkel (Eds.), Handbook of psychotherapy for anorexia nervosa and bulimia (pp. 107-146). New York: Guilford Press.

Garner, D.M., \& Garfinkel, P.E., editors. (1997). Handbook of treatment for eating Disorders. New York: The Guilford Press.

Gilbao-Schechtman, E., Foa, E.B., \& Arnir, N. (1999). Attentional biases for facial expressions in social phobia: The face-in-the-crowd paradigm. Cognition and Emotion, 13, 305-318.

Grabe, S., Ward, L.M., \& Hyde, J.S. (2008). The role of the media in body image concerns among women A meta-analysis of experimental and correlational studies. Psychological Bulletin, 134, 460-476.

Groesz, L.M., Levine, M.P., \& Murnen, S.K. (2002). The effect of experimental presentation of thin media images on body satisfaction: a meta-analytic revlew. International Journal of Eating Disorders, 31, 1 16.

Gross, T.M., Jarvik, M.E., \& Rosenblatt, M.R. (1993). Nicotine abstinence produces context-specific Stroop interference. Psychopharmacology, 110, 333- 336. 
Hansen, C.H., \& Hansen, R.D. (1988). Finding the face in the crowd: An anger superiority effect. Journal of Personality and Social Psychology, 54, 917-924.

Hargreaves, D., \& Tiggemann, M. (2002). The Role of appearance schematicity in the development of adolescent body dissatisfaction. Cognitive Therapy and Research, 26, 691-700.

Harrison, K., \& Cantor, J. (1997). The relationship between media consumption and eating disorders Journal of Communication, 47,4067

Heinberg, L.J., Thompson, J.K., \& Stormer, S. (1995). Development and validation of the Sociocultura Attitudes Towards Appearance Questionnaire. International Journal of Eating Disorders, 17, 81-89.

Herman, C.P., \& Polivy, J. (1975). Anxiety, restraint, and eating behavior. Journal of Abnormal Psychology, 84, 666-672.

Herman, C.P., \& Polivy, J. (1980). Restrained eating. In A.J. Stunkard (Eds.), Obesity (pp. 208-225) Philadelphia: Saunders.

Hillbert, A., Tuschen-Caffier, B. \& Vogele, C (2002). Effects of prolonged and repeated body image exposure in binge-eating disorder. Journal of Psychosomatic Research, 52, 137-144.

Hoistrom, A.J. (2004). The effects of the media on body image: A meta analysis. Journal of Broadcasting and Electronic Media, 48, 196-217.

Irving, L.M. (1990). Mirror Images: Effects of the standard of beauty on the self- and body-esteem of women exhibiting varying levels of bulimic symptoms. Journal of Social and Clinical Psychology, 9, $230-242$.

Jansen, A. (1998). A learning model of binge eating: Cue reactivity and cue exposure. Behaviour Research and Therapy, 36, 257-272.

Jansen, A., Bollen, D., Tuschen-Caffier, B., Roefs, A., Tanghe, A., Braet, C. (2008). Mirror exposure reduces body dissatisfaction and anxiety in obese adolescents: a pilot study. Appetite, 51, 214-217.

Jansen, A., \& de Vries, M. (1995). Pre-attentive exposure to the thin female beauty does not affect women's mood; self-esteem and eating behaviour. European Eating Disorders Review, 10, 208-217.

Jansen, A., Nederkoorn, C. \& Mulkens, S. (2005). Selective visual attention for ugly and beautiful body parts in eating disorders. Behoviour Research and Therapy, 43, 183-196.

Jeffery, R.W., \& Utter, J. (2003). The changing environment and population obesity in the United States. Obesity Research, 11, 125-22s.

Joshi, R., Herman, C.P., \& Polivy, J. (2004). Self-enhancing effects of exposure to thin-body images International Journal of Eating Disorders, 35, 333-341.

Key, A., George, C.L., Beattie, D., Stammers, K., Lacey, H., \& Waller, G. (2002). Body image treatment within an inpatient program for anorexia nervosa: The role of mirror exposure in the desensitization process. International Journal of Eating Disorders, 31, 185-190.

Koster, E.H.W., Crombez, G., Vershuere, B., \& De Houwer, J. (2004). Selective attention to threat in the dot probe paradigm: Differentiating vigilance and difficulty to disengage. Behaviour Research and Therapy, 42, 1183-1192. 
Latner, J.D. (in press). Body checking and avoidance among behavioural weight-loss participants. Body Image.

Lavine, H., Sweeney, D., \& Wagner, S.H. (1999). Depicting women as sex objects in television advertising Effects on body dissatisfaction. Personality and Social Psychology Bulletin, 25, 1049-1058.

Lee, M. \& Shafran, R. (2004). Information processing blases in eating disorders. Clinical Psychology Review, 24, 215-238.

Lubman, D.I., Peters, L.A., Mogg, K., Bradley, B.P., \& Deakin, J.F.W. (2000). Attentional bias for drug cues in apiate dependence. Psychological Medicine, 30, $169-175$

Luce, K.H., \& Crowther, J.H. (1999). The reliability of the eating disorder examination self-report questionnaire version (EDE-Q). International Journal of Eating Disorders, 25, 349-351.

Macleod, C. (2005). The Stroop task in clinical research. In A. Wenzel \& D. C. Rubin (Eds.), Cognitive methods and their application to clinical research (pp.41-62). Washington, DC: APA.

Macleod, C., \& Mathews, A. (1991). Biased cognitive operations in anxiety: accessibility of Information, or assignment of processing priorities? Behaviour Research and Therapy, 29, 599-610,

Macleod, C., Mathews, A., \& Tata, P. (1986), Attentional bias in emotional disorders, Journal of Abnormal Psychology, 95, 15-20.

MacLeod, C., Rutherford, E., Campbell, L., Ebsworthy, G., \& Holker, L. (2002). Selective attention and emotional vuinerability: Assessing the causal basis of their association through the experimental manipulation of attentional blas. Journal of Abnormal Psychology, 111, 107-123.

Mathews, A., \& Macleod, C. (2005). Cognitive vulnerability to emotional disorders. Annual Review of Clinical Psychology, 1, 167-195.

Martin, M.C., \& Kennedy, P.F. (1993). Advertising and social comparison: Consequences for female preadolescents and adolescents. Psychology and Advertising, 10, 513-530.

Mills, J.S., Polivy, J., Herman, C.P., \& Tiggemann, M. (2002). Effects of exposure to thin media images Evidence of self-enhancement among restrained eaters, Personality and Social Psychology Bulletin $28,1687-169$.

Mogg, K., \& Bradley, B.P. (1998). A cognitive-motivational analysis of anxiety. Behaviour Research and Therapy, $36,809-848$.

Mogg, K., Bradley, B.P., Miles, F., \& Dixon, R. (2004). Time course of attentional bias for threat scenes: testing the vigilance-avoidance hypothesis. Cognition and Emotion, 18, 689-700.

Mogg, K., Bradley, B.P., Field, M., \& Houwer, J. (2003). Eye movements to smoking related pictures in smokers: relationships between attentional biases and implicit and explicit measures of stimulus valence. Addiction, 98, 825-836.

Mogg, K., Field, M., \& Bradley, B.P. (2005). Attentional and approach biases for smoking cues in smokers: An investigation of competing theoretical views of addiction. Psychopharmacology, 180, 333- 
Mountford, V., Haase, A., \& Waller, G. (2006). Body checking in the eating disorders: Associations between cognitions and behaviors. International Journal of Disorders, 39, 708-715.

Öhman, A., Flykt, A., \& Esteves, F. (2001). Emotion drives attention: Detecting the snake in the grass. Journal of Experimental Psychology: General, 130, 466-478.

Overduin, J., Jansen, A., \& Louwerse, E. (1995). Stroop interference and food intake. International Journal of Eating Disorders, 18, 277-285.

Placanica, J.L., Faunce, G.J., \& Soames Job, R.F. (2002). The effect of fasting on attentional biases for food and body shape/weight words in high and low Eating Disorder Inventory scores. Wiley Periodicals, 32, 79-90.

Posavac, H.D., Posavac, S.S., \& Posavac, E.J. (1998). Exposure to media images of female attractiveness and concern with body weight among young women. Sex Roles, 38, 187-201.

Reas, D.L., Whisenhunt, B.L. Netemeyer, R., \& Williamson, D.A. (2002). Development of the body checking questionnaire: A self-report measure of Body checking behaviors. International Journal of Eating Disorders, 31, 324-333.

Reas, D.L., Grilo, C.M., Masheb, R.M., \& Wilson, G.T. (2005). Body checking and avoidance in overweight patients with binge eating disorder. International Journal of Eating Disorders, 37, 342-346.

Rieger, E., Schotte, D.E., Touyz, S.W., Beumont, P.J.V., Griffiths, R., \& Russel, J. (1998). Attentional biases in eating disorders: A visual probe detection procedure. International Journal of Eating Disorders, 23, 199-205.

Rinck, M., \& Becker, E.S. (2006). Spider fearful individuals attend to threat, then quickly avoid it: Evidence from eye movements. Journal of Abnormal Psychology, 115, 231-238.

Rinck, M., Becker, E.S., Kellermann, J., \& Roth, W.T. (2003). Selective attention in anxiety: Distraction and enhancement in visual search. Depression and Anxlety, 18, 18-28.

Rinck, M., Reinecke, A., Ellwart, T., Heuer, K., \& Becker, E. (2005). Speeded detection and increased discreased distraction in fear of spiders: Evidence from eye movements. Journal of Abnormal Psychology, 114, 235-248.

Rosen, J. C., Jones, A., Ramirez, E., \& Waxman, S. (1996). Body Shape Questlonnaire: Studies of validity and reliability. International Journal of Eating Disorders, 20, 31.5-319.

Rushford, N., \& Ostermeyer, A. (1997). Body image disturbance and their change with videofeedback in anorexia nervosa. Behaviour Research and Therapy, 5, 389-398.

Robinson, T.E., \& Berridge, K.C. (1993). The neural basis of craving: An incentive-sensitization theory of addiction. Brain Research Review, 18, 247-291.

Rosse, R.B., Miller, M.W., Hess, A.L., Allm, T.N., \& Deutch, S.L. (1993). Measures of visual scanning as a predictor of cocaine cravings and urges, Biological Psychiatry, 33, 554-556.

Rosse, R.B., Johrl, S., Kendrick, K., Hess, A.L., Allm, T.N., Miller, M.M., \& Deutch, S.I. (1997). Preattentive and attentive eye movements during visual scanning of a cocaine cue: correlation with intensity of cocaine cravings. Journal of Neuropsychiatry and Clinical Neuroscience, 9, 91- 93. 
Salemink, E., van den Hout, M.A., \& Kindt, M. (2007). Selective attention to threat: Quick orientin versus slow disengagement and two versions of the dot probe task. Behaviour Research and Thera$p y, 45,607-615$.

Schoemaker, C., Verbraak, M., Breteler, R., \& van der Staak, C. (1997). The discriminant validity of the Eating Disorder Inventory-2. British Journal of Clinical Psychology, 36, 627-629.

Schoenmakers, T., Wiers, R.W., \& Field, M. (2008). Effects of a low dose of alcohol on cognitive biases and craving in heavy drinkers. Psychopharmacology, 197, $169-178$

Seddon, L., \& Berry, N. (1996). Media-induced disinhibition of dietary restraint. British Journal of Health Psychology, 1, 27-33.

Shafran, R., Fairburn, C.G., Robinson, P., \& Lask, B. (2004). Body checking and its avoidance in eating disorders. International Journal of Eating Disorders, 35, 93-101.

Shafran, R., Lee, M., Cooper, Z., Palmer, R.L., \& Fairburn, C.G. (2007a). Attentional bias in eating disorders. International Journal of Eating Disorders, 40, 369-380

Shafran, R., Lee, M., Payne, E., \& Fairburn, C.G. (2007b). An experimental analysis of body checking Behaviour Research and Therapy, 45, 113121.

Shafran, R., Lee, M., Cooper, Z., Palmer, R. L., Fairburn, C.G. (2008). Effect of psychological treatment on attentional blas in eating disorders. International Journal of eating disorders, 41, 348-354.

Smeets, E., Jansen, A., Lindelauf, T., \& Roefs, A. (submitted for publication). Selective attention for unattractive body parts causes body dissatisfaction.

Smeets, E., Roefs, A., Furth, E., \& Jansen, A. (2008). Attentional bias for body and food in eating disorders: Increased distraction, speeded detection, or both? Behaviour Research and Therapy, 46 , $229-238$.

Smith, E., \& Rieger, E. (2006). The Effect of Attentional Bias Toward Shape- and Weight-Related Information on Body Dissatisfaction. International Journal of Eating Disorders, 39, 509-515.

Stapel, D. A., \& Tesser, A. (2001). Self-activation increases social comparison. Journal of Personality and Social Psychology, 81, 742750

Stice, E, (2002). Risk and maintenance factors for eating pathology: A meta-analytic review. Psychological Bulletin, 128, 825-848.

Stice, E., Schupak-Neuberg, E., Shaw, H.E., \& Stein, R.I. (1994). Relation of media exposure to eating

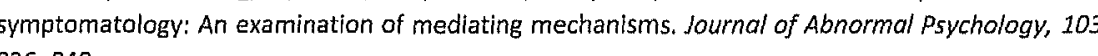
$836-840$

Stice, E., \& Shaw, H.E. (1994). Adverse effects of the media portrayed thin ideal on women and linkages to bulimic symptomatology. Journal of Social and Clinical Psychology, 13, 288-308.

Stice, E., \& Whitenton, K. (2002). Risk factors for body dissatisfaction in adolescent girls: a longitudinal investigation. Developmental Psychology, 38, 669-678.

Stormark, K.M., Laberg, J.C., Nordby, H., \& Hugdahl, K. (2000). Alcoholics' selective attention to alcoho stimuli; automated processing? Journal of Studies on Alcohol and Drugs, $61,18-23$.

114 
Stormer, S.M., \& Thompson, J.K. (1996). Explanations of body image disturbance: A test of maturational status, negative verbal commentary, social comparison, and sociocultural hypotheses. Internationa Journal of Eating Disorders, 19, 193-202.

Schwinghammer, S. A., \& Stapel, D. A. (2006). The effects of different types of self activation on social comparison orientation. Social Cognition, 24, 703-722.

Tiggemann, M., \& Pickering, A.S. (1996). Role of television in adolescent women's body dissatisfaction and drive for thinness. International Journal of Eating Disorders, 20, 199-203.

Tiggemann, M. \& Slater, A. (2004). Thin ideals in music television: A source of social comparison and body dissatisfaction. International Journal of Eating Disorders, 35, 48-58.

Trampe, D., Stapel, D.A., \& Siero, F.W. (2007), On models and vases: Body dissatisfaction and proneness to social comparison effects. Journal of Personality and Social Psychology, 92, 106-118.

Tuschen-Caffier, B., Vögele, C., Bracht, S., \& Hilbert, A. (2003). Psychological responses to body shape exposure in patients with bulimia nervosa. Behaviour Research and Therapy, 41, 573-586.

Vitousek, K.B., \& Steven, D. (1990). The investigation of schematic content and processing in eatin disorders. Cognitive therapy and Research, 14, 191-21.4.

Waller, G., Hamilton, K., \& Shaw, J. (1992). Media influences on body size estimation in eating disordered and comparison subjects. British Review of Bulimia and Anorexia Nervosa, 6, 81-87,

Walters, A. J., \& Feyerabend, C., (2000). Determinants and effects of attentional bias in smokers. Psychology of Addictive Behaviours, 14, 111-120.

Williamson, D.A. (1996). Body image disturbance in eating disorders? A form of cognitive bias? Eating Disorders, 4, 47-58.

Williams, J.M.G., Mathews, A., \& Macleod, C. (1996). The emotional stroop task and psychopathology. Psychological Bulletin, 120, 3-24.

Williamson, D.A., Muller, S.L., Reas, D.L., Thaw, S.M. (1999). Cognitive bias in eating disorders; Implications for theory and treatment. Behovior Modification, 23, 556-577.

Williamson, D.A., White, M.A., York-Crowe, E., \& Stewart, T.M. (2004). Cognitive-behavioral theories of eating disorders. Behavior Modification, 28, 711-738.

Wilson, G.T., \& Fairburn, C.G. (2002). Treatment for eating disorders. In P.E. Nathan \& J.M. Gorman (Eds.). A guide to treatments that work (pp. 559-592). New York: Oxford University Press. 


\section{Chapter 9}

Summary 
Today, in our appearance-focused Western society, looking beautiful, slim, and attractive is a big issue for many women. Over $25 \%$ of all women report feeling extremely dissatisfied with the way their body looks (Bearman, Presnell, Martinez, \& Stice, 2006; Stice \& Whitenton, 2002), and approximately 1 to $2 \%$ of our population suffers from an eating disorder (APA, 1994). There has been a long tradition in eating disorders research but there is still a lot of uncertainty about the causes of eating disorders. At this point, experimental research into the mechanisms that cause and maintain eating disorders is a vital necessity. Cognitive theorists point to the relevance of attentional biases in explaining the etiology and maintenance of eating disorders. An attentiona bias is defined as the tendency to selectively attend to disorder-relevant stimuli (e.g. Mathews and Macleod, 2005; Williamson et al., 2004). The goal of the present dissertation was to gain a better understanding of the role of attentional biases in the origin and maintenance of eating disorder psychopathology, and in particular body dissatisfac tion. Three general themes were addressed: (1) The precise nature of the attentional bias in eating disorders, (2) Attention and body dissatisfaction, and (3) Factors that cause an attentional bias.

Chapter 1 presents an overview on eating disorders, the cognitive theory of eating disorders, and attentional bias research in eating disorders. Furthermore, factors that might cause body dissatisfaction and factors that might cause an attentional bias are discussed. Additionally, the outline of the present dissertation is discussed in this chapter.

Chapter 2 describes a study in which the precise nature of the attentional bias for body- and food-related information in eating disorder patients was examined. The participants, 67 eating disorder patients and 60 healthy controls, completed a body and a food visual search task. This task was used to study whether the attentional favouring of body- and food-related information in eating disorder patients, can be understood in terms of speeded detection or of increased distraction. Speeded detection refers to the faster detection of a disorder-relevant target word, relative to a neutral target of a certain category word among neutral distractor words of another category. Increased distraction refers to the slower detection of a neutral target word of a certain category among disorder-relevant distractor words relative to neutral distractor words of another category. Results indicated that eating disorder patients showed evidence of speeded detection of body-related information, compared with healthy controls. They did not show evidence of increased distraction by this type of information. With regard to food-related information, it was found that compared with controls eating disorder patients showed evidence of increased distraction by high-caloric food words, but no evidence was found of the speeded detection of high-caloric food words. It was concluded that the precise nature of the attentional bias in eating disorder patients is 
dependent upon the type of information they are presented with. Furthermore, it was contended that speeded detection of body-related information might reflect an anxiety response, whereas increased distraction by food-related information might reflect a craving response.

Chapter 3 and 4 describe two studies in which it was attempted to experimentally investigate factors that cause body dissatisfaction. In chapter 3 the focus was on the role of selective attention and in chapter 4 it was on the role of self-activation, in the development of body dissatisfaction.

Chapter 3 addressed the hypothesis that selective attention for unattractive body parts causes body dissatisfaction (Jansen et al., 2005). Forty-seven female undergraduate students with moderate levels of body dissatisfaction were randomly assigned to one of two conditions. In the negative bias training condition, participants were trained to selectively attend to their three most unattractive body parts, and in the positive bias training condition, participants were trained to selectively attend to their three most attractive body parts. State levels of body- and weight satisfaction were assessed before and after the training. After this, participants who completed the negative bias training received a positive bias training which served as a counter induction. After the positive counter induction, state levels of body- and weight satisfaction were assessed one last time. The results illustrate that temporarily inducing an attentional bias for self defined unattractive body parts led to a significant decrease in body- and weigh satisfaction. Unfortunately, training healthy participants to selectively attend to their own most attractive body parts did not result in a significant increase in body- and weight satisfaction. The absence of this effect was explained in terms of the difficuity that might be involved in inducing a positive bias in women who are already reasonably satisfied with their bodies. Moreover, it was contended that the duration of the positiv bias training might have been too short to induce positive changes in the levels of body satisfaction. Interestingly, though, the positive counter induction training did lead to a significant increase in body- and weight satisfaction in participants who were first assigned to the negative bias training. It was argued that this group of participants differed in two ways from the participants who had initially been assigned to the positive bias training. First, they had more room for improvement because they had experienced a recent decrease in body satisfaction as a result of the negative bias training. Second, their relative body dissatisfaction was not that tenacious as it was only recently induced. Encouragingly, the finding that a temporary decrease in body dissatis faction could be reversed by a positive counter induction training shows that changes in a positive direction are possible. Taken together, the findings of chapter 2 support the etiological role of selective attention in body dissatisfaction and are in line with the 
assumption of Jansen et al., (2005). Training healthy participants to view their bodies in a dysfunctional or biased way results in feelings of body dissatisfaction.

The study presented in chapter 4 investigated the causal role of self-activation in women's vulnerability to thin-ideal media images. A sample of seventy-nine female undergraduate students, consisting of thirty-nine restrained eaters and forty unrestrained eaters, were randomly assigned to one of two conditions. In the self-activation condition, participants were given an essay assignment, which was presented as an application letter for a future employer. They were instructed to describe three positive and three negative character traits of themselves in detail and were told to use one of the following words: ' 1 ', 'me', 'myself', or 'mine' in every sentence. In the control condition, participants were given a neutral essay-assignment in which they had to write a short story about a chair and a table. Measures of state body- and weight satisfaction, and of social comparison tendencies were assessed throughout the experiment. The level of self-activation was checked before and after participants were exposed to a series of thin-ideal images. Results demonstrated that self-activated restrained eaters showed a significant decrease in body- and weight satisfaction after exposure to thin-ideal images, in comparison to restrained eaters who were not selfactivated. In contrast, self-activated unrestrained eaters did not experience changes in their body- and weight satisfaction after thin-ideal exposure, as compared to unrestrained eaters and restrained eaters in the control condition. These results illustrate that thin-ideal exposure only had a negative effect on women's body image when two conditions were met: (1) when the participant was 'self-activated' and (2) when the participant classified as a restrained eater. The present results underline that exposure to thin women in the media does not invariably affect all women in the same negative way. Even though, the self-activation manipulation led to increased social comparison tendencies in both restrained and unrestrained eaters, only the body image of selfactivated restrained eaters was affected in a negative way.

Chapters 5 and 6 describe two studies in which two factors that might cause an attentional bias were investigated. Chapter 5 focused on body checking in explaining the attentional bias for body-related information, and chapter 6 focused on craving in explaining the attentional bias for food-related information.

In chapter 5, the causal role of body checking in the development of an attentional bias was investigated by experimentally inducing body checking in a healthy sample. Sixty-six female undergraduate students were randomly assigned to one of three conditions: the body checking condition, the body exposure condition, and the control condition. In all conditions participants were instructed to make a series of length estimations, but in the body checking and body exposure condition they were instructed to do these in front of a mirror. Participants in the body checking condition 
were instructed to estimate the length of three different parts of their body whereas participants in the body exposure condition were instructed to estimate the length of three different parts of a chair. After the manipulation, all participants completed the body visual search task. Results demonstrated that experimentally inducing body checking in healthy participants led to an attentional bias for body-related information. In particular, participants in the body checking condition were faster at detecting bodyrelated target words (i.e., speeded detection) than neutral target words among neutral distractors, relative to participants in the body exposure and control conditions. However, there was no evidence of increased distraction; participants in the body checkin condition were not more distracted by body-related distractors as compared to neutral distractors, when searching for a neutral target word, relative to participants in the body exposure and control condition. Taken together, the findings presented in chapte 5 experimentally show that the act of body checking biases the attentional processing of body-related information. Furthermore, they show that body checking over and above mere exposure to one's body is necessary to produce an attentional bias. In addition to inducing an attentional bias, the body checking manipulation also led to increased feelings of body dissatisfaction which were correlated with the attentional bias for body-related information.

Finally, the study presented in chapter 6 investigated the causal role of craving in the development of an attentional bias, by experimentally inducing chocolate craving in a female sample of chocoholics and non-chocoholics. Thirty-five chocoholics and thirtythree non-chocoholics were randomly assigned to either the exposure condition, in which craving was induced, or the control condition. After the manipulation all partic pants completed the chocolate visual search task. State craving levels were assessed throughout the experiment. Results showed that experimentally induced chocolat craving causes a bias in particularly the increased distraction component of attention in chocoholics. More specifically, chocoholics in the exposure condition were more distracted by chocolate distractors as compared to neutral distractors, when searching for a neutral target picture, relative to non-chocoholics in the exposure condition and chocoholics in the control condition. In addition, self-reported craving was positively correlated with increased distraction in chocoholics and in the exposure condition. Chocoholics in the non-exposure condition were faster to detect chocolate-targets than neutral targets (i.e., speeded detection), relative to non-chocoholics and chocoholics in the exposure condition. However, speeded detection measures were not correlated with self-reported craving. In sum, the findings from chapter 6 shed more light on the factors that might cause or maintain a food-related attentional bias.

In chapter 7 the above reported findings are discussed and a cognitive model of body dissatisfaction is proposed. Suggestions for future research are given and implica- 
CHAPTER 9

tions for the treatment of eating disorders and body dissatisfaction are discussed. Taken together, the findings of the present dissertation underline the importance of attentional biases in understanding eating disorders and emphasize the causal role of these biases in the development of body dissatisfaction. 


\section{Chapter 10}

Samenvatting 
Tegenwoordig wordt in onze Westerse samenleving erg de nadruk gelegd op het uiterlijk. Mooi, aantrekkelijk en slank voor de dag komen, is dan ook erg belangrijk voor veel vrouwen. Meer dan $25 \%$ van alle vrouwen geven aan dat ze extreem ontevreden zijn met hun lichaam (Bearman, Presnell, Martinez, \& Stice, 2006; Stice \& Whitenton, 2002), en 1 tot $2 \%$ van de bevolking lijdt aan een eetstoornis (APA, 1994). Het onderzoek naar eetstoornissen heeft een lange traditie, maar er heerst nog veel onzekerheid over wat eetstoornissen veroorzaakt. We zijn op het punt aanbeland waar experimenteel onderzoek naar de causale en instandhoudende mechanismen bij eetstoornissen van vitaal belang is. Aanhangers van de cognitieve theorie vestigen de aandacht op het belang van aandachtsbiasen in de etiologie en de instandhouding van eetstoornissen. Een aandachtsbias wordt gedefinieerd als de neiging om selectief aandacht te hebben voor stimuli die relevant zijn voor de stoornis waaraan men lijdt (Mathews and Macleod, 2005; Williamson et al.,2004). Het doel van het huidige proefschrift is om meer inzicht te krijgen in de rol van aandachtsbiasen in de oorzaken en instandhouding van eetstoornispathologie, en in het bijzonder lichaamsontevredenheid. Drie algemene thema's werden aangesneden: (1) Een meer gedetailleerde kijk op de aandachtsbias in eetstoornissen, (2) Aandacht en lichaamsontevredenheid, en (3) Factoren die een aandachtsbias veroorzaken.

In hoofdstuk 1 wordt er een overzicht gegeven van eetstoornissen, de cognitieve theorie met betrekking tot eetstoornissen en aandachtsbias onderzoek in eetstoornissen. Bovendien komen mogelijke causale factoren voor lichaamsontevredenheid en aandachtsbiasen aan bod. Tot slot wordt een kort overzicht gegeven van alle hoofdstukken in dit proefschrift.

In hoofdstuk 2 wordt een studie beschreven waarin onderzocht werd hoe het aandachtsbias voor lichaams- en voedselgerelateerde informatie precies opgebouwd is. De deelnemers, 67 eetstoornispatiënten en 60 gezonde vrouwen, deden twee visuele zoektaken: één met lichaamswoorden en één met voedselwoorden. Aan de hand van deze taak was het mogelijk uit te maken of de voorkeur in aandacht voor lichaams- en voedselgerelateerde informatie in eetstoornispatiënten een kwestie was van versnelde detectie of toegenomen distractie. Versnelde detectie verwijst naar de snellere detectie van een stoornisrelevant targetwoord, vergeleken met een neutraal targetwoord van een bepaalde categorie tussen neutrale afleiders van een andere categorie. Toegenomen distractie verwijst naar de langzamere detectie van een neutraal te detecteren woord tussen stoornisrelevante afleiders vergeleken met neutrale afleiders van een andere neutrale categorie. Eetstoornispatiënten gaven blijk van versnelde detectie van lichaamsgerelateerde informatie vergeleken met gezonde vrouwen. Er was geen aanwijzing voor dat dit soort informatie zorgde voor toegenomen distractie. Voor de voedselgerelateerde woorden gold dat, vergeleken met gezonde vrouwen, eetstoornis- 
patiënten tekenen van toegenomen distractie vertoonden door hoogcalorische woorden, maar versnelde detectie van dit soort woorden werd niet waargenomen. Er werd geconcludeerd dat de precieze aard van de aandachtsbias in eetstoornispatiënten afhankelijk is van het type informatie waarmee ze geconfronteerd worden. Bovendien werd gesuggereerd dat de versnelde detectie van lichaamsgerelateerde informatie een angstreactie zou kunnen weerspiegelen terwijl de toegenomen distractie door voedselgerelateerde informatie zou kunnen wijzen op een intens verlangen naar voedse!.

In hoofdstuk 3 en 4 worden twee studies beschreven waarin getracht werd om mogelijke oorzaken van lichaamsontevredenheid experimenteel te onderzoeken. In hoofdstuk 3 lag de nadruk op selectieve aandacht en in hoofdstuk 4 werd aandacht besteed aan de rol van zelf-activatie in het ontstaan van lichaamsontevredenheid.

In hoofdstuk 3 werd de hypothese aangekaart dat selectieve aandacht voor onaantrekkelijke lichaamsdelen lichaamsontevredenheid veroorzaakt (Jansen et al., 2005) Zevenenveertig vrouwelijke eerstejaarsstudenten met een gemiddelde lichaamsontevredenheid werden willekeurig toebedeeld aan één van twee condities. In de negatieve bias training conditie werden deelnemers getraind om selectief aandacht te schenken aan hun drie meest onaantrekkelijke lichaamsdelen. In de positieve bias training conditie werden deelnemers getraind om selectief aandacht te schenken aan hun drie meest aantrekkelijke lichaamsdelen. Voor en na de training werd gemeten hoe tevreden de deelnemers waren over hun lichaam en gewicht op dat moment. Daarna kregen de deelnemers in de negatieve bias training conditie een positieve bias training om mogelijke negatieve effecten van de eerste training ongedaan te maken. Na deze positieve training werden lichaams- en gewichtstevredenheid op dat moment nog een keer gemeten. De resultaten geven aan dat het tijdelijk induceren van een aandachtsbias voor zelfgedefinieerde onaantrekkelijke lichaamsdelen leidde tot een significante afname van lichaams- en gewichtstevredenheid. Het trainen van gezonde deelnemers om selectief aandacht te besteden aan hun meest aantrekkelijke lichaamsdelen leidde echter niet tot een significante toename in lichaams- en gewichtstevredenheid. Het uitblijven van dit effect werd verklaard in termen van een plafond effect. Men kan zich voorstellen dat het moeilijk is om een positieve bias te induceren in vrouwen die al redelijk tevreden zijn met hun lichaam. Bovendien zou het kunnen dat de positieve training te kort was om positieve veranderingen in lichaamstevredenheid teweeg te brengen. Het is echter interessant dat de positieve training om negatieve effecten in de negatieve bias training conditie tegen te gaan wel leidde tot een significante toename in lichaams- en gewichtstevredenheid. Deze groep van deelnemers verschilden op twee punten van de deelnemers in de positieve bias training. Ten eerste was er meer ruimte voor verandering sinds deze deelnemers net voor de positieve training minder tevreden waren met hun lichaam door de negatieve training. Ten tweede was hun lichaamsonte- 
vredenheid niet zo hardnekkig omdat ze net daarvoor geïnduceerd was. Het is moedgevend dat een tijdelijke afname in lichaamsontevredenheid kon omgekeerd worden door een positieve training. Dit toont aan dat veranderingen in de positieve zin alleszins mogelijk zijn. De bevindingen van hoofdstuk 2 ondersteunen samen de etiologische rol van selectieve aandacht in lichaamsontevredenheid. Bovendien zijn deze resultaten in lijn met de aanname van Jansen et al., (2005): het trainen van gezonde deelnemers om hun lichaam op een disfunctionele manier te bekijken, resulteert in lichaamsontevredenheid.

De studie die in hoofdstuk 4 gepresenteerd wordt, onderzocht de causale rol van zelf-activatie in de gevoeligheid van vrouwen voor het slankheidsideaal zoals het doo de media geportretteerd wordt. Een steekproef van negenenzeventig vrouwelijke eerstejaarsstudenten, bestaand uit negenendertig beperkte eters en veertig onbeperkte eters, werden willekeurig toebedeeld aan één van twee condities. In de zelf-activatie conditie kregen deelnemers een schrijfopdracht die omschreven werd als een sollicitatiebrief voor een toekomstige werkgever. Ze kregen de opdracht om drie positieve en drie negatieve karaktertrekken van zichzelf gedetailleerd te beschrijven. Bovendien moesten de deelnemers in ieder zin ' $\mid k^{\prime}$, 'mij', 'mezelf', of 'mijn' gebruiken. In de controleconditie kregen de deelnemers een neutrale schrijfopdracht. Ze moesten een kort verhaal schrijven over een tafel en een stoel. Lichaams- en gewichtstevredenheid op het moment en sociale vergelijkingsneigingen werden meermaals gemeten tijdens het experiment. De mate van zelf-activatie werd gemeten voor en na blootstelling aan een aantal afbeeldingen van vrouwen die voldoen aan het slankheidsideaal. De resultaten geven aan dat beperkte eters met een hoge mate van zelf-activatie een significante afname van lichaams- en gewichtstevredenheid vertoonden na blootstelling aan het siankheidsideaal vergeleken met beperkte eters wiens zelf niet geactiveerd was. Daartegenover staat dat onbeperkte eters met een hoge zelf-activatie geen veranderingen vertoonden in hun lichaams- en gewichtstevredenheid vergeleken met onbeperkte en beperkte eters in de controleconditie. Deze bevindingen illustreren dat blootstelling aan het slankheidsideaal enkel een negatief effect had op het lichaamsbeeld van vrouwen wanneer aan twee voorwaarden voldaan was: (1) wanneer de deelnemer 'zelfgeactiveerd' was en (2) wanneer de deelnemer geclassificeerd werd als een beperkte eter Deze resultaten benadrukken dat blootstelling via de media aan vrouwen die voldoen aan het slankheidsideaal niet alle vrouwen op dezelfde negatieve manier beïnvloedt. Alhoewel zelf-activatie leidde tot een toegenomen neiging tot sociale vergelijking in zowel beperkte als onbeperkte eters, werd alleen het lichaamsbeeld van de beperkte eters negatief beïnvloed.

In hoofdstuk 5 en 6 werden twee causale factoren met betrekking tot een aandachtsbias nader bekeken. In hoofdstuk 5 lag de focus op body checking als oorzaak van 
een aandachtsbias voor lichaamsgerelateerde informatie terwijl in hoofdstuk 6 een intens verlangen naar voedsel (craving) centraal stond als oorzaak van een aandachtsbias voor voedselgerelateerde informatie.

in hoofdstuk 5 werd de causale rol van body checking in de ontwikkeling van een aandachtsbias onderzocht door body checking experimenteel te induceren in een gezonde steekproef. Zesenzestig vrouwelijke eerstejaarsstudenten werden willekeurig toebedeeld aan één van drie condities: de body checking conditie, de body exposure conditie of de controleconditie. In alle condities werden de deelnemers gevraagd lengtes in te schatten, maar de deelnemers in de body checking en body exposure conditie moesten dit voor een spiegel doen. Deelnemers in de body checking conditie moesten de lengte van drie verschillende lichaamsdelen inschatten terwijl de deelnemers in de body exposure conditie de lengte van drie verschillende delen van een stoel moesten inschatten. Na de manipulatie deden alle deelnemers een lichaamsgerelateerde visuele zoektaak. De resultaten laten zien dat het experimenteel induceren van body checking in gezonde deelnemers leidde tot een aandachtsbias voor lichaamsgerelateerde informatie. Om precies te zijn waren deelnemers in de body checking conditie sneller in het detecteren van een lichaamsgerelateerd target (versnelde detectie) dan neutrale targets temidden van neutrale afleiders vergeleken met de deelnemers in de body exposure en controleconditie. Er was echter geen bewijs voor toegenomen distractie; vergeleken met de deelnemers in de body exposure en controleconditie werden de deelnemers in de body checking conditie niet meer afgeleid door lichaamsgerelateerde woorden dan door neutrale afleiders wanneer ze een neutraal woord dienden te detecteren. De bevindingen in hoofdstuk 5 tonen experimenteel aan dat body checking ervoor zorgt dat men een bias ontwikkelt in de aandacht voor lichaamsgerelateerde informatie. Bovendien lijkt het erop dat expliciete body checking nodig is en niet enkel blootstelling aan het eigen lichaam om aandachtsbiases te produceren. De body checking manipulatie leidde niet enkel tot een aandachtsbias, maar ook tot toegenomen gevoelens van lichaamsontevredenheid die gecorreleerd waren met het aandachtsbias voor lichaamsgerelateerde informatie.

Tot slot werd in hoofdstuk 6 onderzocht wat de rol van een intens verlangen naa voedsel (craving) is in de ontwikkeling van een aandachtsbias door het experimenteel induceren van craving voor chocolade in een steekproef van vrouwelijke chocoholics en non-chocoholics. Vijfendertig chocoholics en drieëndertig non-chocoholics werden willekeurig toebedeeld aan een exposureconditie waarin craving geïnduceerd werd of de controleconditie. Na de manipulatie deden alle deelnemers een chocoladegerelateerde visuele zoektaak. Craving werd op verschillende momenten gemeten. De resultaten laten zien dat experimenteel geïnduceerde craving voor chocolade in chocoholics een bias veroorzaakt, vooral in de toegenomen distractie aandachtscomponent. Om 
precies te zijn waren chocoholics in de exposureconditie, vergeleken met nonchocoholics in de exposureconditie en chocoholics in de controleconditie, meer afgeleid door chocolade afleiders dan door neutrale afleiders wanneer ze naar een neutraa woord op zoek moesten. Bovendien was zelfgerapporteerde craving positief gecorreleerd met toegenomen distractie in chocoholics en in de exposureconditie. Chocoholics in de controleconditie waren, vergeleken met non-chocoholics en chocoholics in de exposureconditie, sneller in het detecteren van chocolade woorden vergeleken met neutrale woorden (versnelde detectie). Versnelde detectie maten waren echter nie gecorreleerd met zelfgerapporteerde craving. In conclusie scheppen de bevindingen uit hoofdstuk 6 meer helderheid rond de factoren die mogelijk een voedselgerelateerde aandachtsbias veroorzaken of instandhouden.

In hoofdstuk 7 worden alle bevindingen van dit proefschrift bediscussieerd en een cognitief model van lichaamsontevredenheid wordt naar voor geschoven. Suggesties voor vervolgonderzoek en implicaties voor de behandeling van eetstoornissen en lichaamsontevredenheid worden besproken. De bevindingen van dit proefschrift benadrukken het belang van aandachtsbiasen voor ons begrip van eetstoornissen en onderlijnen hun causale rol in het ontstaan van lichaamsontevredenheid. 
Dankwoord 
Time flies when you're having fun! Vier jaar zijn voorbij gevlogen, maar de talrijke mooie herinneringen aan mijn aio-tijd zullen me voor de rest van mijn leven bijblijven. op deze plek zou ik graag alle mensen willen bedanken die een bijzondere betekenis hebben gehad in de totstandkoming van dit proefschrift.

Te beginnen met de belangrijkste persoon: mijn dagelijks begeleider en promotor Anita! Dankjewel voor alles. Het was geweldig om met jou te kunnen samenwerken. Jouw passie en enthousiasme voor de wetenschap zullen me altijd bijblijven. Je hebt me ontzettend veel geleerd over schrijven, presenteren, en experimenteren. Verder heb je me geleerd om wat minder perfectionistisch te zijn (:) en om met ieder onderzoek en ieder artikel een statement te maken. Dank je wel voor je vertrouwen, je steun, en voor alle kansen die je me hebt gegeven. Bedankt ook gewoon voor alle gezellige tijden. Ik zal nooit die avond vergeten dat we met zijn tweetjes heerlijk zaten te babbelen over het leven onder het genot van een lekker flesje sancerre op een terras in Parijs. Anne, mijn co-promotor, jij ook ontzettend bedankt voor je begeleiding en vertrouwen! Samen brainstormen over onderzoek met jou was altijd superleuk. Van jou heb ik super veel geleerd over data-analyse, experimenten opzetten, en ook over schrijven, dankjewel daarvoor. Anita en Anne, bedankt voor de ruimte die jullie me hebben gegeven om zelfstandig te werken. Ik heb kei veel bewondering voor jullie allebei, en ik ben dankbaar dat ik vier jaar met zulke fantastische onderzoeksters heb mogen samenwerken. Ik kon me geen beter begeleidingsteam voorstellen.

Lieve mensen van de eetclub, Anita, Anne, Carolien, Sjaan, Remco, Sandra, Jen, Hugo, Ramona, Nicolette, Astrid, Janneke, Katrijn, Nele, en Esther, wat was het gezellig en ook vooral leerrijk om met jullie te kunnen samenwerken. Stuk voor stuk zijn jullie hele bijzondere persoonlijkheden en verdomd goede onderzoekers. Ik heb het geluk gehad om van ieder van jullie iets te mogen leren, dank jullie wel daarvoor! Dank ook voor de fijne onderzoeksnamiddagen, de gezellige etentjes, en de onvergetelijke tijden op congres $\odot$. Ik ga jullie missen! Jen, my fabulous friend, thanks so much for all the good times and for your support. I'll never forget! Hugo, waar moet ik beginnen. Vanaf het begin was je mijn maatje, dankjewel voor al je onvoorwaardelijke vriendschap en voor alle diepgaande gesprekken over muziek en het leven. Je bent een schat! Ook een hele dikke merci voor je hulp bij het pimpen van mijn uitnodigingen en coverdesign. Nicolette, Astrid, Esther, Janneke, en Ramona, jullie waren veel meer dan alleen collega's voor mij. Dank voor jullie vriendschap en steun.

Lieve collega's van CPS en het oude EP, bedankt voor de gezelligheid en de leuke babbels in de koffiehoek. In het bijzonder wil ik Tim, Roy, Elke, Christine, Ellen en 
Martien hier vernoemen. Thanks guys, jullie maakten mijn leven op en naast de Uns 40 een stuk leuker!

Lieve Jessie en Truus, jullie stonden niet alleen altijd klaar om te helpen met praktische zaken, jullie deden dat ook nog eens met zoveel positivisme dat het een waar genoegen was om jullie kamer binnen te komen. Bedankt, jullie zijn schatten!

Tijdens mijn aio-tijd heb ik het genoegen gehad om met fantastische personen op de kamer te zitten. Maarten en Tom, toen ik pas begon kwam ik bij jullie terecht. De nieuwe aio van de eetclub bij twee helden van de rechtenclub (-). Bedankt gasten voor jullie steun, en voor jullie deskundig advies over onderzoek en het leven als aio. Ik heb met heel veel plezier de kamer met jullie gedeeld! Saskia, lieve meid, je hebt niet lang bij ons gezeten, maar het was altijd even gezellig. Dankjewel! En dan last but not least: Henry. Lieve Henry, dankjewel, een betere kamergenoot had ik niet durven wensen. Ontzettend bedankt dat je er altijd voor mij was, je hebt me gesteund door dik en dun! Dank ook voor je vertrouwen, en de super gezellige tijden! Ik hoop stiekem dat we nog heel lang kamergenootjes kunnen blijven.

Jongens van de technische dienst, wat zouden mijn experimenten geweest zijn zonder jullie! Ron en Jacco, ik ben nog steeds onder de indruk van het prachtige programma dat jullie voor mijn studie uit hoofdstuk 3 hebben geprogrammeerd. Dank dat jullie altijd "met de glimlach" voor mij klaarstonden.

Tijdens mijn project zijn heel wat proefpersonen getest, en dat heb ik niet allemaal in mijn eentje gedaan. Graag een warm dankjewel aan de volgende dames: Tessa Lindelauf, Ellis Vossen, Laura Ruf en de dames van mijn chocoholics groepje uit 2007.

Eric van Furth, Janus van Liempt, Gabrielle en Alexandra van het Centrum Eetstoornissen Ursula in Den Haag en Oegstgeest, dank jullie wel om me de mogelijkheid te geven een klinische studie te draaien in jullie kliniek. Ik heb genoten van onze samenwerking. Zonder jullie hulp was mijn klinische studie nooit zo vlot gelopen. Janus bedankt voor je gastvrijheid. Alexandra, bedankt voor de gezellige etentjes bij jouw thuis. Gabrielle en Alexandra, ik vond het super gezellig om met jullie op pad te trekken in Mexico toen we gestrand waren door het -door de Mexicaanse griep afgelaste- AED congres.

During my PhD I had the most wonderful chance to visit and collaborate with Marika Tiggemann, Eva Kemps, Jennifer Mills and Sarah Hollitt at Flinders University in Adelaide, Australia. Marika and Eva, thank you so much for the opportunity to work with 
you and for showing me the hospitality of your homes. I really enjoyed our research meetings and I learned heaps from all of you on writing and experimenting. Thanks so much for all the very thorough and extremely fast feedback on my writing. Sarah, thanks for your help on all the practical stuff. I had the most wonderful time doing research at Flinders and I will always cherish my memories of those four months down under. Eva, thank you for making my time in Adelaide so special and for becoming such a great friend. People of the School of Psychology, thanks for making me feel so welcome. I surely enjoyed our laughs during lunch time. Charlotte, Tendayi, Maria, Michael, Puneet and Solle, my dear friends, you guys made my time in Australia unforgettable. am so happy we are all still in touch

Mijn lieve paranimfen: Katrien en Ramona. Wat ben ik fier dat jullie op 9 oktober letterlijk en figuurlijk achter mij zullen staan. Lieve vriendinnetjes, jullie zijn me allebe zo ontzettend dierbaar. Ramona, lieve meid, sinds mijn eerste dag bij CPS zijn wij twee handen op één buik. Bedankt voor je onvoorwaardelijke vriendschap en steun. Katrien my partner in crime, je bent mijn grote rots in de branding. Bedankt voor alle prachtige tijden en om me altijd te doen lachen: "borst vooruit, kont naar achter, en gaan met die banaan" haha $(-) !$

Stoere binken van Garden of Eden, mijn band. Super fel merci voor alle geweldige tijden die we op het podium en in het repetitiekot hebben gedeeld. Bedankt voor jullie vriendschap! Christophe en Martijn, ik kan me geen podium meer voorstellen zonder jullie aan mijn zijde, bedankt voor al die jaren die we samen als vrienden en muzikanten hebben gedeeld. Lieve Luc, je bent al zeven jaar mijn allerbeste vriend. We hebben samen al super veel watertjes doorzwommen, en heel veel prachtige tijden gekend, bedankt voor alles. Je betekent ontzettend veel voor mij! Dankjewel om er altijd voor mij te zijn. Ook bedankt voor je hulp bij mijn coverdesign en uitnodigingen.

Bert Jans, bedankt voor je vriendschap en de talloze filosofische gesprekken die we hebben gehad. Bijzonder hoe gelijk onze levens lopen. Marielle Salden, we zien elkaar niet zo vaak, maar als we elkaar zien dan voelt het net alsof het gisteren was. Je bent een bijzondere vriendin. Claeske, ik heb onze urenlange gesprekken en etentjes bijzonder gewaardeerd. Fijn te zien waar passie ne mens kan brengen, you are an inspiration. Els Merken, merci voor de gezellige lunchkes. Marco, jou zal ik nooit vergeten, merci voor de mooie tijden samen. Eike, wat kunnen we toch altijd goed lachen, merci! Bé je bent een fantastische vrouw, bedankt voor je vriendschap en steun! Sjapoo'kes merc voor de gezelligheid op de maandagavonden. Gies, dankjewel meid, je bent een schat To all my Italian friends, Francesco, Roscio, Chiara, Flavia, and Simone, grazie mille 
Simone you are the best friend someone could wish for. Thanks for everything! Flavia thanks so much for your support and friendship. Even though we are miles apart, we still manage to stay in touch and visit each other from time to time. Johan merci voor de gezelligheid en je telefoontjes tijdens het schrijven. Sabien Tiels, ook jij heel erg bedankt voor je vriendschap. Lieve Ruud, l'll never forget, merci. Susy, bedankt voor je kracht! En voor alle lieve vrienden die ik hier nu per ongeluk vergeet, ook een dikke mercil

Toto, merci voor je steun en geloof in mij!

Tenslotte wil ik mijn lieve familie en in het bijzonder make en papie, bompa, en natuurlijk mama en papa bedanken. Woorden schieten te kort om te beschrijven wat jullie voor mij betekenen. Jullie waren er altijd, maar dan ook altijd voor mij, zowel in goede als in slechte tijden. Lieve mama en papa, dank u wel voor alle kansen die jullie me hebben gegeven, voor jullie onvoorwaardelijke liefde, en voor jullie oneindig vertrouwen in mij. Jullie hebben me geleerd in mezelf te geloven en hebben me gemotiveerd het beste in mijzelf naar boven te halen. Jullie zijn mijn grootste inspiratiebron en zonder jullie had ik dit niet gekund, daarom draag ik dit boekje op aan jullie! Bedankt! 


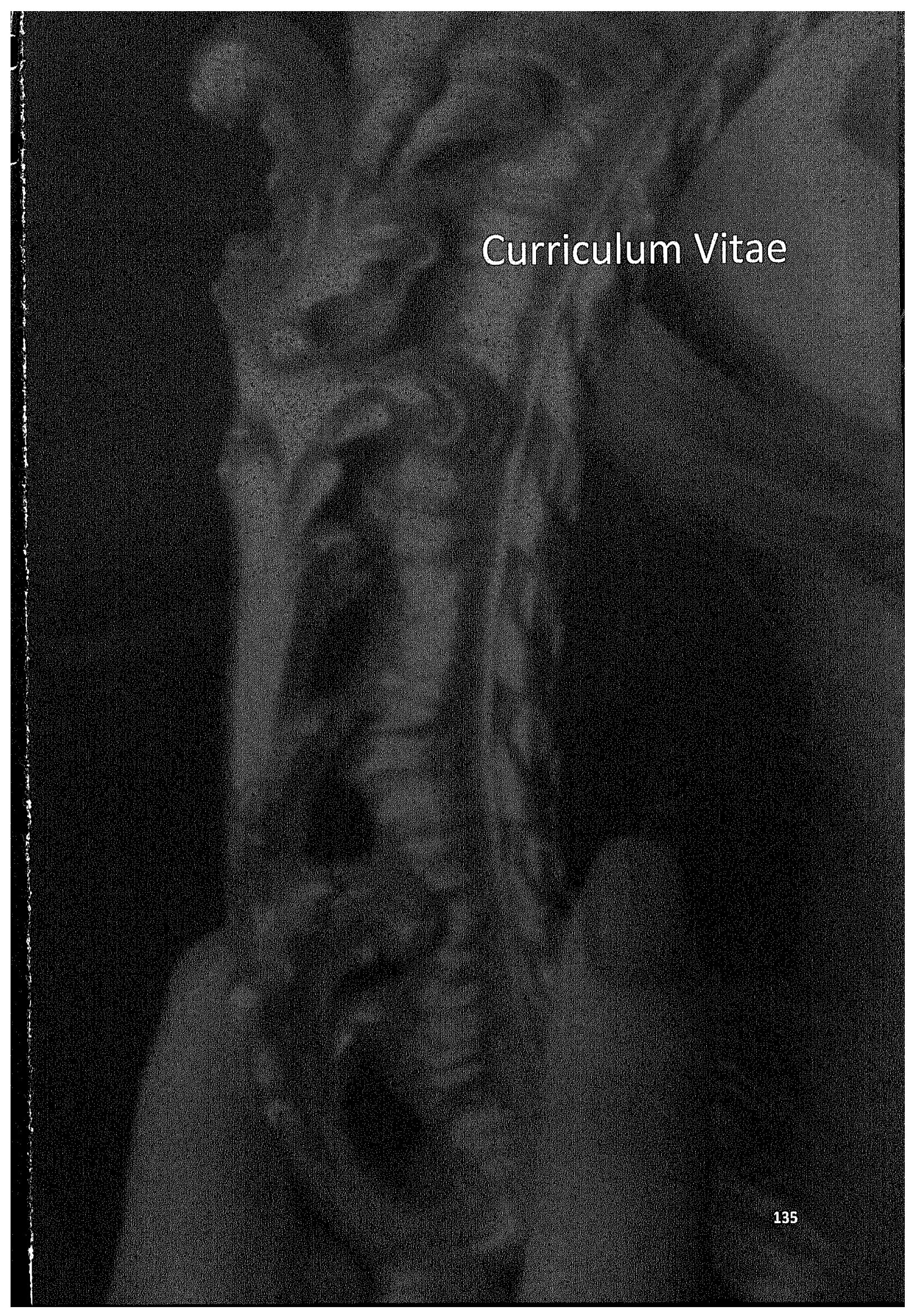


Elke Smeets was born in Genk (Belgium) on August 22, 1983. In June 2001 she graduated from secondary school Heilig-Hart College in Maasmechelen (Belgium). She started studying psychology at Maastricht University in September 2001 and graduated in April 2005. In September 2005 she started her PhD project at the department of Clinical Psychological Science, Maastricht University. She conducted parts of her research in collaboration with Prof. Dr. Marika Tiggemann, Dr. Eva Kemps, and Dr. Jennifer Mills at Flinders University, Australia. From September 2007 until September 2009 she was an elected member of the Faculty Council of the Faculty of Psychology and Neuroscience. Since June 2009 she is a postdoctoral fellow at the Department of Clinical Psychologica science in Maastricht.

\section{Publications}

Smeets, E., Roefs, A., van Furth, E., \& Jansen, A. (2008). Attentional bias for body and food in eating disorders: Increased distraction, speeded detection, or both? Behoviour Research and Therapy, 46, 229-238.

Smeets, E., Roefs, A., \& Jansen, A. (in press). Experimentally induced chocolate craving leads to an attentional bias in increased distraction but not in speeded detection. Appetite.

Smeets, E., Tiggemann, M., Kemps, E., Mills, J., Hollitt, S., Roefs, A., \& Jansen, A. (accepted pending revision). Body checking induces an attentional bias for bodyrelated cues. International Journal of Eating Disorders.

Geraerts, E., Merckelbach, H., Jelicic, M., \& Smeets, E. (2006). Long term consequence of suppression of intrusive thoughts and repressive coping. Behaviour Research and Therapy, 44, 1451-1460.

Geraerts, E., Merckelbach, H., Jelicic, M., Smeets, E., \& van Heerden, J. (2006). Dissociative symptoms and how they relate to fantasy proneness in women reporting repressed or recovered memories. Personality and Individual Differences, 40, 11431151

Geraerts, E., Smeets, E., Jelicic, M., Merckelbach, H., \& van Heerden, J. (2006). Retrievallnhibition of trauma-related words in women reporting repressed or recovered memories of childhood sexual abuse. Behaviour Research and Therapy, 44, 1129-1136. 
Geraerts, E., Smeets, E., Jelicic, M., van Heerden, J., \& Merckelbach, H. (2005). Fantasy Proneness, but not self-reported trauma is related is related to DRM performance of women reporting recovered memories of childhood sexual abuse. Consciousness and Cognition, 14, 602-612.

Giesbrecht, T., Merckelbach, H., \& Smeets, E. (2006). Thought suppression, dissociation, and context effects. Netherlands Journal of Psychology, 72, 73-80.

Martijn, C., Smeets, E., Jansen, A., Hoeymans, N., \& Schoemaker, C. (2009). Don't get the message: The effect of warning text before visiting a pro anorexia website. International Journal of Eating Disorders, 42, 139-145

Merchelbach, H., Smeets, T., Geraerts, E., Jelicic, M., Bouwen, A., \& Smeets, E. (2006) I haven't thought about this for years! Dating recent recalls of vived memories. Applied Cognitive Psychology, 20, 33-42.

Schoemaker, C., Smeets, E., Hoeymans, N., \& Jansen, A. (2007). Pro anorexia weblogs: de onverwachte effecten van een waarschuwingstekst. Maandblad Geestelijke Volksgezondheid, 6, 512-521.

\section{Manuscripts submitted for publication}

Smeets, E., Roefs, A., Lindelauf, T., \& Jansen, A. (2007). Selective attention for unattractive body parts causes body dissatisfaction.

Smeets, E., Jansen, A., Vossen, E., Ruf, L., \& Roefs, A. (2009). Self-activation is necessaryfor high restrained eaters to feel body dissatisfied when viewing pictures of beautiful women.

\section{Conference presentations}

Smeets, E., Roefs, A., van Furth, E., \& Jansen, A. (2006). Attentional bias for body and food related information in eating disorders. Paper accepted for oral presentation at the International Conference on Eating Disorders in Barcelona, Spain.

Smeets, E., Roefs, A., van Furth, E., \& Jansen, A. (2006). Attentional bias for body and food related information in eating disorders. Paper accepted for oral presentation at the European Association of Behavioral and Cognitive Therapies in Paris 
Smeets, E., Roefs, A., van Furth, E., \& Jansen, A. (2007). Attentional bias for body and food in eating disorders: Slowed disengagement, speeded detection, or both? Paper accepted for oral presentation at the annual meeting of the British Feeding and Drinking Group. Newcastle, England.

Smeets, E., Jansen, A., \& Roefs, A. (2007). Selective visual attention for ugly body parts as a causal mechanism for body dissatisfaction? Paper accepted for oral presenttion at the $V$ World Congress of Behavioral \& Cognitive Therapies. Barcelona, Spain.

Smeets, E., Roefs, A., \& Jansen, A. (2007). The influence of implicitly induced socia comparison on body dissatisfaction. Paper accepted for oral presentation at the $V$ World Congress of Behavioral \& Cognitive Therapies. Barcelona, Spain.

Smeets, E., Jansen, A., \& Roefs, A. (2007). Selective visual attention for ugly body parts as a causal mechanism for body dissatisfaction? Poster presented at the annual meeting of the Eating Disorders Research Society, Pittsburg, USA.

Smeets, E., Jansen, A., \& Roefs, A. (2009). The causal role of selective attention for unattractive body parts in body dissatisfaction. Invited talk given at the German Congress on Psychosomatic Medicine, Mainz, Germany.

Smeets, E., Tiggemann, M., Kemps, E., Mills, J., Hollitt, S., Roefs, A., \& Jansen, A. (2009) Body checking induces an attentional bias for body-related cues. Paper accepted for oral presentation at the International Conference on Eating Disorders, Cancun, Mexico.

\section{Awards}

2007: Article award 2007, presented by Experimental Psychopathology (EPP), the Dutch-Flemish postgraduate school for research and education for the article "Attentional bias for body and food in eating disorders: Increased distraction, speeded detection, or both?" by Elke Smeets. 